Portland State University

PDXScholar

8-27-2020

\title{
Trailblazing Transformation: Pioneering Transformative Peacebuilding in Academic Labor Conflicts
}

Sam Frazier Hediger

Portland State University

Follow this and additional works at: https://pdxscholar.library.pdx.edu/open_access_etds

Part of the Higher Education Commons, Labor Relations Commons, and the Peace and Conflict Studies Commons

Let us know how access to this document benefits you.

\section{Recommended Citation}

Hediger, Sam Frazier, "Trailblazing Transformation: Pioneering Transformative Peacebuilding in Academic Labor Conflicts" (2020). Dissertations and Theses. Paper 5569.

https://doi.org/10.15760/etd.7443

This Thesis is brought to you for free and open access. It has been accepted for inclusion in Dissertations and Theses by an authorized administrator of PDXScholar. Please contact us if we can make this document more accessible: pdxscholar@pdx.edu. 
Trailblazing Transformation:

Pioneering Transformative Peacebuilding in Academic Labor Conflicts

$$
\text { by }
$$

Sam Frazier Hediger

\begin{abstract}
A thesis submitted in partial fulfillment of the requirements for the degree of
\end{abstract}

\author{
Master of Science \\ in \\ Conflict Resolution
}

Thesis Committee:

Rachel Halfrida Cunliffe, Chair

Amanda Smith Byron

Robert Gould

\title{
Portland State University
}

2020 


\section{(C) 2020 Sam Frazier Hediger}

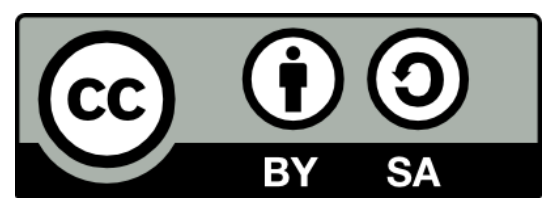

This work is licensed under the Creative Commons Attribution-ShareAlike 4.0

International License. To view a copy of this license, visit

http://creativecommons.org/licenses/by-sa/4.0/. 


\begin{abstract}
Unionized contingent faculty in the United States face an increasingly difficult economic landscape in their labor-management conflicts with university administrations. These unions, comprised of graduate student employees and adjunct instructors, won significant victories for their members but have failed to shift the broader patterns of casualization, unsustainable compensation, and job precarity, stemming from the systemic debasement of higher education institutions and the American labor movement, both of which pose significant challenges to conventional conflict resolution strategies. To find a path forward, this thesis explores the nature and possibility of transforming of the academic labor conflict, using a transformative peacebuilding approach to identify the underlying forces driving the current discord and creating a framework to affect long-term, constructive change. Analysis of the literature surrounding higher education and organized labor revealed the hegemonic influence of neoliberalism as the systemic force driving the conflict. This thesis answers that system with the Systems Ecology Framework of Transformative Care, a schema that combines the transformative peacebuilding framework, ethics of care, and a socio-ecological model for union organizing to contextually reduce the harm caused by neoliberalism and increase justice for stakeholders in the academy. It closes by offering recommendations for union strategy and further applications for conflict transformation in complex social conflicts.
\end{abstract}


Dedication

To a world now lost. For a world that must be better. 


\section{Acknowledgments}

I would like to express my deepest gratitude to my advisor, Rachel, for helping me better appreciate and tackle the magnitude of this project, as well as doing her utmost to wrangle me throughout its completion. I would also like to thank the faculty in the Department of Conflict Resolution who have inspired me with their perspectives, teaching, humanity, and support during my time as a graduate student. Finally, I must thank my friends and loved ones for the support and encouragement that sustained me to the end of this road. 
Abstract

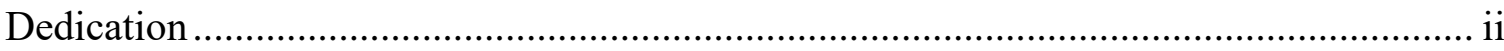

Acknowledgments.................................................................................................. ii

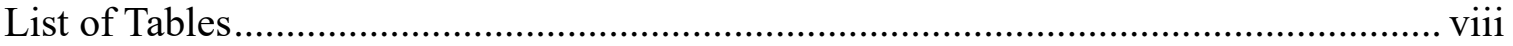

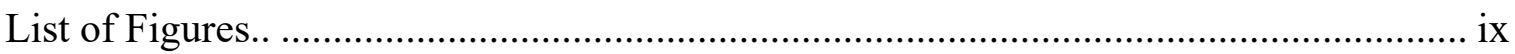

Glossary and List of Abbreviations.......................................................................... xi

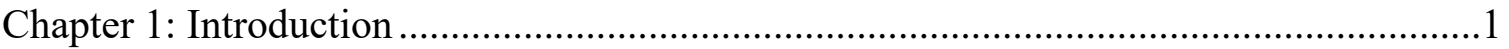

Getting My Bearings: Understanding the Conflict Through the Standard Toolkit...........3

Uncharted Territory: Establishing the Need for Research ..............................................8

Calibrating a Compass: Lederach's Transformative Model of Peacebuilding ................9

Triangulating the Destination: Identifying Research Questions .......................................14

Marking the Mileposts: Research Questions ...........................................................15

At the Trailhead: An Overview of the Text..................................................................16

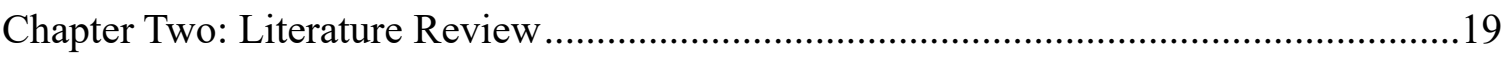

The River Runs Through It: Neoliberalism and its Effects on Higher Education .........19

The Commodification of Learning in the Academy ……...........................................22

Divestment, By the Numbers: The Statistics on Public Support of Higher Education..24

A continual trend of withdrawal: State spending per full-time equivalent student....25

Making up the difference: Tuition recovery and its impact on students....................26

From Graduate Student to Graduate Student Employee: Debt, Desperation, and

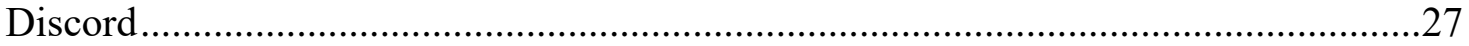

The Corporate University: Administrative as Management and Faculty as Labor........29

Money equivalence: The demise of the professor and the rise of contingent faculty.

Low wages, low power, low stability, and low morale: The challenges faced by

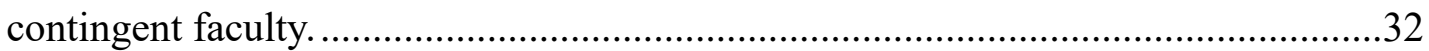

Administrative intensity: Competition in a finite resource pool.................................34

Looking at the overall impact of administrative intensity in the academy. ................37

Corporate management behaviors: Stratification and unaccountability. .....................38 
A

Answering How and Why Higher Education Changed over the Past Century..............40

On Rocky Ground: Organized Labor in the United States and the Academy ..............41

Bread and Roses in the Ivory Tower: The Academic Labor Movement.......................43

Un Au Coup par Coup Résistance: The Obstacles Faced by Organized Labor.............45

Public approval and the effects of cultural opposition to union values. ....................47

The changing landscape of the American economy, alienating union relevance.......47

Institutions and the nature of union organizing in American society.......................48

Political adversity and the deconstruction of union protections. .............................49

“Don't Mourn, Organize!": The Research and Strategies of Union Revitalization.......50

Modernization: Bringing union strategy into the $21^{\text {st }}$ century. ..............................50

Representative spaces: Understanding union identity for both members and

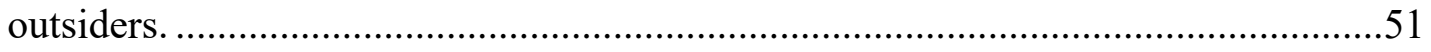

Collective action repertoires and connectedness: The impacts of union action in the

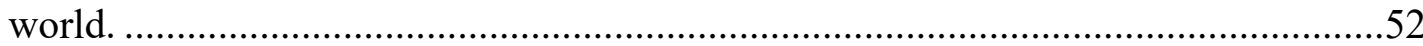

Answering How and Why the Labor Movement Declined .....................................53

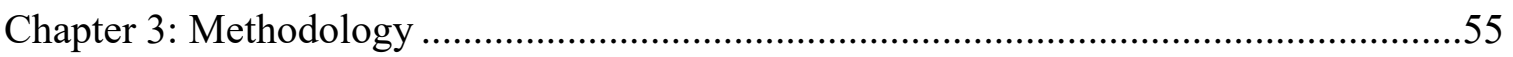

Siting Landmarks for Peace: Understanding the Transformative Framework ..............55

The four domains of conflict and their change goals.........................................56

Basecamp to Summit: Creating the "Big Picture" View of a Conflict ..........................57

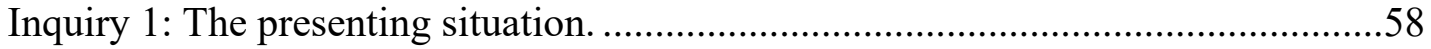

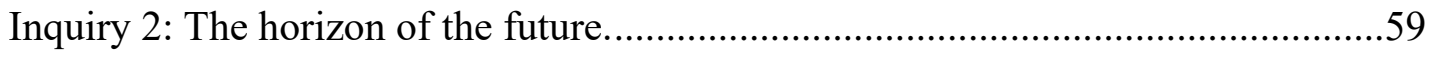

Inquiry 3: The development of change processes...............................................59

The relational nature of the lenses of inquiry and their relationship to transformation.

Building Switchbacks: Process-Structures and Transformational Platforms ...............60

Stepping Off the Beaten Path: Resolution, Revolution, and Their Limits....................62

Cartography of the Academic Labor Conflict: Applying the Transformative Framework .64

Applying the presenting situation lens of inquiry. ...............................................64

Applying the horizon of the future lens of inquiry..............................................64

Applying the creation of change processes lens of inquiry..................................65 
vi

Home Territory: Grounding the Research in the GEU-PSU Conflict.........................66

Marking the Way: Sources of Data, Charts, and Rationales for Use ...........................66

Charts and diagrams created during research along with rationales........................69

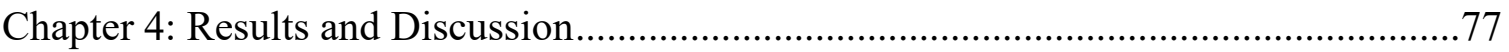

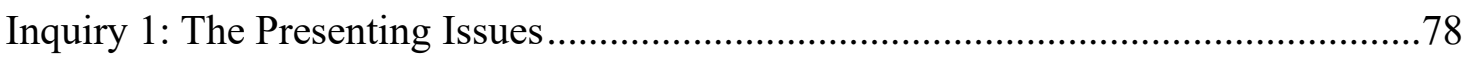

The rise in graduate student debt and its impacts on borrowers............................78

The academy as a marketplace of ideas: Consequences of HEI corporatization.......82

Unsustainable wages and precarious conditions in HEI personnel practices. ...........91

Understanding organized labor through the presenting issues..............................95

The labor movement's long, slow fall from power. .............................................96

Under the bed and around every corner: The political adversity faced by organized labor.

The failure of American labor institutions and the subversion of its dispute resolution system.

The economic (r)evolution: Globalization, deregulation, and free trade agreements.

The decline of public support for organized labor. .............................................. 100

A clear view: The results of the first lens of inquiry. .........................................101

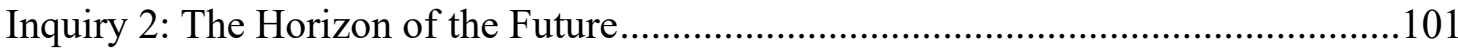

The contradictions of capital: Inequity, accumulation, and crisis..........................102

The myth of the rational actor: Individuals under neoliberal ideology...................105

A different path: Liberating individual freedom from neoliberalism. ....................107

Academic labor: Sighting the light of peace in a horizon clouded by

governmentality.

Inquiry 3: The Development of Change Processes

The personal domain: A Promethean coinage of humanity through the fire of the market and the clay of self-interested individualism.

The relational domain: Viewing a connected world from a disconnected market calculus.

The structural domain: The visible structures that evoke the invisible hand of the market.

The cultural domain: Where the business is greed, and business is good. 
Identifying the change process to deploy care ethics.

Uniting the World of the Workers: The Socio-Ecological Model of Union Organizing

Toward a Systems Ecology of Transformative Care..................................................124

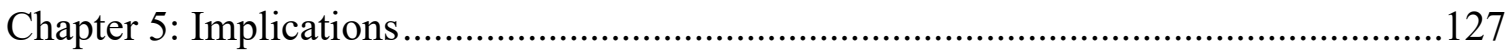

Surveying the Map of the Academic Labor Conflict ..............................................129

Implications for the Academic Labor Conflict at Portland State University ...............130

Modernization, innovation, and strategic renewal: The development of innovations in strategies and organizational health. .......................................................... 131

Representative spaces: How unions represent themselves to their members, their adversaries, and others.

Collective action repertoires: The development of tactics to succeed in union actions.

Connectedness: The means by which unions conceptualize and incorporate outsiders.

Summarizing the implications for the academic labor conflict. 138

Implications for Peacebuilding and Conflict Resolution Practice

Works Cited.....

Appendix A: Average Staff Salaries in the U.S. 4-Year Public Universities and Portland State.

Occupational Classifications.

Appendix B: National Union Membership to Percentage of Total U.S. Wealth Owned by Top 10\% of Households, 1917-2015 (Bivens et al., 2017; World Inequality Database, 2020) 


\section{List of Tables}

Table 1: Average Graduate Student Loan Debt, 2000-2016 ......................................... 27

Table 2: Average, Public 4-Year and PSU Student Tuition and Fees, 1963-2017, in Constant 2019-2020 Dollars (IPEDS, 2020; Snyder et al., 2019) .................................. 80 Table 3: Total Headcounts by Occupation at Portland State University for the years 2001, 2006, 2012, and 2018 (IPEDS, 2020) 


\section{List of Figures}

Figure 1: Lederach's (1995) Adaptation of Curle's (1971) Progression of Conflict Diagram.

Figure 2: State Spending per Full-Time-Equivalent Student, 2000-2018 (Baum \& Johnson, 2015; SHEEO, 2019) 26

Figure 3: Average Higher Education Institution Growth of Full-Time Equivalent (FTE) Faculty and Contingent Faculty, 2000-2012 (Desrochers \& Kirshstein, 2014). 32

Figure 4: Change in Ratio of Instructional Staff to Non-Instructional Professionals in HEIs, 1990-2012 (Desrochers \& Kirshstein, 2014).

Figure 5: Average Change of Staffing by Occupational Category, 1990-2012 (Desrochers

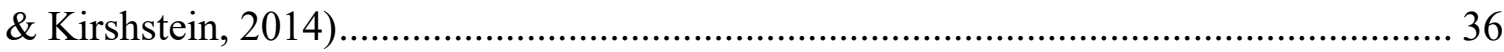

Figure 6: Lederach's (2014, p. 31) Transformative Lenses of Inquiry ........................... 58 Figure 7: Change in Average Annual Student Tuition and Fees Over Time at Public, 4Year Higher Education Institutions, 1963-2017, in Constant 2019-2020 Dollars (Snyder et al., 2019)

Figure 8: Tuition as a Percentage of Total HEI Core Revenues, 1993-2018 (IPEDS, 2020; SHEEO, 2019) 82

Figure 9: Average Higher Education Institution Revenue per Full-Time Equivalent Student, in Constant 2019-2020 dollars, at Public, 4-Year Research Universities, 20002010 (Kirshstein and Hurlburt, 2012)

Figure 10: Percentage of Full-Time Faculty in All U.S. Postsecondary Institutions, 1970-

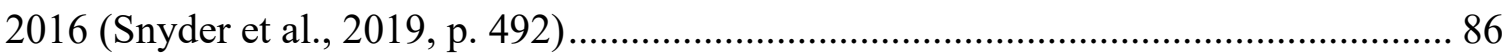

Figure 11: Portland State University Staffing by Occupation, 2001 (IPEDS, 2020)....... 89 Figure 12: Portland State University Staffing by Occupation, 2006 (IPEDS, 2020) ....... 89 Figure 13: Portland State University Staffing by Occupation, 2012 (IPEDS, 2020) ....... 90 Figure 14: PSU Staffing by Occupation, 2018 (IPEDS, 2020).................................... 90 Figure 15: Percentage Change in Average U.S. Postsecondary Faculty Salaries After Adjusting for Consumer Price Index for All Urban Consumers, 1971-2018 (AAUP, 2018)

Figure 16: Percentage of U.S. Workers Claiming Membership to a Labor Union, 19172014 (Bivens et al., 2017) - Data Table in Appendix B.

Figure 17: Percentage of Union Membership to Percentage of Total Wealth Owned by Top 10\% and 1\% of Households in the U.S., 1917-2014 (Bivens et al., 2017) World Inequality Database, 2020) 103

Figure 18: Pocock's (2012) Visual Adaptation of Bronfenbrenner's (1981) Socio-

Ecological Model of Human Development .

Figure 19: The Systems Ecology Framework of Transformative Care, Adapted from Lederach (2014), Pocock (2012), and Tronto (2017).

Figure 20: The Cycle of Conflict, Adapted from Lederach (2014, p. 35) 
Figure 21: Long-Term Change Through the Transformational Platform (Lederach, 2014,

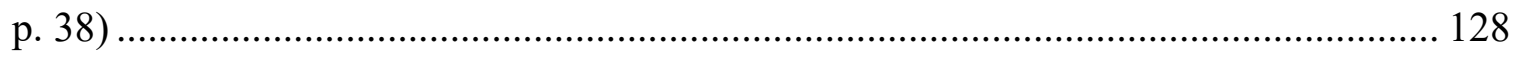




\section{Glossary and List of Abbreviations}

- Note: All currency figures in the document have been adjusted for the fiscal year 2019-2020 inflation.

- Adjunct Faculty: Non-tenure-track, postsecondary instructors contracted by colleges and universities at less than part-time employment.

- Administrative Intensity: From Rutherford's (2016) definition, the ratio of executive, administrative, or managerial staff concerning workers producing goods or services.

- American Association of University Professors (AAUP): A professional association and labor union representing postsecondary faculty in the United States.

- American Federation of Teachers (AFT): A labor union representing teachers in the United States.

- Change Processes: From Lederach's (2014) framework of conflict transformation, referring to solutions identified from the three lenses of inquiry that can be used through a transformational platform to address the epicenter and episodes of discord in a conflict system.

- Collective Bargaining Agreement: An agreement between a labor union and management of an organization.

- Commodification: From Ball's (2012) definition, a process by which entities, such as workers in a capitalist society, are abstracted into an economic value through the processes of objectification, fungibility, commensurability, and money equivalence.

- Conflict Domain: From Lederach's (2014) framework of conflict transformation, referring to the four dimensions by which a conflict can be understood and interpreted.

- Conflict Transformation, Transformative Peacebuilding, Transformative Framework: From Lederach's (2014) framework of conflict resolution, which seeks to reconcile the relationships between adversaries by reducing violence and increasing justice, addressing the underlying forces driving complex conflict systems.

- Confrontation: From Adam Curle's (1971) Progression of Conflict, confrontation represents the use of strategic nonviolence to build power in low-power parties, opening the door to negotiation and reconciliation.

- Conscientization: From Adam Curle's (1971) Progression of Conflict, conscientization represents the building of awareness, knowledge, and politicization of unjust and inequitable relations in conflict before building power through Confrontation. 
- Consumer Price Index for All Urban Consumers (CPI-U): A yearly measure of the cost-of-living increase resulting from inflation. It is used to adjust figures such as salary to account for changes in annual inflation.

- Contingent Faculty: A term to refer to the combination of graduate student employees and adjunct faculty in colleges and universities.

- Cultural (Domain): From Lederach's (2014) framework of conflict transformation, referring to one of the four dimensions Lederach discusses conflict affects and can be understood through the social narratives and stories constructing individuals, communities, and societies.

- Democratic Care: From Tronto's (2017) definition, a framework of interaction and governance based on the philosophical principles of care ethics.

- Descriptive: From Lederach's (2014) framework of conflict transformation, referring to the process of describing the effects of conflict as understood through the four conflict domains.

- Epicenter: From Lederach's (2014) framework of conflict transformation, referring to the underlying systems and structures driving episodes of discord in a complex conflict system.

- Episode: From Lederach's (2014) framework of conflict transformation, referring to a discrete expression of conflict in a complex conflict system.

- Executive, Administrative, and Managerial (EAM): An occupational classification defined by the U.S. Department of Labor (2018), denoting personnel engaged in the management of other employees.

- Full-Time Equivalent (FTE): A statistic derived by combining the total hours of enrollment or employment at an organization and dividing that number by the hours utilized by a full-time actor in that organization.

- Graduate Employees Union (GEU): A graduate student employee labor union at Portland State University.

- Graduate Student Employees (GSEs): Post-baccalaureate students employed at a higher education institution.

- Higher Education Institution (HEI): A term referring to public and private postsecondary education organizations, typically including both 2- and 4-year institutions.

- Homo Economicus: From Read's (2009) definition, referring to the conceptualization of individuals as market-rational entities.

- Integrated Postsecondary Education Data System (IPEDS): A statistical database maintained by the U.S. Department of Education.

- Interest-Based Bargaining (IBB): From Roger et al. (2011), a form of principled negotiation wherein disputants negotiate to fulfill the underlying 
interests informing their positions, potentially generating mutually beneficial agreements and outcomes.

- Iron Law of Oligarchy: From Michels' (1915) sociological framework, referring to the tendency for organizations to abandon activist ideals over time in favor of regime maintenance and protection.

- Lenses of Inquiry: From Lederach's (2014) framework of conflict transformation, referring to one of the three lenses of inquiry - the presenting situation, horizon of the future, or development of change processes - by which the epicenter of a conflict can be identified by tracing current expressions through patterns found in historical events, and solutions can be created to deploy through a transformational platform.

- Macrosystem: From Pocock's (2012) definition, referring to the larger field in which the microsystems and mesosystems of an entity are situated, as described by Pocock in her application of Bronfenbrenner's (1981) socioecological model of human development to union organizing.

- Market-Rational: From Saunder's (2010) definition, the conceptualization of individuals as rational, self-interested, utility-maximizing agents concerning interactions in the marketplace.

- Mesosystem: From Pocock's (2012) definition, referring to the intersections of microsystems described by her application of Bronfenbrenner's (1981) socioecological model of human development to union organizing.

- Microsystem: From Pocock's (2012) definition, referring to the discrete fields described by her application of Bronfenbrenner's (1981) socio-ecological model of human development to union organizing.

- National Center for Education Statistics (NCES): A database maintained by the U.S. Department of Education.

- National Labor Relations Act (NLRA): An American legislative document outlining the legalities and protections afforded workers in the workplace. Enforced by the National Labor Relations Board.

- National Labor Relations Board (NLRB): The enforcing body of the National Labor Relations Act, enforcing the regulations set out by the legislation and adjudicating disputes set before the board.

- Neoliberalism: From Saunder's (2010) definition of the subject, a set of economic, social, and political policies, positions, and practices bounded around three core principles: The establishment of free markets, the minimization of the state, and the valorization of individualism.

- Non-Tenure-Track (NTT): Postsecondary instructors not employed in a tenure-line position. 
- Overaccumulation: From Kotz's (2008) definition, referring to the inability for neoliberal markets to reconcile the overproduction of goods and services with the inability of devalued labor to consume said goods and services.

- Pattern bargaining: From Rosenfeld's (2014)'s definition, referring to a process of union bargaining in which collective bargaining agreements are negotiated at a regional or national level between a collective of unions and businesses in an industry.

- Personal (Domain): From Lederach's (2014) framework of conflict transformation, referring to one of the four dimensions Lederach discusses conflict affects and can be understood from an individual's identity and worldview.

- Portland State University (PSU): A public, 4-year research university located in Portland, Oregon.

- Portland State University Faculty Association (PSUFA): A labor union representing non-tenure-track, postsecondary teachers at Portland State University.

- Prescriptive: From Lederach's (2014) framework of conflict transformation, referring to the process of prescribing action and strategy to reduce violence and increase justice through the conflict domains.

- Procedural Justice: From Lederach's (2014) framework of conflict transformation, referring to the agency and autonomy disputants have in conflict.

- Progression of Conflict: From Adam Curle (1971), a model of understanding conflict that represents a potential path toward dynamic, stable peace from unjust relations through a process of conscientization, confrontation, negotiation, and reconciliation.

- Relational (Domain): From Lederach's (2014) framework of conflict transformation, referring to one of the four dimensions Lederach discusses conflict affects and can be understood from the relationships and interactions stakeholders have with each other.

- Relational Theory of Power: From Wilmot and Hocker (2011), this concept refers to the idea that power is interdependently bound between parties in conflict, providing inroads for low-power stakeholders build power by increasing interdependence.

- Resolutionary: From Lederach (1995), referring to peacebuilding efforts that primarily use dispute resolution strategies such as negotiation and mediation to support reconciliation of all parties in a conflict. Often in tension with revolutionary. 
- Revolutionary: From Lederach (1995), referring to peacebuilding efforts that primarily use activism and advocacy to support one party in a conflict. Often in tension with resolutionary.

- Service Employees International Union (SEIU): A labor union representing numerous industries in the United States, including postsecondary teachers.

- Structural (Domain): From Lederach's (2014) framework of conflict transformation, referring to one of the four dimensions Lederach discusses conflict affects and can be understood through the abstract and actual constructions, institutions, and organizations that reduce or drive violence and injustice in a conflict system.

- Substantive Justice: From Lederach's (2014) framework of conflict transformation, referring to the basic needs disputants need to have met in conflict.

- Socio-Ecological Model of Human Development: A framework developed by Urie Bronfenbrenner (1981) to contextually understand the different fields of life a person exists in as they grow and develop.

- State Higher Education Executive Officer's (SHEEO) Association: A national association of the chief executive officers for postsecondary institutions in the United States.

- Systems Ecology Framework of Transformative Care (SETC): A framework of transformative peacebuilding through union organizing that I developed to address the epicenter of neoliberalism in the academic labor conflict. It combines Pocock's (2012) use of Bronfenbrenner's (1981) socio-ecological model of human development, Lederach's (2014) conflict transformation framework, and Tronto's (2017) philosophy of democratic care.

- Tenure/Tenure-Track (T/TT): Postsecondary instructors employed in a tenureline position.

- Transformational Platform: From Lederach's (2014) framework of conflict transformation, referring to an adaptable, dynamic framework capable of guiding peacebuilding efforts to address both the epicenter and episodes of a complex conflict system. 
Trailblazing Transformation:

Pioneering Transformative Peacebuilding in Academic Labor Conflicts

\section{Chapter 1: Introduction}

In 2018, the Graduate Employees Union (GEU) of Portland State University (PSU) ratified their first collective bargaining contract, becoming one of the newest labor unions to represent graduate student employees (GSEs) in the United States, and thrusting themselves into a complicated and increasingly embittered struggle over the priorities, policies, and very nature of the academy. They contend with adversity from the university's administration and a volatile economic landscape while trying to safeguard the interests of graduates, both as students and employees. I first encountered this conflict in the winter of 2019 when I was engaged in practicum work with the Department of Conflict Resolution. In my initial contact with the union, we discussed some of GEU's experiences with the administration: Stymied and frustrated negotiations, promises made between parties that felt unfulfilled and broken, and other organizational challenges. The sense I took away from these conversations was that the first waves of energy rising with the union's origination kept crashing against walls of bureaucratic resistance - that they lacked a road map to direct their actions and work. Seeing an opportunity to better understand this conflict and potentially put my skills and experience to use, I began consulting on GEU's behalf to analyze the conflict, offer coaching, and build recommendations to support the relationship and interactions between the parties. Several factors informed my choice to work directly with the union. First, it represented my best entry point into the conflict, in that the relationship between GEU and PSU was closed off to easy intervention or participation from outsiders. Third-party 
'neutrals' - unaffiliated mediators and arbitrators - were only employed in specific, regulated circumstances. These neutrals can help resolve particular conflicts, but their influence ended the moment the parties left the negotiating table. They, for example, cannot follow up to ensure accountability for agreements or to repair damaged relationships.

Second, my genealogy of ideas and background in activism led me to the assumption that unions were often disadvantaged parties in the labor-management relationships. Having grown up poor in a progressive, pro-union household, I held the belief that organized labor was typically the 'underdog' in conflicts - that management often exploited workers in organizations. My experience working with the Oregon Student Public Interest Research Group and other forms of environmental and labor activism reinforced this, as did my academic lineage reading the likes of Saul Alinsky (1989) and Michel Foucault (1995). Alinsky (1989, pp. 31-35) wrote of the distinctions between the "Haves," "Have-a-Little, Want Mores," and "Have-Nots," and the impositions inflicted on the economically and socially marginalized. The complexity of Alinksy's ideas is expanded by Foucault's (1995) explorations into the ways that capitalism and institutions influence and control our ways of thinking, acting, and being. These concepts resonated with my own experiences of poverty, speaking to the constant feeling of disempowerment, of having my actions directed by others above me, of the external and internal script about my worth, obligations, goals, and self. In this sense, my identity resonated with the union. As a graduate student experiencing the very issues they clashed with the university administration about - my precarious job position, economic instability, and the slew of psychological, logistical, and emotional 
consequences that followed those realities - the message of the Graduate Employees Union struck a chord with me. I very much wanted them to succeed, for their benefit and mine.

These feelings and my assumption of GEU's underdog status stood tempered by my training in conflict resolution. Wilmot and Hocker (2011) speak of the fact that all parties in conflict feel disadvantaged by their adversary. The principles of interest-based bargaining (IBB) speak to the value of everyone winning at the negotiating table (Roger et al., 2011). The conflict resolution literature cleaves to the idea that peace involves justice and equity for each person within conflict. Consequently, I knew that the solution lay not in the demonizing or harming the university administration, but in transforming the relationships in the conflict to reflect justice and peace. These ideas mediated my ideological motivations as I stepped into my consulting role.

\section{Getting My Bearings: Understanding the Conflict Through the Standard Toolkit}

Over my time working with the union, I discovered that conventional conflict resolution methods utilizing mediation, negotiation, and other dispute resolution strategies failed to elicit meaningful change. My background and experience drew from both interpersonal and workplace mediation. The department of conflict resolution trained me in working with disputants to address deeper issues within their relationships - to facilitate the possibility of reconciliation and restoration. Combined with my experience mediating workplace disputes among volunteers for the Burning Man Project, my toolkit utilizes:

- Interpersonal negotiation and mediation, drawing heavily from Wilmot and Hocker (2011), which offered a robust look at the discrete and 
relational conflicts that occur between individuals, examining dimensions of power, identity, restoration, and forgiveness.

- Collaborative negotiation through interest-based bargaining (Fisher \& Shapiro, 2006; Roger et al., 2011), which offers a method for negotiation that seeks to address and support the underlying interests of parties.

- Trauma-sensitive frameworks (Herman, 2015; Van der Kolk, 2015), which explore how trauma - both in its acute and systemic forms impact individuals' abilities to exist and participate socially.

- Workplace and organizational dispute resolution (Bollen et al., 2016), working primarily within the administrative and personnel structure of an organization to address conflicts within and between departments.

With this body of work, I felt confident in my capacity to support the union in its negotiation work. From my initial conversations, the conflict between GEU and the university administration seemed like a straightforward issue of communication and negotiation. However, to supplement my knowledge, I engaged in background research both on the specific context graduate student employees existed in and labor unions more broadly, seeking to understand their cultural and social location within this conflict. Starting with an exploration of GEU's positions and the factors leading to its founding, I discovered a number of economic and social realities present not only at PSU but endemic to universities and GSEs across the U.S.

The rise of American GSE unions is a relatively recent phenomenon, with earlier research characterizing their organizing efforts as primarily political in nature (Rhoads \& Rhoades, 2005). These reasons included resisting the increasingly corporate nature of the university, the use of graduate student employees as low-cost tools to educate undergraduate students, and fearing the loss of the historical relationship of apprenticeship between graduate students and faculty. These views implied a rewritten cultural script and a departure from the historical university practices students understood, clashing with their expectations around their current work and professional 
futures (Hurlburt \& McGarrah, 2016). Later articles placed more emphasis on economic issues: The lack of sustainable compensation, benefits, significant job precarity, and dimming prospects for future employment as instructors and researchers (Bauer, 2017; Cadambi Daniel, 2016; Kroeger et al., 2018).

The same source that fueled the shifts in graduate student education drove analogous changes amongst a rapidly rising class of postsecondary instructors: nontenure-track (NTT), part-time adjunct faculty (Cadambi Daniel, 2016; Halverson Cross \& Halverson, 2017; Ramirez, 2018; Rhoades, 2015). The situational, logistical, and political alignment of these two groups commonly integrates them into a collective category known as contingent faculty (AAUP, 2017). Together, contingent faculty now make up the dominant source of instruction at higher education institutions (HEIs) - public and private postsecondary education organizations (Desrochers \& Kirshstein, 2014). However, as a group, they all struggle with economic and social instability within the academy, made worse by the changes they perceive in the fabric of higher education. This sparked my curiosity: What caused these circumstances in postsecondary education?

Regardless of the source, these changes drove contingent faculty to organized labor to protect their well-being. In this respect, unionization provided some significant victories for adjuncts and graduate student employees, leading to better wages and job security (Cadambi Daniel, 2016; Ramirez, 2018; Rogers et al., 2013). However, these successes paled in comparison to the dramatic impacts organized labor has historically wrought in improving working conditions and compensation. At the height of their influence, unions set the standard for wages in several industries and helped completely rewrite workplace safety conditions across the United States (Freeman \& Medoff, 1984). 
Yet today, the power of organized labor has fallen to its lowest point in a century, struggling against a globalizing economy, political opposition, and low membership (Rosenfeld, 2014), despite three decades of research surrounding its revitalization (Murray, 2017). Even within the academy, which has experienced a paradoxical explosion of union growth (Kroeger et al., 2018; Sproul et al., 2014), organized labor has thus far failed to reverse the larger patterns leading to the creation of contingent faculty positions, to reduce student debt or tuition fees, or to change the decision-making practices of HEIs (Desrochers \& Kirshstein, 2014; Sproul et al., 2014). Here, another question presented itself: Why was organized labor unable to create significant change in this context?

This research problematized my understanding of the GEU-PSU conflict, but it was in applying my skills that confirmed a deeper issue within the discord. I found that none of the strategies I employed during my time with the union created meaningful change within the conflict. Mediation of the interpersonal issues between disputants failed due to the limited nature of labor-management interactions and the frequent cycling of negotiators for both sides. I offered to help the union utilize integrative negotiation also known as interest-based bargaining (IBB) - which presents significant potential to improve relationships and constructive outcomes for parties (Fisher \& Shapiro, 2006; Roger et al., 2011; Wilmot \& Hocker, 2011). However, I quickly learned that GEU - and labor unions more generally - already know of interest-based negotiation but rejected its use, arguing that it weakened economic outcomes in bargaining (Miller et al., 2010).

This perception surprised me, though on one level, it makes sense: Labormanagement relations are often adversarial and bereft of trust, an environment that makes 
utilizing interest-based negotiation challenging (Roger et al., 2011). However, management negotiators tended to be enthusiastic about IBB, seeing it as the best path forward for long-term positive relations in organizations (Miller et al., 2010, pp. 195196). This drew my curiosity, as I expected both parties would reject integrative negotiations due to a lack of trust and experience with the method, yet that assumption was wrong on both counts.

Further research into the use of IBB in labor-management negotiations showed that, while it improves relationships and outcomes in joint governance, it also consistently resulted in poorer economic outcomes for unions (Leavy, 2015; Miller et al., 2010; Paquet et al., 2000). Faced with these challenges, I realized that conventional dispute resolution strategies might cause harm in this conflict. Critical scholars in the field note that where systemic power disparities exist, high power parties can easily coopt negotiation and mediation processes, reinforcing oppression and inequity (Practitioners Research and Scholarship Institute, 2008; Wing, 2008).

Groups subordinated by systemic forces tend to have distrust, knowledge, and experience of speciously neutral processes, as expressed by black communities in victimoffender mediation (Practitioners Research and Scholarship Institute, 2008) and indigenous communities in regards to academic research (Smith, 2012). The Graduate Employees Union, by virtue of being a contingent faculty union without strong job protections, represented one of these low-power parties. To offer an example by way of exception, the combined healthcare unions representing workers in Kaiser Permanente hospitals successfully employed integrative negotiation in their bargaining with the hospital network to produce a landmark bargaining agreement that provided for the needs 
of the organization, staff, and patients (Kochan et al., 2009; McKersie et al., 2008).

Because the unions organized bargained across the broader network, which allowed them to pool the power of each union, integrative negotiation functioned toward its intended purpose. This exception illustrates both the need for equity between disputants and, in turn, the consequences resulting from its lack in the academic labor conflict. Combining the research around labor's inability to meet its needs through integrative negotiation and the challenges they faced through their dispute resolution system, this indicated systemic problems that needed to be addressed, posing a third question: What are the forces affecting this conflict?

\section{Uncharted Territory: Establishing the Need for Research}

Coming to understand the factors involved in this conflict, I needed to shift my approach to peacebuilding. The disparities between the Graduate Employees Union and university administration made conventional dispute resolution a potentially harmful exercise, and the significant systemic forces needed elucidation to understand their effects on the discord. Unfortunately, when I turned to past peacebuilding literature around the subject, I found the academic conversation strangely silent. Given that this conflict affects a significant element of academe in addition to workers more broadly in the United States, I found the lack of prior research conspicuous.

This conflict directly affects not only my life but those of my friends and colleagues becoming professionals in this field. It directly addresses the integrity of higher education institutions and the creation, dissemination, and maintenance of knowledge in the Western tradition, and therefore should concern all those who participate within the academy. Expanding outward, labor in the United States is itself 
suffering from wage stagnation and increasing economic inequality (Mishel et al., 2015). While the U.S. holds ambivalent views toward labor unions, research generally credits organized labor with significantly reducing wealth disparity and improving workplace conditions (Collins \& Niemesh, 2019; Western \& Rosenfeld, 2011), making its decline a significant concern for future peace. I felt that a conflict of this magnitude should register importance within the peacebuilding field.

Regardless of why the conflict resolution literature has not committed more fully to this conflict, it should do so going forward. I sought to accomplish this by charting a map of the conflict and blazing a trail toward constructive peacebuilding, both within its micro-expression between GEU and PSU and its macro-expressions in the broader academic labor conflict. To do this, I needed to employ a methodology capable of addressing the broader systemic forces affecting both higher education and organized labor, that can align the disparate elements of the conflict to the dimensions binding them together, and articulates a framework for constructive action toward peace.

\section{Calibrating a Compass: Lederach's Transformative Model of Peacebuilding}

The theorist John Paul Lederach offers just such a methodology, called conflict transformation (2014), which I use here whenever describing an approach as transformative. This peacebuilding perspective views entrenched conflict systems as a complex interrelationship between the visible, discrete episodes of conflict and the underlying epicenter that informs and drives the episodes (2014, p. 28). Lederach uses the metaphor of topography to illustrate this process (2014, p. 12): In conventional resolution approaches, practitioners focus their efforts on the readily visible mountains and high peaks of stress and discord in conflict. Resolving these events is crucial work, as 
they often represent areas of intense pain or hardship, but the challenge comes once the crisis passes. Conventional techniques often stop once a dispute resolves, but in complex conflicts - such as the GEU-PSU context - these issues inevitably resurface as the underlying epicenter drives structural and relational inequities and discord between the parties. The transformative framework argues that resolving the conflict requires understanding the whole of its geography, so that the underlying elements of the epicenter can be challenged in each episode of conflict, reducing its impact within the larger conflict systems, and supporting a longer-term transition to more dynamic, peaceful relations (Lederach, 2014).

Importantly, the transformative framework explicitly tackles the challenge of power disparities cited by critical conflict scholars as a location of harm and co-optation in conventional resolution strategies. Lederach (1995, pp. 11-16) writes of the "long view of conflict," drawing from peace theorist Adam Curle's (1971) Progression of Conflict, in which he argues that many conflicts progress in a series of stages, as visualized by Figure 1. 
Figure 1: Lederach's (1995) Adaptation of Curle's (1971) Progression of Conflict Diagram

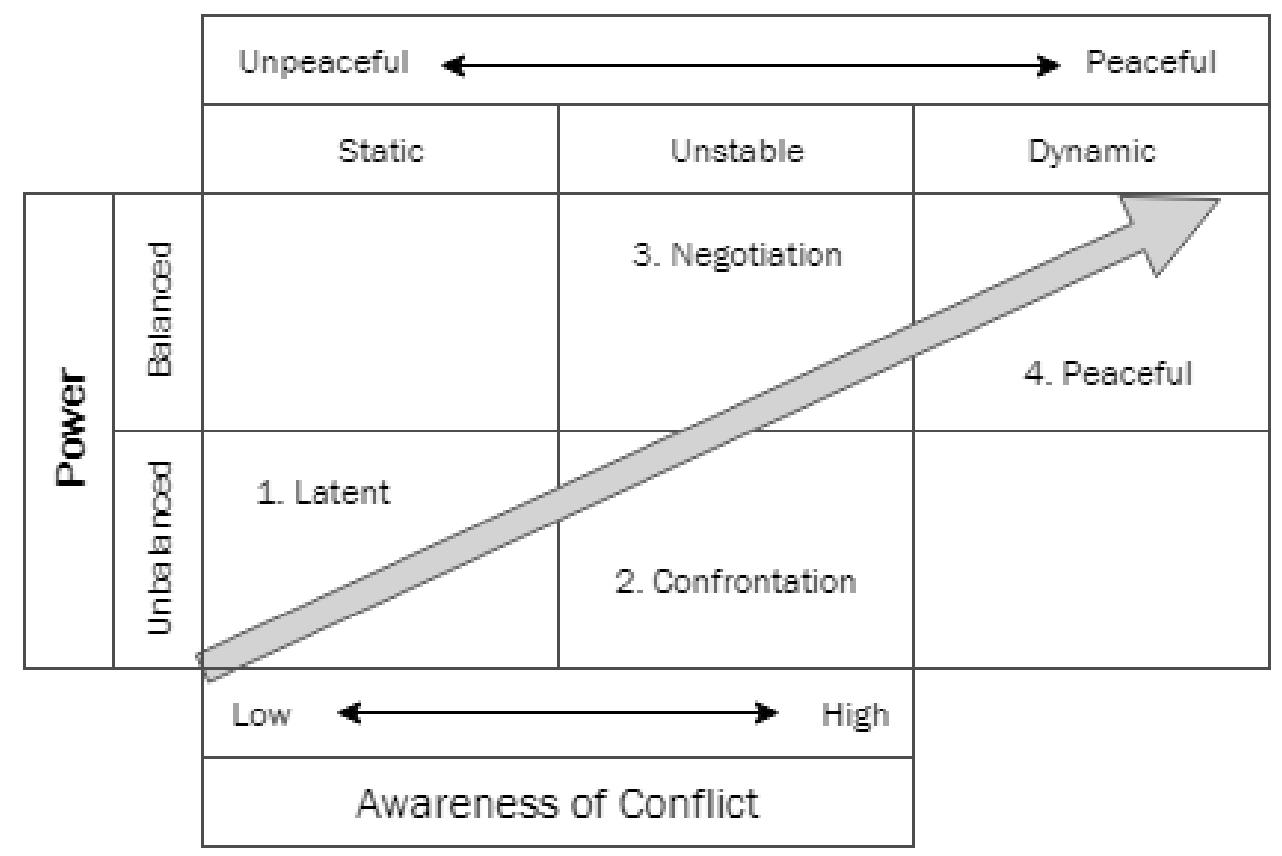

Within the transformative framework, a latent conflict between two unequal parties may progress through a series of phases from unbalanced, unpeaceful relations toward dynamic, stable peace. This first occurs with the injured party building awareness of the unjust circumstance, both within their group and in parties surrounding the conflict (Lederach, 1995). One of the challenges Beth Roy discusses in her essay, "Power, Culture, Conflict," (2008) is the idea that those who benefit from inequities in power are often entirely unaware of the privileges their power grants them and - as a result - unable to understand its dynamics in conflict. To ground this in our current context, workers in labor-management settings may agitate for better economic conditions to the bewilderment and offense of managers, who are literally unaware of either the effects of their decision-making or the impacts of their power. Through the building of awareness, which Lederach terms conscientization, the dynamics of injustice and violence are 
brought to light, leading to the second phase of the conflict: Confrontation (2014, pp. 12$13)$.

If the conflict does not resolve during the awareness phase, the injured party seeks ways to balance the inequity of power that exists between the parties (Lederach, 1995). According to the relational theory of power described by Wilmot and Hocker (2011), power between parties is interdependent - that is, bound up in their interactions, obligations, and agreements. Subordinate parties can effectively and constructively increase their power within a conflict by taking actions to either increase or decrease this level of interdependence, by preserving their power or increasing it relative to their adversary. In Roy's article (2008), she cites a woman in a research group withdrawing from participation to preserve her integrity and power in the face of inequitable relations with her colleagues. In labor-management conflicts, strikes represent a powerful way of highlighting interdependence: Managers, unaware of the way power affects their relationship with their employees, are confronted by organized workers ceasing production and demanding change, illustrating the interdependent relationship between each group (Godard, 2011; Rosenfeld, 2014; Vandaele, 2016).

Lederach (1995) writes that confrontation requires the use of strategic nonviolence to constructively balance power between disputants, and peacebuilding interventions should take an advocacy approach to support reaching equity between the parties. Without relative parity, the foundational principles of neutrality and equal regard used in conventional resolution risk co-optation by high-power parties, as low-power parties are unable to speak, be heard, or hold their opponent accountable (Wing, 2008). If peacebuilding efforts do not address these underlying issues, they only resolve the 
episodes of conflict without repairing the injustices present in its epicenter that give rise to those episodes (Lederach, 1995, p. 16, 2014, p. 28). However, when these interventions account for systemic and structural issues, they open the door for conventional resolution strategies that support reconciliation and, ultimately, evolution toward stable, dynamic peace.

Lederach is careful to note that confrontation does not necessarily guarantee a pathway toward negotiation and mediation (1995, p. 14). Instead, he seeks to reframe a historical tension within the peacebuilding field between revolutionary practitioners, who advocate on behalf of one side, and resolutionary practitioners, who advocate for all sides within a conflict $(1995$, p. 11). His answer to this tension is revolutionary in that it is resolutionary: Instead of arguing for one side or the other, he writes that each is necessary in the pursuit of justice. In fact, justice is the key component driving the actions within each phase of the progression of conflict. Those who choose to advocate for one side do so to seek justice for those harmed in the conflict. At the same time, those who employ resolution seek justice for everyone within the conflict. The strategies employed in confrontation highlight the injustice of the situation, while stable peace predicates itself on a just relationship between its parties. This justice principle flows through every element of the transformative framework, both in Lederach's earlier account of conflict and his later articulation of the transformative approach $(1995,2014)$.

Understanding these elements serves the purpose of this text in two ways. First, it equipped me with a compass whose cardinal directions point toward peace by orienting my investigation of the conflict through both the presenting disputes and the dimensions connecting them together. Second, it situated my peacebuilding approach within the 
realm of advocacy, standing for justice on the side of those harmed by its absence. In doing so, I acknowledge the desired obsolescence of this research; the ideas presented here represent the conflict as it exists now, though I hope the future will render them antiquated as the conflict evolves toward peace. However, becoming obsolete here does not mean becoming irrelevant; it stands for foundational justice for the labor movement, to seek eventual justice for all people within the conflict. Mechanically, the framework provided a way to explore and grapple with the systemic elements present within the GEU-PSU conflict, facilitating the development of the research problem and questions.

\section{Triangulating the Destination: Identifying Research Questions}

The transformative framework guides our perception not only to the mountains of discord that represent discrete episodes of conflict but to the whole of the conflict system's geography. The terrain's other features - its valleys, forests, and rivers represent the other dimensions of the conflict that affect these episodes, from the contextual fields present in the conflict to the relationships of each disputant, or even their sources of power. This process helps identify the conflict system's epicenter, which connects the elements of the geography that inculcate episodes of conflict (Lederach, 2014). The challenge here is that this conflict represented uncharted territory: Lacking information from the academic literature, I first needed to understand the lay of the land to map out these features and dimensions. This positions the central problem of this research: Identifying the nature and possibility for transformation of the conflict between the Graduate Employees Union and administration of Portland State University.

To answer this question, I first needed to solve several unknowns. A pivotal element was to recognize the epicenter driving the conflict episodes. To recall my 
questions earlier in the introduction, each concerned the source of significant changes in both higher education and organized labor. I believed investigating them would lead to the epicenter, facilitating the creation of what Lederach calls a transformational platform to affect sustainable change within the conflict system (2014, pp. 36-39). This platform simultaneously engages the epicenter of complex conflicts through its micro-expressions in each episode of discord. This platform represented the final step in deploying the transformative framework. I have collected each of these secondary questions below for organizational clarity.

\section{Marking the Mileposts: Research Questions}

The central purpose of this research was to answer: What is the nature and possibility for transformation of the conflict between the Graduate Employees Union and administration of Portland State University? To answer this central question, this text needed to explore the following secondary questions:

- How and why has higher education in the United States changed over the last century?

- How and why has organized labor in the United States declined in power over the last century?

- What are the underlying elements affecting the academic labor conflict in the United States?

Answering these questions revealed the epicenter of the conflict by connecting the contextual elements identified in both higher education and organized labor to the systemic forces affecting those elements. These connections brought into focus why these events - these episodes of the conflict - occur. Simultaneously, revealing the epicenter helped identify a transformational platform through which change can occur in both the episodic high peaks of stress and harm as well as the geographic system connecting the 
mountains together. Lederach (2014) writes that peacebuilding must address both to accomplish real transformation of the conflict.

\section{At the Trailhead: An Overview of the Text}

Beginning with an investigation of the first research question, I learned that in the 1970s, higher education experienced a series of legislative and political changes defined by a hegemonic social and economic ideology known as neoliberalism. An evolution of traditional liberal theory, neoliberalism seeks to privatize apparatuses of the state, asserting the virtue of the marketplace to efficiently valuate and distribute public goods and services, while conceiving of individuals as determinant consumers of governance. Through its auspices, neoliberalism reshaped colleges and universities from institutions serving the public through education and knowledge generation to corporate enterprises selling education to student consumers and knowledge to the highest bidder in the marketplace.

Over the proceeding decades, these policies shifted the cost of education onto students, leading to the dramatic rise of tuition and debt. Education and research, once the portfolio of full-time, tenured professors, increasingly fell to casualized, contingent faculty: Contracted adjunct instructors and graduate student employees with a fraction of the pay, benefits, and job security as their fully-employed colleagues. Research, administrative decision-making, and instruction progressively reflected the interests of private entities in the marketplace, overshadowing and replacing priorities toward societal welfare. Together, these elements created the conditions driving contingent faculty unionization as they sought to protect their well-being and view of higher education's mission. 
Outside the halls of the academy, neoliberal policy affected similar changes in other facets of the American economic landscape, resisted largely by a stagnating and archaic labor movement. Through a combination of hostile political opposition, the degradation of protective institutions, a globalizing economy, and a multigenerational shift in society's social and cultural affect, labor unions fell from their height of power and membership in the middle of the $20^{\text {th }}$ century to their lowest point today. Despite these developments, two factors represent bright spots in the dark times of the labor movement: The consistent, substantial growth of academic unionization, propelled primarily by contingent faculty, and a robust dialogue in the literature around revitalizing union strategies and tactics. However, neither academia's surge in organized labor nor its labor studies discussion has generated significant change in the conflict, and the patterns driving the corporatization of the university and the decline of the labor movement continue apace.

The literature review sets the stage for Lederach's transformative analysis. By examining the presenting issues through a lens that connects current events to their patterns and history, I connected the systemic effects of neoliberalism in higher education to its influence in the broader economy and labor movement. I argued that the episodic struggles faced by the professoriate, its graduate student apprentices, and the broader efforts of organized labor are bound together by the systemic and structural encroachment of neoliberalism - the epicenter driving the episodes. Its philosophical axioms of commodification, hyper-individualism, and market rationality systematically reframed how we relate to education, each other, communities, and society at large. The nature of knowledge work in the academy, the identities of its workers, and the economy itself 
filter through the influence of systemic neoliberalism. Therefore, creating transformative change in any of those spheres requires a reckoning of all its effects.

Having identified neoliberalism as the epicenter of the academic labor conflict, I then descriptively explored its impacts on the dimensions of higher education, the labor movement, and its stakeholders. From these descriptions, I identified prescriptive pathways to reduce violence and increase justice using the ethics of care to supplant neoliberalism's philosophical framework and strategic nonviolence to confront the inequalities between HEI administrations and academic labor. I then combined these approaches with a model of socio-ecological of union member identity to create the Systems Ecology Framework of Transformative Care (SETC). This framework acts as Lederach's transformational platform, capable of both addressing the epicenter and episode in each of the dimensions of the academic labor conflict. Finally, the implications of the model are discussed, first by exploring its applications in labor discord in higher education, its wider application to the labor movement, and finally, for the fields of peacebuilding a conflict resolution. 
Chapter Two: Literature Review

\section{The River Runs Through It: Neoliberalism and its Effects on Higher Education}

According to the sociologist Gerald Turkel (2009), before the 1970s, the state and federal governments of the United States conceptualized of higher education institutions as a public good, funding them through direct institutional support. However, beginning with the Higher Education Amendments of 1972, Congress began to restructure colleges and universities as private participants in the market, enacting legislation to significantly deregulate and corporatize them to while simultaneously withdrawing public funding (2009, p. 2). To help individuals pay for the resulting increase in tuition fees, legislators concurrently expanded the Pell Grant system to provide low-income students with financial aid. However, by the 1980s, the rising cost of tuition soon outpaced all sources of student aid, forcing students to take out loans to make up the difference (p. 3). These first policy shifts set into motion many of the changes leading to the dimensions of conflict experienced today, but knowing how this happened does not explain why it happened. The 1972 Education act amendments are mostly known for the implementation of Title IX and federal prohibition of gender discrimination in higher education. How did these amendments lead to the conflict we see today, and why were they constructed this way?

The answer, according to numerous scholars (Baum \& Johnson, 2015; Brown, 2011; Currie, 1998; Davies \& Bansel, 2007; Ginsberg, 2011; Jemielniak \& Greenwood, 2015; Saunders, 2010; Savage et al., 2012; Turkel, 2009) is the result of a hegemonic ideology known as neoliberalism. According to Daniel Saunders (2010), succinctly defining the term is difficult due to its popularity, spurring both use and misuse. 
However, he frames it as a set of economic, social, and political policies, positions, and practices bounded around three core principles (2010, p. 45):

- Belief in the benevolence of the free market, defined here as net-positive effects created by governance through market-based economic forces.

- The minimization of state influence and regulation in the economy, argued by the idea that a society governed by a genuinely free market produces the greatest amount of good for its people.

- The centering and valorization of individuals as market-rational agents: Governing society through utility-maximizing, self-interested choices as consumers in the marketplace, naturally leading to efficient social goods and policies.

Neoliberalism evolved out of traditional liberal economic theory, which posits markets as the most effective mechanism to regulate and valuate resources and goods within a society efficiently (McCarthy \& Prudham, 2004). Traditional liberalism makes a distinction between parts of society administered by the state and those regulated by the market, stating that some facets of society best serve the public good when governed by democratically represented institutions. Examples of this include education, utilities, or healthcare systems in some countries. 'New' or 'neo'-liberalism removes the distinction between the state and the market (Saunders, 2010), arguing that the market itself makes for the most efficient and democratic determinant of governance, pointing to the power taken away from individuals through institutions managed by representatives that are unaccountable to them.

This leads to the final principle of neoliberalism: an all-consuming emphasis on individuals as the primary actors of governance in a society. Drawing from behavioral economics, it conceives of individuals as rational, utility-maximizing agents, meaning they tend to make self-interested choices aimed at receiving the most benefit for each action they take (Hodgson, 2012). Neoliberal ideology argues that truly democratic 
governance requires the free participation and decision-making of individuals, touting the marketplace as the most efficient forum for this process. Saunders (2010, pp. 47-48) writes that in the framework of a neoliberal state, the decisions of a person to purchase goods or services represents the ultimate expression of government approval - literally, to vote with one's money. Following this logic, individuals would no longer need to rely on the integrity of an elected representative to ensure the proper function of state apparatuses. To place the neoliberal state into context, instead of taxing individuals and using those resources to then pay for public institutions such as schools, these schools would be administered by the market - whose value would be determined by individuals as consumers. Individuals, acting as agents of governance, would choose a school based on the best value - as in the most effective education - for the best price (Saunders, 2010).

These principles explain the historical restructuring of higher education (Turkel, 2009). Universities found themselves reorganized as market-based entities accountable to the governance of students reconstructed as consumers. Further legislation reframed the mission and goals of HEIs to act as private enterprises in this marketplace, leading to the loss of public funding and the shifting of the cost of education to individuals through increased tuition (Slaughter, 1998; Turkel, 2009). From a neoliberal perspective, this forced institutions to survive on the merit of their policies and practices, efficiently mediated by the marketplace. That same perspective argues this reorganization facilitated democratic governance through individuals, allowing them to choose institutions that provide the best education at the best price, even as the cost of education expanded. 
Turkel (2009) writes that when these changes occurred, Congress at first softened the impact for low-income students by expanding the Pell Grants and other federal aid programs. However, these sources of aid quickly lagged behind the skyrocketing cost of tuition fees, leaving low-income students few options other than borrowing to attend universities (Addo et al., 2016; Lipman, 2011). This result not accidental; its cause rests in the relentless neoliberal logic of market efficiency and its deconstruction of state and public services. The principle that successfully moved the legislature to deregulate, privatize, and defund HEIs makes the same case against all forms of government support and social welfare, arguing that these programs are economically irrational and better administrated by the marketplace (Saunders, 2010, p. 47). The casualties of this assertion included financial aid for low-income and marginalized students - a historical fact reflected in the rise in student debt amongst these demographics (Addo et al., 2016; Giroux, 2014; Turkel, 2009).

\section{The Commodification of Learning in the Academy}

Externally, neoliberalism instigated a sea change in the higher education policies and practices, reshaping how HEIs comported themselves in American society and the way students accessed education. Saunders (2010, pp. 47-48) writes that, as a hegemonic social system, neoliberalism affects every element of life both within and beyond the university. The logic of market rationality states that decisions made by individuals should reflect a self-interested desire to improve one's well-being. Within the neoliberal academy, students came to view their education through this economic calculus, translating each choice into consideration for how their education would benefit their wealth in the future. 
The education scholar Stephen Ball (2012, p. 25) details how this procedure occurs in the discussion of commodification describing a series of four abstractions that reimagines people and ideas as commodities within a knowledge market:

1. Students, faculty, and the ideas they generate are first objectified and instrumentalized - that is, neoliberalism abstracts holistic entities into a set of values conceptualized as a means to an end, in this case, the market rationality.

2. Objectified entities are then made fungible, in that the various values - utility, labor, applicability, et cetera. - of a given object are considered freely interchangeable with no impact on the final value of that object. As a result, each value may be considered equivalent to another value; the utility of a single idea or person can be freely compared against their cost to the university, for example.

3. The fungible values of an object are then made commensurable, meaning each value is described using a single, continuous variable. For example, to make hours of work commensurable for each variable of an object defines each dimension of value by the amount of time expended to arrive at the value and may rank some values as worth more time than others.

4. In a neoliberal society, the standard variable used to describe objects is money equivalence, where their economic value understands all dimensions of a commodified object. Subsequently, a professor understood through commodification is represented by their ultimate dollar value to the university, often expressed by their salary. Their passion, ideas, labor, pedagogy, and ethics are all converted into a dollar sign.

To apply this formula to the world, Saunders (2010, p. 54) writes that over time, students reinterpreted postsecondary education from an intrinsic endeavor based on selfdevelopment and -improvement to external goals focused on financial success. Instead of seeing higher education as a pathway to better themselves or society, they construct it as a stepping-stone toward higher economic status. Faculty did not escape this effect either, orienting their work to be valuable to business interests in the market (2010, p. 54), placing their research at risk for co-optation or external control by private entities (Jacob, 2009). At the institutional level, neoliberal ideology incentivized privatized HEIs to 
participate in the market through legislation granting them ownership over patents and research partnerships with corporate interests (Bal \& Dóci, 2018; Shore \& Taitz, 2012; Turkel, 2009).

Combined with the loss of public funding, this framework forced universities to seek revenue through the sale of knowledge and research, prioritizing grants and funding opportunities with direct applications to business and technology (Saunders, 2010). One example of this can be found in the United Kingdom's Research Excellence Framework, which assigns an economic value to different kinds of knowledge and then determines research funding research based on those values (Ball, 2012, pp. 25-26). Taken together, these outcomes led to the devastation of "unmarketable" programs such as the fine arts, social sciences, and humanities (Brown, 2011). Students, driven by fear of debt, find themselves funneled into degrees they believe will provide them the highest economic stability and away from other fields that may benefit them or society (Callender \& Jackson, 2008; Sieg \& Wang, 2018).

These effects have been discussed descriptively thus far. However, to truly understand the direct impacts on colleges and universities, we must look at the actual data involved in the loss of funding, changes in policies, and effects on students and the professoriate. In the next section, we move from the top of the effects discussed here to explore how neoliberalism affects each category of the academy. These statistics provided the fuel that lit the fire of unionization in higher education.

\section{Divestment, By the Numbers: The Statistics on Public Support of Higher Education}

The first, and perhaps best place to start, begins with the loss of state funding for higher education, specifically for Oregon and more broadly in the United States. Public 
funding for HEIs comes from both state and federal sources, though the funding streams tend to operate differently. According to a report by the Pew Charitable Trusts (Urahn et al., 2015), the federal government provides funding primarily through financial aid for successive students in the form of Pell Grants, veterans' benefits, and research grants. In turn, states provide most of the funding for the general operations of public HEIs. Having already established that sources of student aid are insufficient to support students in paying for postsecondary education, I will focus on state funding for higher education.

\section{A continual trend of withdrawal: State spending per full-time equivalent student.}

A report from the Urban Institute exploring state spending per full-time equivalent (FTE) student - a statistic derived by combining the total hours of enrollment or employment at an organization and dividing that number by the hours utilized by a fulltime actor in that organization - between the years 2001 to 2014 (Baum \& Johnson, 2015) found that, on average, state spending for HEIs in the U.S. dropped from a high of $\$ 10,855$ in $2000-01$ to $\$ 7,516$ in $2013-14$, a $31 \%$ decrease. The numbers are even grimmer for Oregon: State spending decreased from $\$ 9,323$ in 2000-01 to $\$ 4,559$ in 2013-14, a 51\% decrease. A more recent report from the State Higher Education Officers Association (SHEEO) (2019) shows some positive developments: Average state spending per FTE student rose to $\$ 8,173$ in $2017-18$, showing only a $25 \%$ decrease overall from 2000-2018. For Oregon, it rose to $\$ 6,491$, reflecting a 30\% decrease overall between 2000-2018. To visually organize these statistics, I captured both reports in Figure 2, with the discrepancies in the data for the 2013-2014 year on each report averaged out. While these recent numbers represent an improvement over past years, they still reflect a continual divestment of state support of higher education. 
Figure 2: State Spending per Full-Time-Equivalent Student, 2000-2018 (Baum \& Johnson, 2015; SHEEO, 2019)

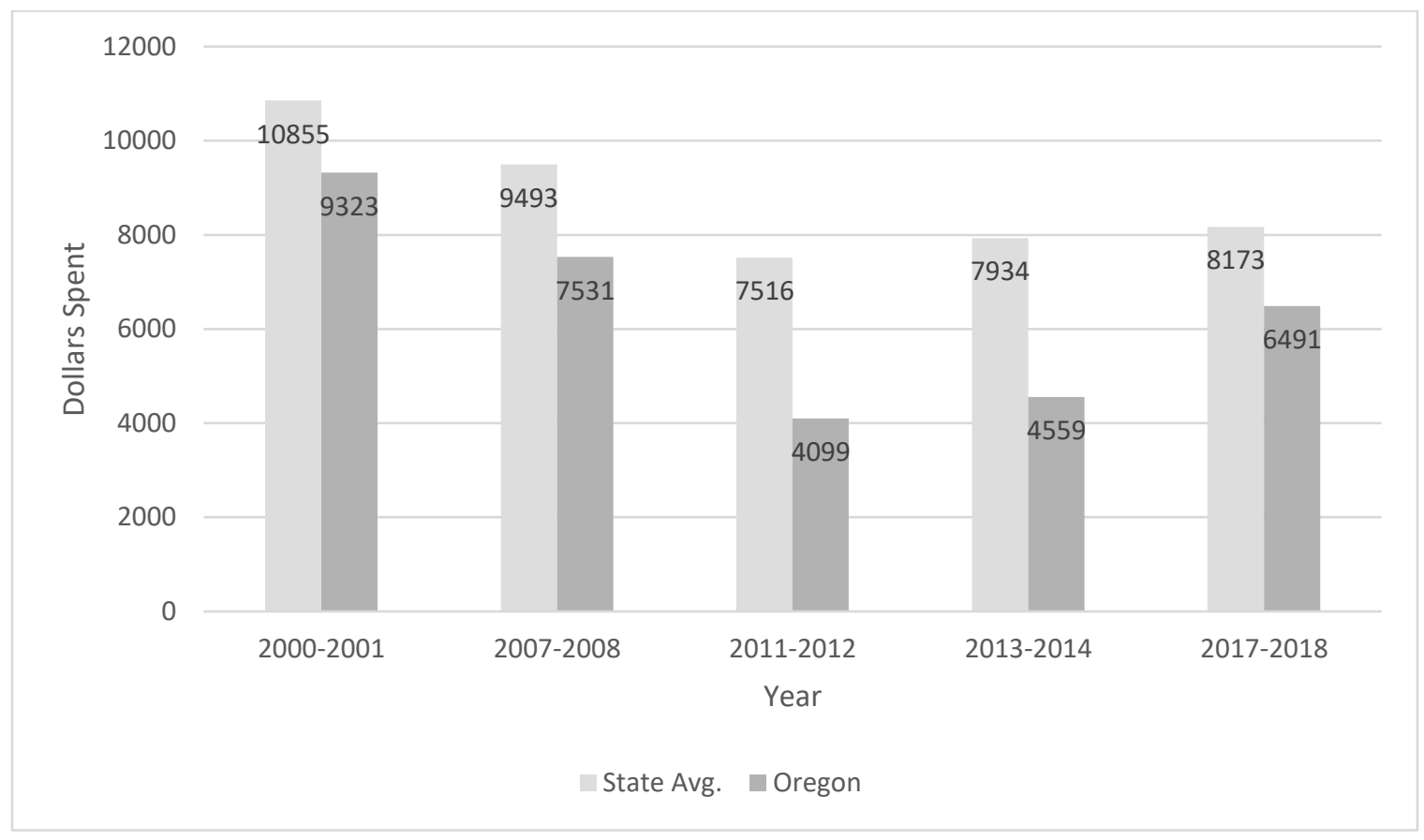

Making up the difference: Tuition recovery and its impact on students.

Turkel (2009) notes that due to the restructured, corporatized mission of higher education and the loss of public funding, universities have categorically increased tuition recovery from students, a fact reflected in the data. The SHEEO (2019) report found that in 1993 the percentage of HEI revenue generated from tuition stood at 30.8\%. However, by 2017 , that number grew to $46.4 \%$. This trend of rising tuition significantly impacted postsecondary students. Between 1990 and 2014, the average cost of undergraduate tuition at 4-year public colleges and universities skyrocketed almost $160 \%$, after adjusting for inflation (Desrochers \& Kirshstein, 2014). Many students lack the personal resources to cover the gap between sources of financial aid and tuition fees, forcing them to seek out loans to make up the difference (Turkel, 2009). For graduate students, the 
resulting debt dramatically impacted their future opportunities, choices, and behaviors within higher education.

\section{From Graduate Student to Graduate Student Employee: Debt, Desperation, and Discord}

According to the National Center for Education Statistics (NCES) (2018), 60\% of master's degree recipients, $48 \%$ of research doctorate recipients, and $75 \%$ of professional doctorate recipients held loan debt in 2015-16. The average level of debt incurred by these students rose sharply between 2000-01 and 2015-16. Table 1 displays these differences and the percentage change between the years.

Table 1: Average Graduate Student Loan Debt, 2000-2016

\begin{tabular}{|l|c|c|c|}
\hline & Avg. Debt: 2000-01 & Avg. Debt: 2015-16 & \multicolumn{1}{|c|}{ Change } \\
\hline Degree & \multicolumn{1}{|c|}{ Master's Degrees } \\
\hline Business Administration & $\$ 51,754$ & $\$ 72,390$ & $+39.9 \%$ \\
\hline Education & $\$ 35,158$ & $\$ 60,270$ & $+71.4 \%$ \\
\hline M.A. (Not Education) & $\$ 48,042$ & $\$ 79,487$ & $+65.5 \%$ \\
\hline M.S. (Not Education) & $\$ 49,024$ & $\$ 68,023$ & $+38.8 \%$ \\
\hline Doctorate (Not Education) & $\$ 52,846$ & $\$ 107,875$ & $+104.1 \%$ \\
\hline Doctorate in Education & $\$ 73,482$ & $\$ 122,179$ & $+66.2 \%$ \\
\hline Medical (M.D. or D.O.) & $\$ 136,154$ & $\$ 268,596$ & $+97.3 \%$ \\
\hline Law (L.L.B. or J.D.) & $\$ 89,969$ & $\$ 158,865$ & $+76.6 \%$ \\
\hline
\end{tabular}

Unfortunately, current research implicates a multitude of deleterious effects with high levels of debt. A meta-analysis of 65 articles on the subject (Nissen et al., 2019) categorized the results from this research. The authors found that high levels of debt during academic study: 
- negatively impacted academic performance.

- increased rates of drop-out.

- increased rates of employment unrelated to the field students pursued.

- adversely affected mental and psychological health.

- increased strain of familial relationships.

- increased rates of isolation and loneliness.

Additionally, the analysis also noted that debt created far-reaching effects after graduation as well (2019, p. 47):

- negatively impacting net worth and career prospects.

- increasingly the likelihood that graduates will hold other kinds of debt.

- enlarging social and economic inequality.

- increasing economic stress.

- influencing graduates to postpone getting married or buying a house.

External to the meta-study, other scholars noted that student debt

disproportionately affects marginalized groups (Addo et al., 2016) and can constrain the type of degree and field of study students pursue (Callender \& Jackson, 2008).

Fortunately, while the rise in tuition fees for graduate students is punishing, some have the option of seeking employment in the university to receive tuition remission to mitigate this cost, creating the motivation to become graduate student employees. This dimension contextualizes one element driving the present academic labor conflict. One of the catalysts of GSE unionization stems from the precarity they experience regarding their positions. Graduate student employees face unstable jobs that can be cut or altered without a contract to protect them, receive almost no benefits, and unsustainable compensation for work crucial to the university (Bauer, 2017; Julius \& Gumport, 2002). When this occurs, GSEs must contend, unsupported, with the inaccessible price tag of their education. 
Stepping away from students, the policies and practices of the neoliberal university also affected a crucial change in the way HEIs approached instruction and staffing. These changes led to the rise of NTT, part-time adjunct faculty who experienced the same issues as GSEs. Additionally, as colleges and universities came to resemble private enterprises, they also increasingly employed non-instructional professionals, placing increased budgetary pressure on the personnel choices for these institutions. The next section explores how these practices came into existence and their effects on contemporary universities.

\section{The Corporate University: Administrative as Management and Faculty as Labor}

As colleges and universities acquainted themselves with neoliberal ideology, they increasingly focused on efficiently pursuing revenue generation while cutting costs through their decisions around research, staffing, and curriculum (Saunders, 2010). On the one hand, this arose from an absolute necessity caused by the loss of public support. However, another cause originates from the culture of market rationality arising from neoliberal thought. Saunders writes that neoliberalism's effects reshape the goals and practices of HEIs to match the characteristics of private enterprises (2010).

This argument is repeated elsewhere by the scholar Arthur Taylor (2017).

Reflecting on the relationship between private business and its intersection into university administrations, he writes that successful businesses need to be "agile," able to efficiently pursue revenue, favoring prescriptive, top-down management styles able to make and enforce decisions quickly (2017, p. 116). A corporation's goals orient it to generating wealth for its shareholders - the "owners" - who direct its decisions and priorities. At HEIs, these actors include the institution's presidents, provosts, and trustees who are 
increasingly drawn from the private sector, further reinforcing neoliberal values (Ginsberg, 2011; Giroux, 2014).

Taylor (2017) writes that, historically, HEIs employed a collaborative governance model to university administration, where faculty and administrators worked in tandem for an institution's benefit. Through the influence of neoliberal ideology, this practice eventually gave way to a governance culture reminiscent of the traditional labormanagement dyad found in the business world: Top-down, authoritative direction from executive administration acting as bosses, with faculty expected to acquiesce and respond as employees. In this format, administrative management made programming decisions, set research priorities, set staffing policies, and controlled all other high-level dimensions of orchestrating the university, viewing each of these dimensions through the lens of market rationality (2017).

Unmarketable programs - those that could not generate revenue for the institution - were reduced or cut entirely, despite their social value (Taylor, 2017, p. 120). The value of knowledge, determined by its capacity to bring in wealth for the university, increasingly focused on applications and technologies for the market (Saunders, 2010). Taylor (2017, p. 118) argues that while this formula works for the corporate world, it is anathema to the conceptualization of the university as an institution focused on emancipatory education and socially-valuable knowledge. Saunders (2010, p. 62) carries this argument forward, remarking that HEIs began reenvisioning students as customers to which education was a product to be sold.

These practices partially set the stage for the backlash of faculty unionization. Early arguments for GSE unionization focused on the consequences of these decisions 
(Rhoads \& Rhoades, 2005), and the argument still holds salience for fields under attack, such as the social sciences and humanities (Brown, 2011; Jemielniak \& Greenwood, 2015). Economic issues, arising from the staffing determinations made by neoliberal university administrations, complemented and worsened these pedagogical concerns. In their pursuit of efficiency and market rationality, HEIs across the country began reshaping the profession of teaching, leading to the rise of contingent faculty.

\section{Money equivalence: The demise of the professor and the rise of contingent faculty.}

Instruction represents by far the largest spending category of HEIs (Desrochers \& Hurlburt, 2016), making it the logical location for cost-cutting by administrative decision-makers. The tenure system, long-criticized as economically indefensible (Saunders, 2010), saw itself supplanted by contingent faculty, who experienced massive growth over the last half-century (Halverson Cross \& Halverson, 2017; Julius \& Gumport, 2002). In 1969, only $3.3 \%$ of the faculty hired for teaching positions were described as non-tenure-track. By $2015,70 \%$ of instructional staff and $50 \%$ of new parttime faculty appointments were considered non-tenure-track (AAUP, 2017). According to one report looking at the growth of contingent faculty across the United States (Kroeger et al., 2018), GSE positions grew from 317,525 in 2005 to 370,710 in 2015 , a $16.7 \%$ change, second only to contingent faculty positions, which grew $21.5 \%$ over the same period. Another report exploring staffing trends at HEIs between 2000 and 2012 (Desrochers \& Kirshstein, 2014) found that, at 4-year public universities, the hiring of FTE faculty remained flat or even contracted, with new professorial hires keeping pace with relative changes in student enrollment. Figure 4 helps illustrate this to greater effect, showing the effective negative growth of full-time faculty in favor of contingent faculty. 
Figure 3: Average Higher Education Institution Growth of Full-Time Equivalent (FTE) Faculty and Contingent Faculty, 2000-2012 (Desrochers \& Kirshstein, 2014)

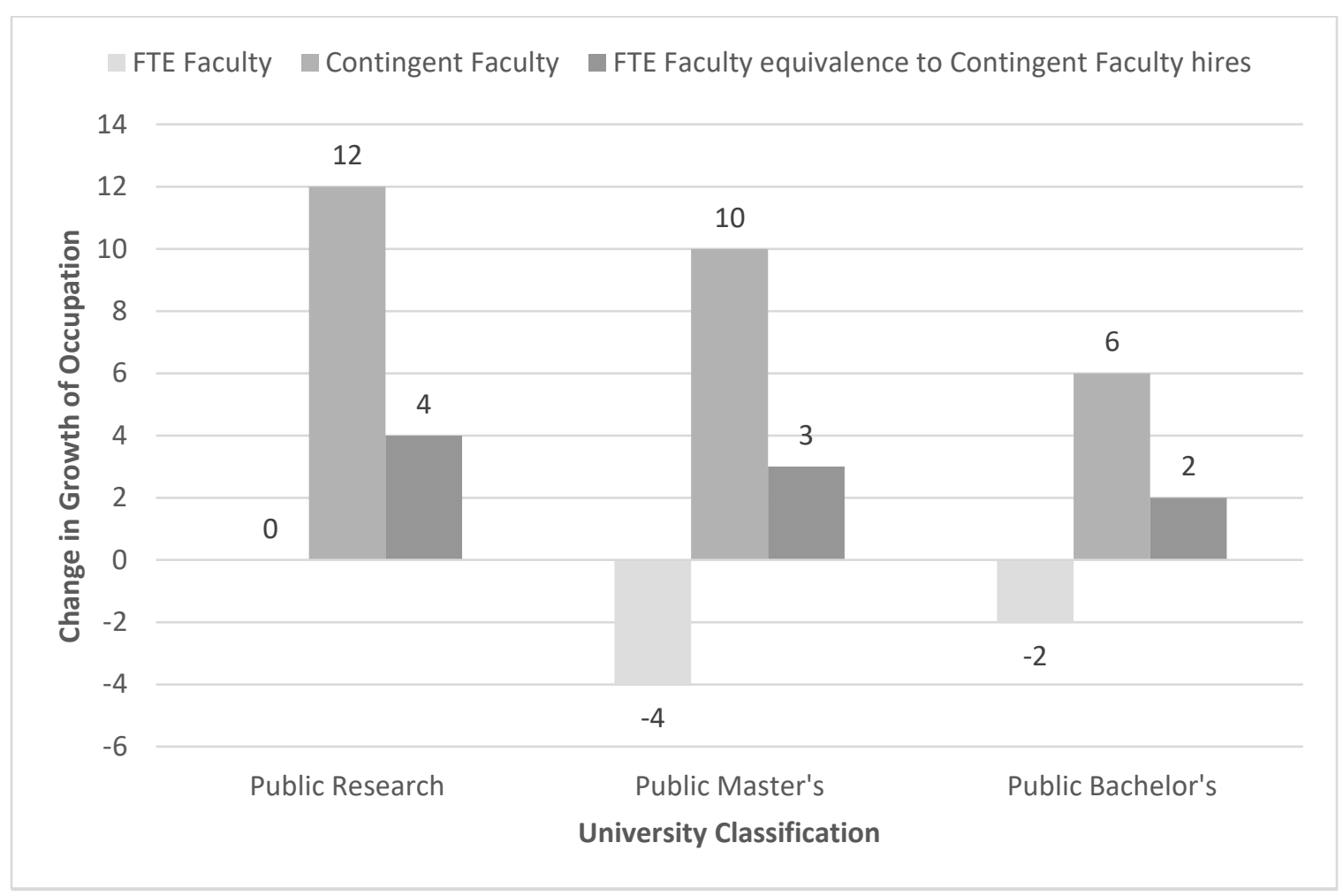

In pursuit of efficiency, corporate universities must cut costs wherever possible and commodify personnel, making contingent faculty the logical choice as an economically rational replacement for the traditional professoriate. As a result, contingent faculty now stand as the fastest-growing segment of instructional personnel at HEIs (Desrochers \& Kirshstein, 2014). While this practice serves to provide more instructional staff for students in the classroom, it comes at a cost to the well-being of those teaching the classes.

Low wages, low power, low stability, and low morale: The challenges faced by contingent faculty.

Several elements contribute to the economic and social instability experienced by contingent faculty: unsustainable compensation, non-existent benefits, a lack of career development and networking opportunities, and precarious job security (Bauer, 2017; 
Cadambi Daniel, 2016; Curran et al., 2015; Desrochers \& Kirshstein, 2014; Kitchen II, 2010). In many instances, contingent faculty end up making less than minimum wage for their work as postsecondary teachers (Cadambi Daniel, 2016). In the case of adjunct faculty, the lack of a stable contract means an instructor may be cut from a class with little to no warning if enrollment requirements are not met, or forced to work outside of a contract's terms in order to fulfill their academic obligations (Ramirez, 2018).

GSEs suffer the same risk if program cuts eliminate a position in the middle of the year, leaving the student without a source of funding for their degree (Julius \& Gumport, 2002). Finally, while contingent faculty provide the bulk of credit hour instruction at universities, they often have no say in course development or curriculum programming (Bauer, 2017; Hurlburt \& McGarrah, 2016). The bargaining agreements of PSUFA and GEU have spared adjuncts and GSEs from several of these hardships, but other issues remain, and all of them paint a picture of the reality faced by contingent faculty here at PSU and across the United States. These facts paint a picture of the reality of modern, neoliberal higher education.

Whether or not administrative decision-makers in HEIs are comfortable with this state of affairs, little effort has occurred at the national level to change these policies, which continue unabated (Kezar \& Sam, 2013). A third element also placed economic pressure on instructional staffing from a different sector of the university. Over the past three decades, HEIs have shown a remarkable rise in the ranks of non-instructional professionals employed at universities. Combined with significant increases in the compensation of senior administrators in university governance, these cemented the unsustainable conditions leading faculty to organize. 
Administrative intensity: Competition in a finite resource pool.

The term administrative intensity refers to the "bureaucratic component of organizations," (Rutherford, 2016, p. 342) the proportion of managerial and professional staff in comparison to production-related employees, in this case, instructional staff who produce knowledge and education. Since the 1990s, the share of administrative intensity at colleges and universities has sharply risen, placing increased economic pressure on the personnel budget of these institutions (Desrochers \& Kirshstein, 2014). Figure 5 shows the changing ratio of instructional staff to non-instructional professionals between 1990 and 2012 across different types of higher education institutions, with some categories at or near a 1:1 ratio of instructional staff to bureaucratic personnel (2014).

Figure 4: Change in Ratio of Instructional Staff to Non-Instructional Professionals in HEIs, 1990-2012 (Desrochers \& Kirshstein, 2014)

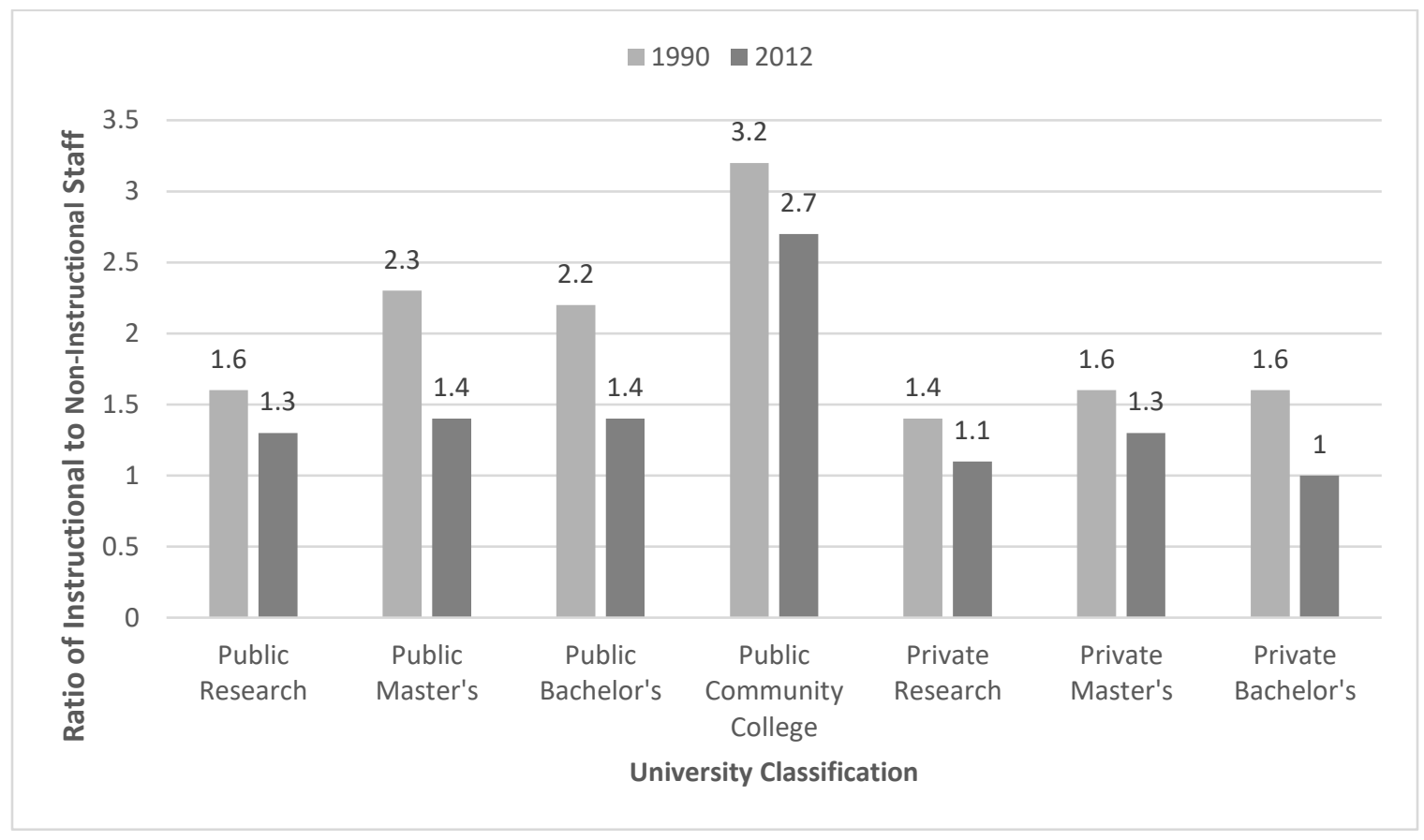

By any measure, these statistics show that bureaucratic professionals occupy a significant portion of HEI budgets, creating increased competition for the finite resource 
pool in academic institutions. However, what, exactly, do these positions do? For this paper, I used the following definitions (Desrochers \& Kirshstein, 2014, p. 6; U.S. Bureau of Labor Statistics, 2018):

- Instructional staff, including tenure and tenure-track (T/TT) faculty, contingent faculty, and graduate student employees involved in the instruction of students, research, and public service projects of the university.

- Executive, administrative, managerial (EAM) personnel, a specialized category of bureaucratic staff directly involved in the leadership, policies, and management of the university and its varied apparatuses. Examples include presidents, vice presidents, and provosts.

- Non-instructional professionals, hereafter referred to as professionals, represent bureaucratic employees who manage the operations of HEIs as well as other staff professionals who provide student services, academic, and institutional support for HEIs. Examples include human resources, business analysts, counselors, librarians, information technology staff, lawyers, and health workers.

- Nonprofessional staff, who occupy specialized positions supporting other positions or providing services for the institution. Examples include campus maintenance workers, clerks and office support, and service workers, including police officers.

The Desrochers and Kirshstein (2014, pp. 11-12) report found that, across the period, the overall share of nonprofessional staff in all HEIs shrank, mostly due to departed positions not being rehired. Instructional staff represented the largest category of growth, though the report attributes this growth primarily to contingent faculty. EAM positions characterized a relatively small share of jobs in HEIs and tended to remain proportional to student growth. Right behind contingent faculty, non-instructional professionals made up the second-largest category of growth. Figure 6 shows this change over time for different kinds of postsecondary institutions between 1990 and 2012 (2014). 
Figure 5: Average Change of Staffing by Occupational Category, 1990-2012 (Desrochers \& Kirshstein, 2014)

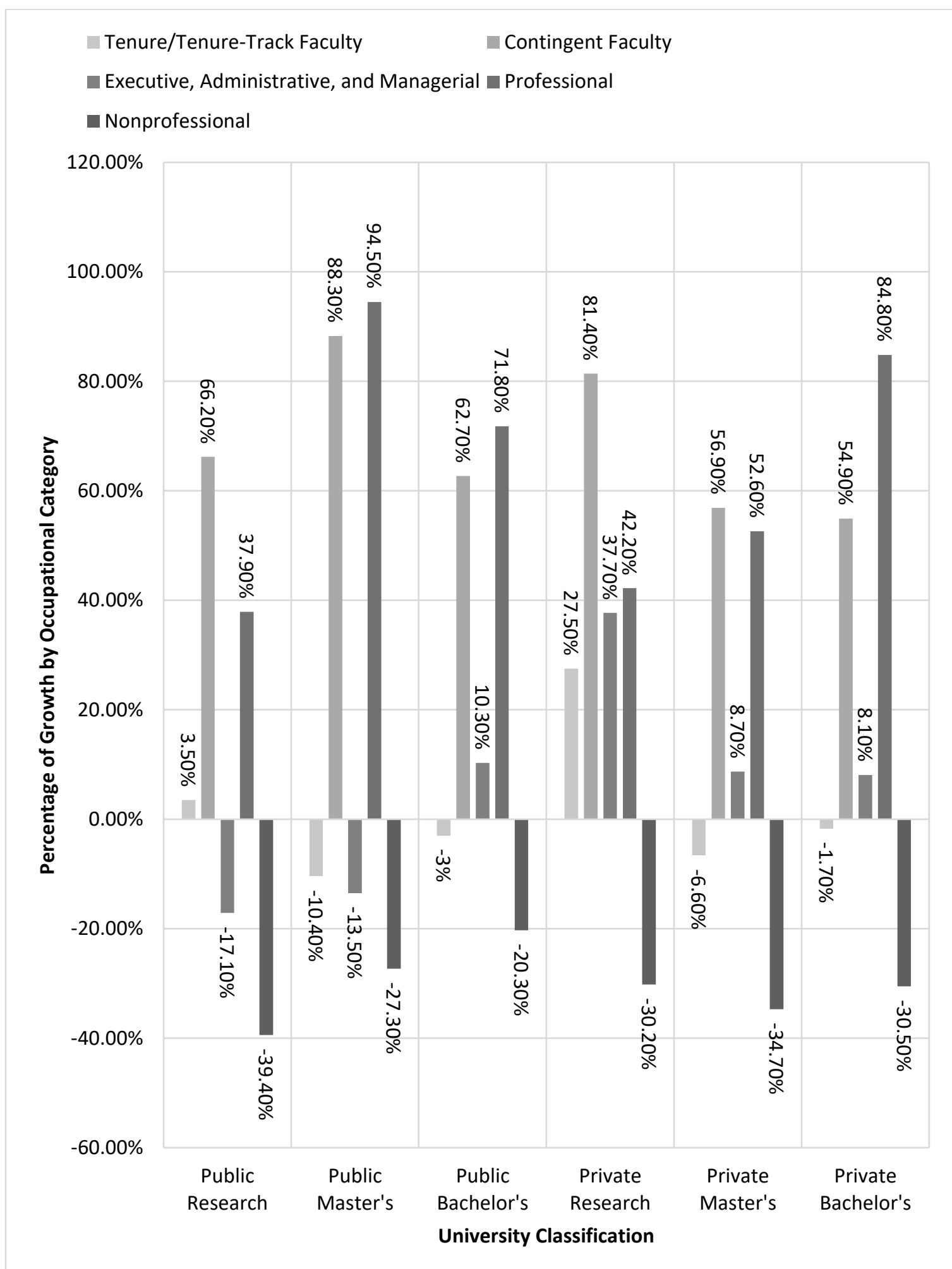


Looking at the overall impact of administrative intensity in the academy.

Does this mean that added administrative jobs are to blame for increasing the labor conflict? The answer is somewhat complicated. All other things being equal, the increase in administrative positions does place additional stress on the budget at HEIs, driving conflict over finite resources (Romine et al., 2018). In many cases, however, universities added these positions to support students, maintain information technology infrastructures, or respond to government mandates to provide psychological counseling and physical healthcare (Desrochers \& Kirshstein, 2014).

As to whether these approaches benefit students, the research is still relatively unexplored. However, several recent studies point to some positive outcomes for student retention and graduation rates, though only within specific parameters (Andrews et al., 2017; Romine et al., 2018; Rutherford, 2016). Each note that complex organizations such as universities benefit from robust bureaucratic apparatuses to facilitate the various dimensions of the institution. Rutherford (2016) found that HEIs held a parabolic relationship to the increased administrative intensity and student degree attainment, a finding later confirmed by Andrews et al. (2017). This “inverted U-shaped” relationship showed that the benefits of bureaucratic personnel at a university held at around $30 \%$, after which the costs began to outweigh the benefits (2016, p. 361). Andrews et al. (2017, p. 134) additionally commented that HEIs, with a large number of departments, gained more from a more extensive bureaucracy. Romine et al. $(2018$, p. 158) stated that increased administrative intensity helped with student retention and mitigating the disadvantages experienced by marginalized groups. 
Importantly, each of the studies cautioned that their findings were further complicated by the challenge of understanding the variables around student success and other costs of administrative intensity, requiring both further research and careful planning. Overall, however, the increase in administrative intensity appears to hold some positive effects for the university and its students, especially for complex universities with many departments. Some of the conflict may arise from the fact that administrations act as top-down decision-makers with no accountability to those they manage, engaging in behaviors inconsistent with their rationale for cutting costs in other parts of the university. This practice establishes perceptions of power disparities and enmity between administrators and faculty, reinforced by the lack of collaboration and transparency created by the corporate management of HEIs. In the next section, I explore how this element fits right alongside the programming and staffing decisions of universities in driving faculty unionization.

\section{Corporate management behaviors: Stratification and unaccountability.}

Two landmark books by Henry Giroux (2014) and Benjamin Ginsberg (2011) employ a keenly critical view of university administration, pointing to several instances of corruption (2011, p. 87; 2014, p. 121), mismanagement (2011, pp. 72-87), and unethical dealing with business interests (2011, pp. 92-93; 2014, pp. 138-142). Ginsberg's (2011) assessment of university administration borders on vitriolic, but his views reflect a cynicism and distrust commonly held by adversaries in conflict. Additionally, their fears are not necessarily unwarranted. At a time when universities fail to provide sustainable compensation for contingent faculty, HEIs have faced increasing 
scrutiny in the public consciousness for the outsized compensation awarded to executive administrators (Krupnick \& Marcus, 2015; Stripling \& Fuller, 2011; Wexler, 2016).

One article (Essaji \& Horton, 2010) describes the widening pay gap between senior administrators and professors at public universities in Ontario, finding that between 1996 and 2006, senior administrative salaries rose 43\%, with president and provost salaries growing $63 \%$, bringing them closer in line to private institutions. The authors carefully note several potential causes for this rise, such as the increasing complexity of administering HEIs. However, Essaji and Horton (2010, p. 319) also advance an economic hypothesis drawn from the private sector, called "skimming," where corporate CEOs seek increasing rents - "payments that exceed marginal productivity." In the business world, these rents amount to self-interested and unjustified pay increases that are usually resisted by board members, social norms, and scrutiny from other stakeholders - such as employees - in an organization. Where rent-seeking behavior occurs, this presents a likely source of conflict between faculty and administration (Essaji \& Horton, 2010).

Irrespective of the actual validity of administrative compensation at HEIs, this disparity drives conflict in the academic labor context. For example, the total compensation of former PSU president Rahmat Shoureshi was \$782,100 (Bauman et al., 2020) - the equivalent of roughly 35 adjunct fully-appointed adjunct faculty positions at Portland State. His severance package, totaled at \$855,985 (Manning, 2019), would fund another 38 fully-appointed adjunct faculty jobs for an entire year. Just as happened - or rather, did not happen - with corporate leaders during the 2008 financial crisis (Buell, 2016), the mistakes and transgressions made by administrative leaders in HEIs lack any 
form of effective accountability, reinforcing the perceptions of power disparity held by faculty. These actions fuel adversarial perspectives such as those articulated by Ginsberg (2011) and further drive the conflict context, adding fuel to the fire that eventually drove faculty to respond by unionizing.

\section{Answering How and Why Higher Education Changed over the Past Century}

The hegemonic influence of systemic neoliberalism fundamentally changed postsecondary education in the U.S. Through a series of reformations, colleges and universities found themselves reshaped from institutions built to promote the public good to private enterprises plighted to the pursuit of revenue for their survival. This change resulted in a cascade of effects that witnessed the withdrawal of public funds from HEIs, a shift in their culture and policies, a massive rise in tuition recovery from students, the growth of administrative intensity, and a personnel transition from the full-time, salaried, protected, and benefitted professoriate to contracted, precarious, unstable contingent faculty.

Simultaneously, the academy's restructuring saw the cost burden of education shifted onto individuals, initially supported with financial aid for low-income students. However, these sources of aid failed to keep up with the rising tide of tuition fees, forcing students to finance their education through loan debt. Graduate students sought work as employees of the university to lower these costs, working alongside adjunct instructors to become part of the contingent faculty. Together, this group of academic employees contends with unsustainable wages, precarious job stability, and an increasingly alienated, unaccountable, and opaque university system that serves private business interests over the good of students or society. These elements sketched the landscape of 
American higher education and answered my first research question, bringing the text one step closer to understanding the labor conflict context. From here, I turned to my second question, seeking to understand how and why organized labor in the U.S. declined in power over the last century.

\section{On Rocky Ground: Organized Labor in the United States and the Academy}

Historically, the labor movement in the U.S. focused on protecting the economic welfare of workers, primarily in blue-collar industry, utilizing the combined power of employees in the workplace to resist the formal power embedded in management and owners of organizations (Calhoun, 2002). Where a single worker often lacked the power to negotiate effectively for increases in wages or workplace regulations, employees working together in a union could pool their influence to achieve such change. In their seminal text on the subject, Freeman and Medoff (1984) wrote that union strategies typically involved nonviolent forms of direct action, including public relations campaigns, negotiations, boycotts, and - in several cases - strikes and sit-ins. In the contemporary era, unions are legally recognized entities, represented in a workplace by a collective bargaining agreement (CBA), the joint agreement between a labor union and management of an organization. These documents lay out accords and regulations agreed to by both the workers and management of a business (1984).

The history of organized labor in the United States has seen several dramatic shifts over the last hundred years. In a retrospection on Freeman and Medoff's work, labor scholar Jake Rosenfeld (2014) explains that for a significant part of the $20^{\text {th }}$ century, unions enjoyed a significant amount of influence in both the political and social landscape of the U.S. However, by the 1970s, this power had begun to wane, plagued by 
challenges both within the movement and beyond it. Internally, unions stagnated from a lack of strategic innovation, recruitment, and singular focus on concrete economic issues to the exclusion of other social justice concerns. Externally, the movement faced an increasingly complex globalized economy and stiffening political resistance from corporate interests and political leaders in the United States. Two decades into the $21^{\text {st }}$ century, the labor movement stands at the same level of influence it at its lowest point a century earlier (2014).

However, within that time, trade unions left an impressive legacy that reduced economic disparity across the U.S. (Collins \& Niemesh, 2019). Indeed, the labor studies literature reflects a significant negative correlation between the share of wealth owned by the wealthiest of American households and the labor union membership (Bivens et al., 2017; Kochan \& Riordan, 2016; Mishel et al., 2015). While the dimensions of economic equity and wealth distribution are far too complex to be explained by a single relationship, scholars note that when unions were at their apex, all workers benefited from an increased share of wealth and workplace protections (Collins \& Niemesh, 2019; Freeman \& Medoff, 1984; Rosenfeld, 2014).

One crucial element to note in the decline of union power, however, is that this loss has not been consistent across all industries in the U.S. In some parts of the workforce, including postsecondary education, union membership continues to grow (Sproul et al., 2014). The next section explores the history of academic unionization and its successes. These connect to the research on union revitalization, and the work to rebuild the power once wielded by organized labor. 


\section{Bread and Roses in the Ivory Tower: The Academic Labor Movement}

In a historical treatment of the subject, education scholar Timothy Reese Cain (2010) explores the century-long history higher education maintains with the organized labor movement. Cain writes that while faculty unions came into the popular consciousness in the 1960 s, their origin technically started in 1915 with the founding of the American Association of University Professors (AAUP), though this group did not operate as a standard labor union. Fearing the repercussions from association with radical labor, the AAUP explicitly and fervently described itself as nonunion, focusing instead on defining the principles of academic freedom and the concept of tenure. The first trade union association of teachers arrived a year later when, in 1916, when four disparate teachers' unions came together under the American Federation of Labor to form the American Federation of Teachers (AFT) (2010, pp. 885-886). At the time, AFT focused exclusively on K-12 education, but in 1918 they expanded their membership policies to include faculty in higher education. While the two groups disagreed on the point of unionization at the time, the shared concerns of both organizations echo loudly with today: Resisting the influence of business interests in the profession and practice of ideas (2010, pp. 898-899).

Academic unionization accelerated in the 1960s and 1970s, growing to represent $27 \%$ of all faculty in the United States in 2014 (Sproul et al., 2014). This growth occurred mainly in public universities in labor-friendly states due to the National Labor Relations Board v. Yeshiva supreme court ruling, which characterized faculty in private-sector universities as management due to their outsized influence on institutional governance (Julius \& DiGiovanni Jr., 2019). To this day, faculty unionization in the private sector 
remains hamstrung, limiting membership amongst the traditional professoriate. The academic labor movement entered its modern era with the rise of contingent faculty in the 1990s and the issues they confronted in the neoliberal universities (2019, p. 131). As contracted personnel with little agency in university governance, these employees did not fall under the Yeshiva ruling, allowing them free association with unions. Additionally, the 2016 ruling by the NLRB, allowing graduate student employee unionization further expanded the organizing capacity of contingent faculty (Kroeger et al., 2018).

Consequently, postsecondary education experienced an upswelling of union recruitment in recent years. From 2003 to 2013, union membership amongst colleges and universities experience an average annual membership growth rate of $12.83 \%$, primarily driven by contingent faculty (Sproul et al., 2014). Over the 14 years from 1998 to 2012, the ranks of adjunct faculty represented by unions almost doubled, growing from 75,882 to 147,021 members (Julius \& DiGiovanni Jr., 2019, p. 131). More than 65,000 graduate students claimed membership to GSE unions, representing 20\% of the GSE demographic (Sproul et al., 2014, p. 8).

Contingent faculty found value in hitching their fortunes to the organized labor movement. Indeed, research bears out that academic unions have created improvements in compensation and the employment conditions of adjunct and GSE work (Halverson Cross \& Halverson, 2017; Julius \& Gumport, 2002; Kroeger et al., 2018; Rogers et al., 2013; Wickens, 2008). There is even evidence that the presence of faculty unions increases university performance and efficiency (Cassell \& Halaseh, 2014). At a time when other union industries suffer setbacks, academic organized labor has succeeded in at least some of its goals. The literature attributes much of this success to the innovative 
strategies and tactics employed by contingent faculty unions (Ramirez, 2018; Rhoades, 2015). To better understand these strategies, I turned to the labor studies literature to explore the challenges faced by unions and the three-decades of work looking at how to restore its power in the American workforce.

\section{Un Au Coup par Coup Résistance: The Obstacles Faced by Organized Labor}

In recent decades, a robust dialogue began to form around rebuilding union influence (Murray, 2017). To see where this research endeavors, it is necessary first to appreciate from which it comes. At the turn of the millennium, the sociologists Kim Voss and Rachel Sherman (2000) identified several issues within the organized labor that led to its stagnation, made worse by external opposition. In their work, they apply Robert Michels' (1915) iron law of oligarchy to analyze the U.S. labor movement. This theory argues that all organizations, as they mature, display a tendency to gravitate away from democratic governance and radical goals, progressing toward oligarchic leadership and conservative goals aligned to the interests of maintaining its leadership.

In Voss and Sherman's (2000, p. 310) analysis, they note that the labor movement employed a radical activist approach early on in its work, using disruptive direct-action tactics to achieve its goals and pursuing social justice policies for all employees in the workforce. This activism spurred the growth that led to organized labor's power through the 1930 s to the 1970 s. However, at the zenith of their influence, they argued that unions began to exhibit Michels' oligarchic tendencies, abandoning radical politics in favor of concrete economic goals, disruptive tactics for comfortably non-confrontational negotiation, and limiting recruitment efforts to existing industries. 
Rosenfeld (2014) points to other sources of weakness, including the movement's singular focus on workplace economic concerns to the exclusion of other systemic forces like racism, alienating and excluding significant populations and social movements. It took the work of the Hispanic labor organizer, Eliseo Medina, to effectively mobilize large swaths of immigrant and women workers under the Service Employees International Union (SEIU) when prior organizers ignored the value of these demographics. Other marginalized black and brown communities have only recently been approached for union membership, though these groups themselves have a long and troubled history with union racism, highlighting organized labor's struggles with these systemic effects (2014, pp. 131-159). Together, these variables weakened the labor movement's capacity to both adapt to, and withstand, the external forces marshaling against them.

Though Rosenfeld (2014, p. 11) acknowledges the internal problems facing organized labor, he warns that these issues must be seen within the greater context of the external influences affecting the labor movement. He argues that these pressures represented a more significant threat than the internal problems faced by labor, highlighting two circumstances occurring today (2014, pp. 12-13): First, Rosenfeld writes of the fact that even with the advent of new strategies, unions have failed to recruit many new members to the movement. Second, he points to parallel issues experienced by other labor movements around the world, such as in the United Kingdom, Canada, and Australia. To Rosenfeld, the real obstacles organized labor faces come from external forces, marking out four in particular: Public approval and support for union work, the 
changing economic landscape, the institutions defining and protecting the labor movement, and political opposition (2014).

\section{Public approval and the effects of cultural opposition to union values.}

Rosenfeld notes that rates of public approval - at the time of his writing suffered from historic lows $(2014$, p. 14). Recent research shows that this trend has reversed itself, with union approval reaching a 15-year high (Saad, 2018), but the reasoning behind Rosenfeld's writing demands attention. Various forces - such as American conservatives and business interests (Powell Jr., 1971) - have long fought organized labor's public image, from media outlets such as The Wall Street Journal to industry associations such as the National Association of Manufacturers (Rosenfeld, 2014, p. 17). He writes that public approval remains an essential element of this external opposition, as it influences each of the other three dimensions discussed.

\section{The changing landscape of the American economy, alienating union relevance.}

Rosenfeld's (2014, p. 18) second dimension focuses on the economics of the U.S. and its transition toward global trade from the 1970s onward. At the beginning of the decade, economic downturns weakened worker power, as employers had an easier time cycling labor due to high unemployment, but Rosenfeld argues the real change occurred when industries entered the global economy. With cheaper labor suddenly available across the world, it incentivized corporations to outsource their production to other countries where they could pay a fraction of the labor costs in the U.S. Additionally, relaxed trade regulations allowed increasing competition from other countries, forcing many companies where unions existed to close. Technological innovations further 
reduced labor needs and, taking each element together; these changes to the economy chipped away at union membership over the following decades (2014, p. 19).

\section{Institutions and the nature of union organizing in American society.}

The third dimension focuses on the way unions in the U.S. negotiated their collective bargaining agreements with employers (2014, pp. 19-21). Rosenfeld notes that the success and survival of unions depend heavily on the level of protection and societal access a country offers its workers through its institutions. Citing countries such as Norway as an example, he writes that the country's institutional construction of labor allowed its unions to favorably bargain with entire industries at the national level as well as administer its unemployment program. These elements not only helped the Norwegian labor movement negotiate beneficial working conditions for union and non-union workers alike but effectively allowed their labor movement to contribute to the country's macroeconomic policy (2014, pp. 19-20).

These institutional elements did not exist in the U.S. Its unemployment insurance program remains solely in control of the Department of Labor, and while the movement maintained industry-level pattern bargaining through the mid- $20^{\text {th }}$ century, industries successfully broke this form of negotiation in the 1980s. This change forced unions to bargain unfavorably per individual businesses. Simultaneously, Rosenfeld (2014, p. 22) writes that as political forces continually weakened the National Labor Relations Act (NLRA), the legislation protecting unions. This allowed enterprises to subvert the NLRA's regulatory body, the National Labor Relations Board (NLRB) to simultaneously flout regulations without consequence and turn its dispute resolution mechanisms against the unions. Thus, the lack of institutional access to governance at the societal level, 
combined with the degradation of the organization protecting labor interests, substantially contributed to the decline of the membership and influence of American unions.

Importantly, these effects were facilitated by the final dimension of Rosenfeld's analysis: Legislation and regulation imposed by hostile political opposition across the government of the U.S (2014).

\section{Political adversity and the deconstruction of union protections.}

Rosenfeld devotes a substantial section to discussing the political attacks that took place against organized labor over the last half-century (2014, pp. 21-30). Here, he writes of the progressively destructive effects anti-union neoliberal opposition has had on the regulations governing unions, from congressional opposition shaping legal language against unionization votes to the direct intervention of President Ronald Reagan against the labor movement during the air traffic controller strike of the 1980s. These consequences weakened enforcement mechanisms protecting unions against unfair labor practices, with Rosenfeld citing an example where a company faced almost no penalties to committing over 20 labor law violations following a seven-year legal battle through the NLRB (2014, p. 24).

He argues that even as American society continually evolved with new laws and regulations, these political forces prevented a similar evolution in labor laws. The result progressively eroded the relevance of unions in the economic and social landscape of the U.S., contributing in dramatic ways to the decline of union power seen today $(2014, p$. 29). These external elements, along with the internal challenges described earlier, offer a compelling picture of the issues organized labor struggled against in recent years. Despite 
this, a host of creative strategies arose to meet these problems, exploring ways to increase recruitment, improve bargaining, and better address the needs of union members.

\section{“Don't Mourn, Organize!": The Research and Strategies of Union Revitalization}

In an article discussing three decades of revitalization research, labor studies scholar Gregor Murray (2017, p. 11) identified and explored four separate themes tackling different challenges faced by unions:

- Modernization, innovation, and strategic renewal, which looks at the organizational structures and strategies employed by unions to identify how to improve them.

- Representative spaces, which focus on how the union represents itself to its members, other organizations, and society at large.

- Collective action repertoires, which examines ways that labor unions to expand their impact by diversifying their actions.

- Connectedness, which delves into how unions can connect to unincorporated groups and society at large.

This research focuses on English-speaking countries such as the U.S. and U.K., but draws on work from other global countries as well, providing a rich resource of potential avenues for union rebirth.

\section{Modernization: Bringing union strategy into the $21^{\text {st }}$ century.}

Murray (2017, pp. 11-13) remarks on the broader revitalization strategies the labor studies literature discussed - innovative approaches to achieving goals, using technology, and internally administering union organization. Many of these strategies are already employed by contingent faculty unions today (Bauer, 2017; Ramirez, 2018; Rhoades, 2015), which have helped win them some of the benefits seen in outcomes of unionization. However, as Rosenfeld (2014, p. 158) discusses in his book, the victories won using these innovations nonetheless failed to reverse the decline of union membership. The issue here rests in the fact that without addressing both elements of the 
two-pronged challenge - both the internal organizational issues and the systemic forces influencing these conflicts - the individual battles unions win may yet cost them the war.

\section{Representative spaces: Understanding union identity for both members and outsiders.}

The representative spaces segment (Murray, 2017, p. 13) discusses research concerning how organizations represent themselves to their members, their workplaces, and their communities. It cautions against simply seeking sources of power through union mergers and centralization, noting that consolidating union power through mergers requires the subsequent capacity to leverage each union in the bargaining process. Further, Murray reflects on the challenges around how to organize in communities to recruit new members, especially given a legal and political climate so hostile to union interests (2017, pp. 14-15).

He points to the evidence-based practices that systematically identify the elements common in successful campaigns (K. Bronfenbrenner et al., 1998), but notes that unions have generally been slow to take up these strategies (Murray, 2017, p. 14). While this inertia could result from the organizational stagnation identified by Voss and Sherman (2000), he theorizes that the more substantial obstacle exists lies in reconciling unions with the identities workers who traditionally existed outside of organized labor's purview: Casualized workers, women, and migrants (Murray, 2017, p. 15). Addressing that challenge requires a reflective look at unions themselves and begins to grapple with the larger systemic issues influencing the labor context. 


\section{Collective action repertoires and connectedness: The impacts of union action in the} world.

In the final two themes, collective action repertoires and connectedness, Murray (2017, pp. 15-22) explores the changing nature of both employment and workers themselves. These focus on how unions engage with communities and the individuals within them, whether through coalition-building, organizing, or by courting traditionally excluded communities. These themes extend the concept of social movement unionism, an organizing strategy that seeks to build power through community coalitions and ties to other social justice movements (Tattersall, 2011; Waterman, 1993). The problem Murray (2017, pp. 15-19) identifies is one of disconnection: Regardless of who labor unions work or align with, the organizing experience of its veteran leadership relates to a labor context a generation removed from the present day. He writes that tactics employed by current union leadership fail to account for casualized jobs, the globalized infrastructure of labor, and other developments caused by neoliberal systems.

Murray (2017, p. 14) writes that these older cohorts are not necessarily obsolete, but that new leaders who understand the current labor context need a seat at the organizing table. He asserts that, historically, unions tended to address the needs of workers during a time when the workforce was comprised mainly of full-time, ethnically homogenous men working careers that provided the sole income for households $(2017$, pp. 21-22). However, the workplace is now commonly made up of women, immigrants, and casual workers, such as adjuncts, that have different needs and contexts from traditional union members. Labor strategies need to not only incorporate these new 
workers but train them into leadership, as they have the best perspective on the issues facing their demographics today.

Murray (2017, p. 23) closes his piece by concluding - much in the same way as Rosenfeld (2014) - that strategic innovations are not enough to reverse the labor movement's fortunes, especially in the face of weakened institutional support. As occurred in higher education, neoliberalism shifted every aspect of the economic lives of workers, and meaningful change requires addressing those changes holistically. The fundamental purpose of unions - well-being, equity, and dignity for workers - remains unchanged. Each of the four themes must be appropriately satisfied using new, participatory methods that account for the identities and realities of modern workers. This argument requires an approach to organized labor that engages not only the economic concerns of workers but their social and relational contexts, all of which have radically shifted in recent years (Murray, 2017, p. 23).

\section{Answering How and Why the Labor Movement Declined}

Organized labor once held a great deal of power in the United States, helping to reduce wealth disparity for all workers, regardless of their membership to a union. However, beginning in the 1970 s, the movement began a slow yet steady decline in both membership and influence, resulting in its paucity today. Unions struggled against an assortment of challenges, both within its structural administration and from external adversities. Internally, unions struggled against the organizational stagnation described by Voss and Sherman's (2000) application of Michels' (1915) iron law of oligarchy. From the outside, Rosenfeld (2014) described a combination of cultural, social, and political pressures that weakened union influence and the enforcement mechanisms protecting 
them. Despite these weaknesses, specific sectors of union organizing - including postsecondary academic labor - have experienced consistent growth and success.

To understand why I explored the factors leading to union decline and the subsequent research around its revitalization. Scholars in a variety of fields and across many cultures spent decades trying to reverse these trends, as explored in Murray's (2017) meta-analysis of their work. He organized these efforts into four themes, which focus on identifying new strategies, reconstructing union identity and community, and shifting the way the labor movement impacts society and the people within it. This research answers my second research question yet leaves the third incomplete. However, the knowledge gleaned from my exploration of higher education offers a glimpse at a potential systemic element affecting the labor union: Neoliberalism. Through the application of Lederach's (2014) transformative methodology, I will show how the ideology at the heart of the changes in the academy was the simultaneous architect of organized labor's downfall. 
Chapter 3: Methodology

\section{Siting Landmarks for Peace: Understanding the Transformative Framework}

To briefly review the structure and purpose of this text, my fundamental goal was to determine the nature and possibility of transformation in the GEU-PSU labor conflict. To answer this question, I employed Lederach's (2014) transformative methodology, which seeks to create peace by transforming the relations between adversaries, increasing justice, and decreasing violence in their relationship. The framework accomplishes this by creating sustainable, peaceful change along four dimensions: Personal, relational, structural, and cultural. These domains look at how injustice and violence occur at different levels in a conflict and seek to address these elements descriptively and prescriptively (2014, p. 23).

Description and prescription situate the solution of a conflict within the shared experiences and worldviews of the disputants. This hinges on a challenging yet critical consideration: When we seek to create peace, we must first ask whose peace we are building. An obstacle to sustainable peace occurs when any one party - including the peacebuilder - decides what increasing justice or decreasing violence looks like for the other parties. Attempting to enact objective criteria of justice unitarily is inherently problematic and can disempower, harm, or coerce disputants - especially disadvantaged ones (Avruch \& Mitchell, 2013; Lederach, 1995; Smith, 2012). Parties may, however, agree to a shared vision of justice and harm reduction, and I contend that this is the crux of Lederach's (2014) assertion.

Understanding and transforming conflict descriptively means reconciling how it affects and challenges our understanding of the world, our relationship to our adversary, 
and our understanding of the systems and contexts in which we participate (2014, p. 23). Without descriptive participation from each party, peacebuilding efforts cannot fully understand nor resolve the conflict. By ignoring a participant's world, those actors are, in a sense, erased. Therefore, each participant's worldview must be present in any long-term peacebuilding process, though this requires prescriptive mediation of the conflict (2014).

Prescriptively viewing conflict means taking action to ensure disputants can communicate and interact with each other equitably through the parties' relationships, structures, and contexts (2014, pp. 23-24). If parties cannot communicate or accord, if they inflict coercion through power disparities, or if they lack accountability with one another, their descriptive contributions to transformation become meaningless. Thus, reducing violence and increasing justice requires both description and prescription from all parties in the long-term transformation of a conflict (2014).

\section{The four domains of conflict and their change goals.}

Lederach (2014, pp. 23-25)describes four domains present in a conflict, each representing a different way that conflict invades and transforms the parties in discord. The transformative framework elicits these domains descriptively, then delineates prescriptive change goals to improve capacity, equity, and accountability. These goals are equally important, interconnected, and may proceed in any order - structural goals may improve the effectiveness of relational interventions, or vice versa. The importance lies in understanding and addressing each of them. The four domains are as follows (2014, p. 25):

- The personal level, where conflicts alter our understanding, valuation, and autonomy of self. Affecting transformative change here seeks to maximize well-being, capacity, and autonomy. 
- The relational level, where discord distorts the communication and interactions of disputants. Transformation involves creating dialogue, expanding understanding, and building interdependence between parties.

- The structural level, which focuses on the larger institutions, organizations, and systems affecting and affected by conflict. Creating transformative change here requires addressing the underlying factors driving conflicts, reducing harm through nonviolent intervention, and constructing new structures that support sustainable peace.

- The cultural level, which examines how conflict broadly affects our communities and identities, facilitating injustice and violence. Here, transformative peacebuilding seeks to understand the cultural factors fueling the conflict and uses interventions to shift these elements.

Ultimately, it is the conjunct disputants who must decide the form and function of

the change goals. While a peacebuilder may conceptualize what an increase in justice or a reduction in violence looks like, they must exercise care and reflection with their views in a conflict. Practitioners risk disempowering, depriving, overriding, or otherwise harming parties through the privilege of their power and expertise (Trujillo et al., 2008), subverting the possibility of transformation (Lederach, 1995; Schirch, 2013). Among other goals, the transformative framework strives to nurture procedural justice - to maximize the agency and autonomy of the participants in conflict - and substantive justice - meeting the basic needs of a conflict's stakeholders (Lederach, 2014). As an insider to this conflict, I speak from the perspective, and in advocacy, of academic labor in the descriptive and prescriptive understandings of these conflict domains.

\section{Basecamp to Summit: Creating the "Big Picture" View of a Conflict}

Lederach $(2014$, p. 27) writes that in order to accomplish change within the four domains, we must adopt a "big picture" view of the conflict, which connects episodic disputes to the underlying epicenter seeding the discord. To construct this broader view, he offers an analytical framework composed of three lenses of inquiry: The "presenting 
situation," the "horizon of the future," and the "development of change processes" (2014, pp. 30-33). These lenses linearly establish themselves but relationally influence each other. To visually organize these lenses and their relationships, I have adapted Lederach's diagram in Figure 8.

Figure 6: Lederach's (2014, p. 31) Transformative Lenses of Inquiry

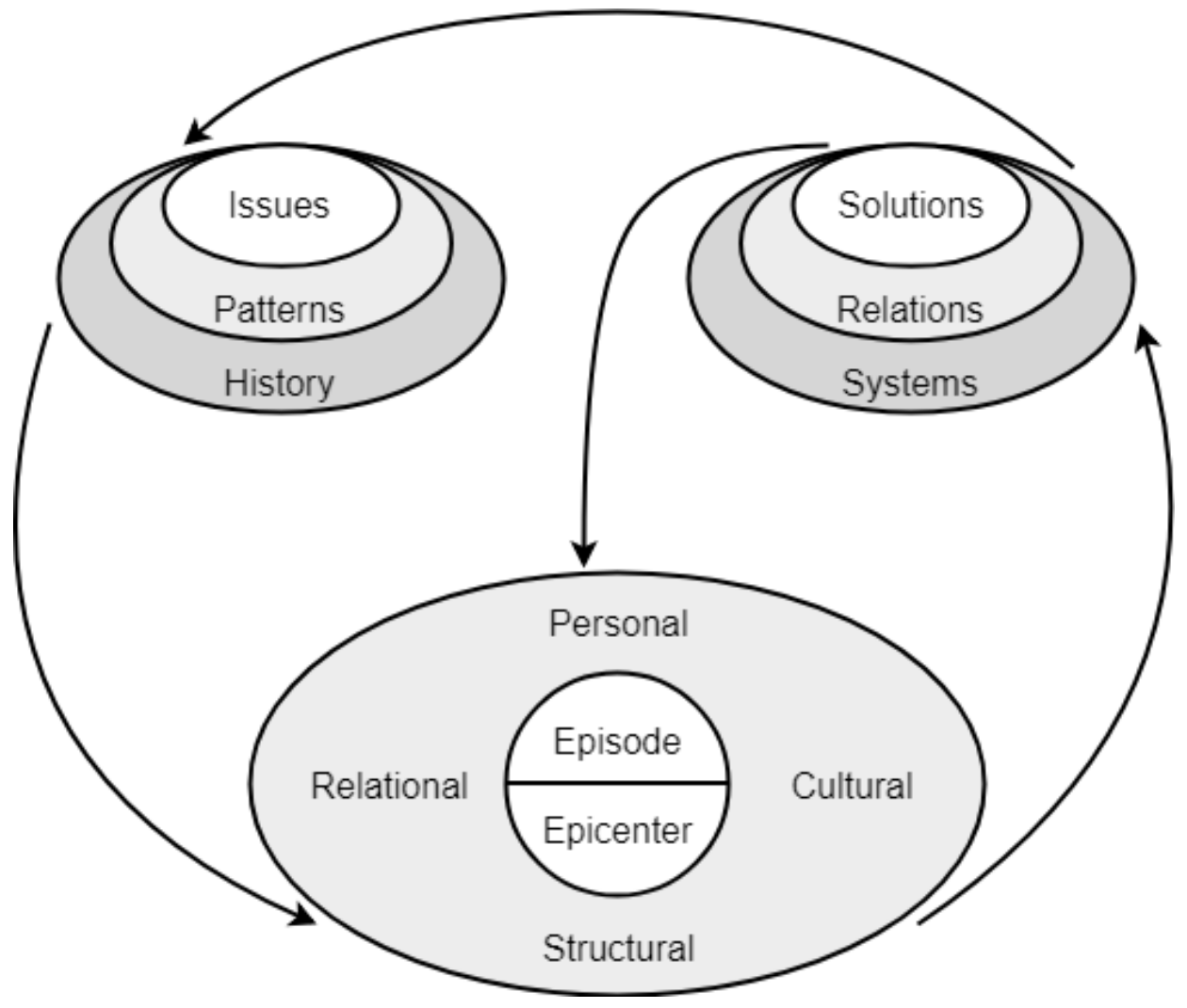

\section{Inquiry 1: The presenting situation.}

The first inquiry lens takes the issues experienced in the present conflict and connects them to patterns in historical events. Lederach writes that the presenting issues provide openings to understand the past but cannot change it, instead providing opportunities moving forward to create constructive change and restoration. Finding where these connections occur create opportunities to understand how the conflict affects each of the personal, relational, structural, and cultural conflict domains. In a sense, the 
presenting situation descriptively illustrates the conflict, expanding insight into the effects and experiences adversaries have in addition to helping identify the underlying patterns - the epicenter - fueling discord. However, recognizing these patterns is not, by itself, enough to create change. The presenting situation requires the prescriptive elements of the second lens of inquiry to support peaceful intervention (2014, p. 30).

\section{Inquiry 2: The horizon of the future.}

Where the presenting situation establishes the milieu of the conflict's past and present, the second lens of inquiry invokes the story of the future (2014, pp. 30-31). To characterize this lens' transitive nature, Lederach employs the metaphor of a horizon, writing that it "Can be seen but not touched. It can provide orientation, but it requires constant journeying each day." The horizon of the future represents the other side of transformation's descriptive coin, reflecting what parties hope to change about the conflict prescriptively. This lens guides the creation of change processes - how parties seek to reshape each of the domains of the conflict. However, just as our view of the horizon transposes when we travel, this lens evolves with the conflict's progression and interventions, requiring continual reorientation toward peace (2014, pp. 30-31).

\section{Inquiry 3: The development of change processes.}

The final inquiry lens reconciles the past, present, and future of the prior lenses with the domains of the conflict. This process examines how the conflict affects the personal, relational, structural, and cultural dimensions of discord and seeks to create interdependent and complementary processes to affect change in both the episodic disputes that arise and the epicenter driving the conflict. Moreover, like the first and second lenses, the development of change processes iteratively transforms as events take 
place within the conflict context. As the epicenter shifts in influence and relevance or episodes of conflict imprint on the domains, they affect how parties view the future and understand the past (2014, pp. 31-33).

\section{The relational nature of the lenses of inquiry and their relationship to transformation.}

Lederach (2014, pp. 30-34) notes that transformative peacebuilding is both linear and circular, constructing the elements of understanding in order but then interlinking and interacting with each other in a complementary and interdependent manner. This requires regular reflection and reassessment within each lens, to understand how they change and affect one another. The mechanisms of this process may appear complicated, but it operates on deceptively simple philosophical principles: Equity of communication, capacity, and accountability between parties and maximization of their agency and autonomy in reconciling their past, present, and future (2014).

Together, these lenses create a map that leads us on an expedition from the basecamp of a conflict's events, patterns, and histories toward the summit of sustainable peace. This map contextualizes the features of the discord's terrain, illuminating how the epicenter gives rise to the mountains of harm and stress caused by episodes of conflict. It helps us avoid pitfalls, morasses, and dead ends, and helps orient us toward the "true north" of sustainable peace. The final component of the transformative framework helps us build the trail that will lead us out of the wilderness.

\section{Building Switchbacks: Process-Structures and Transformational Platforms}

Lederach (2014, pp. 34-35) writes that actual transformation of conflicts is a challenging and sometimes frustrating process, fraught with experiences of progression followed by impasses and setbacks. However, he goes on to say that - like the linearity 
and circularity constructed in other parts of the transformative framework - its application also carries these characteristics. We must view transformation must as a "process-structure," a 'both-and' - something that carries both the frustrating cycle of success and setback and the forward momentum of linear progression (2014, pp. 36-37). It does this through frameworks that simultaneously resolve episodic disputes and the underlying factors driving them.

Lederach (2014, p. 37) calls these frameworks transformational platforms, adaptive and dynamic ways of understanding both the epicenter and episodes of a conflict context. Each episode represents the cycle of success and setback: A dispute arises, is resolved, but then resurges at a later event, beginning the process once more. Within conventional resolution methodologies, this process represents a never-ending cycle because they do not adequately confront the underlying forces giving rise to each episode of conflict. In engaging with the epicenter, the transformational platform affects longterm change in the conflict, altering how the epicenter expresses itself in the future. Over time and with vigilance to the changing nature of the three lenses, the disparate domains of the conflict may shift toward less violent, more just relations. The transformative framework provides the architecture for sustainable, dynamic peace (2014).

To bring Lederach's idea in line with my metaphor, the transformational platform builds switchbacks on the long road to peace. In hiking terminology, switchbacks are elements of trail built with intentional zigzags or reversals. While they increase a hike's duration, switchbacks also make the journey easier while concurrently reducing erosion in the geography. Here, they facilitate constructive resolutions to episodes of conflict and 
prevent erosion into further discord and destruction, helping build capacity and agency in all parties during the peacebuilding process.

\section{Stepping Off the Beaten Path: Resolution, Revolution, and Their Limits}

Parties can only realize the end goals of transformation when they meet and decide together what those aspirations are and how to reach them. In firmly locating myself as an insider in the conflict in the position of advocating for academic labor, I have necessarily precluded this work from accomplishing the end goals of transformation. There is no exploration of the decision-making frameworks utilized by university administrations, and I make no attempt at incorporating their views or perspectives. Nevertheless, this approach contributes to the longer timeline of transformative peacebuilding.

Recall the Curle's (1971) Progression of Conflict, as described by Lederach (1995, pp. 12-13): As conflicts move from unpeaceful relations between adversaries toward sustainable peace, they progress through a series of stages. This process begins with conscientization, which builds awareness of injustice and violence, then moves to confront and rebalance disparities of power. These initial steps build the foundation to facilitate conventional resolution processes like mediation and negotiation to reconcile the relationship between adversaries and realize the final goals of transformation and dynamic peace. Lederach (1995) argues that negotiation and mediation can only be effective when the needs and interests of all parties involved in the conflict are heard, understood, and legitimized. When significant disparities exist between disputants, it reduces the voice and agency of disadvantaged actors, to claim importance for their issues, and to demand accountability from their adversary. In these instances, high-power 
parties can co-opt conventional resolution strategies for their benefit, reinforcing existing harms and injustices (1995, pp. 12-13), a sentiment echoed by other scholars in the field (Practitioners Research and Scholarship Institute, 2008; Roy, 2008; Wing, 2008).

Lederach (1995, pp. 12-15) writes that, in these instances, a stance of activism and advocacy are necessary to the peacebuilding process. Those benefitting from inequitable or oppressive arrangements rarely hear, let alone take seriously, the issues raised by those they marginalize. Strategic, nonviolent confrontation is needed to highlight the interdependent nature of the relationship between the parties and increase the power of disadvantaged parties relative to their adversary (Chenoweth \& Stephan, 2012; Wilmot \& Hocker, 2011), opening the door for conventional negotiation and mediation. Lederach (1995, pp. 15-23) writes that peacebuilding requires both revolution and resolution. Both perspectives stand for justice: The revolutionary perspective stands for one side in its pursuit, while the resolutionary stands for all sides in seeking it (2014, p. 15).

The limits of the revolutionary perspective, then, is that it only builds the foundation for negotiation and mediation. The well-trodden roads of dispute resolution, which utilize the conventional conflict processes in the NLRB and higher education institutions, have failed to secure justice for academic workers and the labor movement more broadly. Furthermore, the literature is rife with evidence showing the inequity of power between academic labor and university administrations, necessitating an activism approach that stands in advocacy for unions. Therefore, the application of the methodology, its results, and its conclusions reflect this perspective. 
Cartography of the Academic Labor Conflict: Applying the Transformative Framework

Applying the presenting situation lens of inquiry.

To identify the nature and possibility of transformation in the GEU-PSU conflict, I used the lenses of inquiry to analyze the presenting situations of the academic labor discord as it exists in the areas of higher education and organized labor. With regards to higher education, I identified as issues the contentions commonly associated with contingent faculty unionization: Student debt, corporatization of the university, compensation, and job precarity. I then connected these to the historical events leading to the contemporary issues experienced, linking each to the pattern of neoliberalism identified by the scholars in the literature.

With regards to organized labor, I identified as issues the elements surrounding union conflicts: Systemic issues within the labor-management dispute resolution process, low membership and power, and opposition in both the structural and political spheres of society. These connected to the historical events surrounding organized labor to identify the patterns present in the conflict and answer the third research question - connecting a systemic force present in the academic labor conflict.

Applying the horizon of the future lens of inquiry.

The second lens of inquiry defines the horizon of the future, articulating the hopes and desires for change and situating potential solutions within the relationships and systems they affect. In writing for conscientization and confrontation, my goal here is to expand the possibilities for this lens. To do this, I first looked at the overall impacts of neoliberal policies in relation to its stated outcome of individual freedom, problematizing 
its explicit goal with its implicit outcome. I then liberated the neoliberal value of individual freedom by situating it within the transformative framework's goal of procedural justice.

Regarding academic labor, I identified the inherent violence and deprivation generated by neoliberal policy through the conflict domains and discussed the need for an alternative schema of interaction. This approach needed to support equitable participation from higher education's stakeholders and simultaneously fulfill their basic, substantive needs. Adopting this architecture allowed the transformative framework to guide future organizing strategies while remaining sensitive to the contextual needs of separate expressions of the academic labor conflicts. These goals framed the development of the change processes discussed in the final lens of inquiry.

\section{Applying the creation of change processes lens of inquiry.}

The third lens of inquiry developed change processes to address the episodes and epicenter of the conflict, with the ultimate outcome of defining a transformational platform to guide peacebuilding work. Lederach (2014, pp. 21-23) argues that the transformative framework should:

1. Reduce violence by addressing the episodes of conflict as well as its epicenter in our actions and interventions.

2. Promote justice by increasing substantive justice, in which participants have their basic needs met, and procedural justice, which maximizes the participants' agency and autonomy in decisions and actions affecting them.

To address these needs, I connected the descriptive elements of the conflict

domains in the first lens to the prescriptive goals identified in the second lens, identifying change processes to both reduce violence and create adaptable and equitable transformation in each conflict domain. These processes acknowledged the need for 
individual freedom liberated from neoliberalism and the need for a schema of interaction beyond neoliberal constructions. To promote substantive justice, I identified an ontology of interaction that defines irreducible values in the stakeholders of the academic labor conflict. To increase procedural justice, I described a strategy of strategic nonviolence to balance the power inequity between the conflict's disputants. I then deployed these change processes to address the academic labor conflict's domains through an adaptable, transformational platform capable of conscientizing and confronting neoliberalism in the short-term while supporting the long-term transformation of the conflict.

\section{Home Territory: Grounding the Research in the GEU-PSU Conflict}

To ground this work within the GEU-PSU conflict, I explored data specific to Portland State University and the dimensions of the conflict around personnel, compensation, and tuition. These statistics located the university concerning other American HEIs and provided a concrete example of the changes wrought by neoliberalism in higher education. This context helped cement the validity of the ideas discussed in the literature and lay the groundwork for future peacebuilding interventions on its campus. Finally, as PSU is a high-research doctoral university, much of my data analysis focuses on similar classes of universities. More research is required to better understand similar contexts at other classes of HEIs, though the broader research thus far indicates similar trends at other institutions.

\section{Marking the Way: Sources of Data, Charts, and Rationales for Use}

This text relies entirely on secondary research, using only publicly available sources of information. I drew data from the following sources: 
- From the Integrated Postsecondary Education Data System (IPEDS) (2020): Statistics from Portland State University for the variable "Tuition and fees as a percentage of core revenues," calculated according to the Governmental Accounting Standards Board (NCES, 2020) for the years 2006-2018. These statistics were used to track tuition and fees as a total percentage of HEI revenue over time in understanding university funding decisions.

- From IPEDS (2020): Statistics from Portland State University by reported data under the category "Human Resources," for 2000, 2006, 2012, and 2018 , looking at occupational categories. These statistics were used to contextualize the GEU-PSU conflict, tracking changes in total share of occupational positions at PSU throughout the 18 years from 2000-2018 and comparing them national trends regarding tuition fees. Occupational categories were separated by full-time faculty comprised of T/TT faculty plus full-time NTT faculty, contingent faculty made up of NTT adjunct faculty plus GSEs, and categories for EAM, professional, and nonprofessional personnel as distinguished by the Department of Labor occupational classifications (2018).

- From IPEDS (2020): Statistics for the average annual cost of tuition and fees at Portland State University for undergraduate and graduate students the years 2001-02 to 2017-18. These statistics were used to track the percentage change over time of student tuition and fees for the period.

- From the State Higher Education Executive Officers Association report "State Higher Education Finance: FY 2018" (SHEEO) (2019): National statistics for tuition and fees as a percentage of total HEI revenue for the years 1993-2018. These statistics were used to track tuition and fees as a total percentage of HEI revenue over time in understanding university funding decisions, comparing them to tuition fee trends at PSU.

- From the HEI personnel database of the Chronicle of Higher Education, hereafter referred to as "Chronicle Data" (2020): Available average salaries for personnel from Portland State University; instructional occupations from 2003-2017, and non-instructional occupations from 2012-2017. This information was used to contextualize the differences in compensation provided in different occupational classes.

- From the Economic Policy Institute, "How today's unions help working people" (Bivens et al., 2017): Statistics for the percentage of workers claiming membership to a labor union in the United States for the years 1917-2015. This information was used to show the trend of union 
membership over the past century in comparison to the percentage of wealth owned by the top $10 \%$ and $1 \%$ of households in the U.S.

- From the World Inequality Database (2020): Percentage of total wealth owned by the top $10 \%$ and top $1 \%$ of households in the United States for the years 1917-2015. These statistics were used to show the trend of wealth owned by the top $10 \%$ and $1 \%$ of households over the past century in comparison to the percentage of organized labor members over the same period.

- $\quad$ From the Digest of Education Statistics 2017 (Snyder et al., 2019): Statistics for the average annual cost of tuition and fees, in constant 2018 dollars, in the U.S. for undergraduate students from 1963-64 to 2017-2018 as well as graduate students from 1989-90 to 2017-18. These statistics were used to show the percentage change over time of student tuition and fees for the period.

- From the Digest of Education Statistics 2017 (Snyder et al., 2019): Statistics for the percentage of full-time faculty at all HEIs in the U.S. for the years 1970 to 2016 . These statistics were used to show the declining trend of full-time faculty at colleges and universities.

- From the report "Revenues: Where Does the Money Come From?" by the Delta Cost Project (Kirshstein \& Hurlburt, 2012): Statistics for the revenues of average HEI per FTE student, in constant 2012 dollars at public, 4-year research universities in the U.S., categorically broken down by source of funds, for the years 2000 to 2010. These statistics were used to establish the changing patterns of funding over this decade concerning public institutional support, tuition recovery, and market-based behavior, defined here as revenues generated that are not from public sources or related to instruction, such as tuition and fees.

- From "The Annual Report on the Economic Status of the Profession, 2017-18" by the American Association of University Professors (2018): Statistics for the percentage change in average salaries for all academic ranks of faculty, after adjusting for the change in the consumer price index for all urban consumers (CPI-U) from 1971 to 2018. The report adjusts the salary growth rate for the CPI-U, which represents the total increase in the cost of living due to inflation, from the percentage income growth of faculty over the period. The data was used to highlight the relatively flat income growth over the period, complementing the more recent data in Appendix A. 
Charts and diagrams created during research along with rationales.

Additionally, I constructed a series of charts and diagrams to display the information collected visually. Each entry overviews the basic chart design, sources of data used, rationale for creation, and decisions around style and design.

A chart showing the average annual tuition and fees in the U.S. collected from undergraduate students for the years 1963-64 to 2017-18, and graduate students for the years 1989-90 to 2017-18. The rationale for this chart was to visualize the rise in tuition over the period in a way that Table 2 could not show. The chart uses the data from Table 3, which itself originates from the Digest of Education Statistics 2017 (Snyder et al., 2019). For visual clarity, several data points from the table were removed, and the data labels are presented next to each point.

A chart showing the tuition recovery from students as a percentage of tuition as core revenues of HEIs for 1993-2018, with statistics for PSU from 2006-2018. The rationale for the chart was to highlight the increasing share of revenue HEIs gather from students. I added statistics from PSU to show the university's comparative relationship to national trends. The chart originates from the SHEEO (2019) report, with data for PSU added by me from the IPEDS (2020) self-report survey from the university for each year displayed. The chart is constructed for visual clarity around the trends, and the periods for PSU reflect total available data from IPEDS.

A chart showing the revenues of average HEI per FTE student at 4-year, public research universities in the U.S., categorically broken down by source of funds, for the years 2000-2010. The rationale for this chart was to show the changes, in both total funds and by the percentage of total revenues, of HEIs, highlighting the loss of 
public institutional support and the rise of both tuition recovery and market-based behavior such as the non-instructional sale of goods and services facilitated by neoliberal policy. The data are drawn from the Delta Cost Report "Revenues: Where Does the Money Come From?” (Kirshstein \& Hurlburt, 2012), and I calculated the percentage revenue of each category for each year. The design choices of the chart reflected a desire to prevent the addition of unnecessary charts and to ensure visual clarity. As such, I employed a combination chart displaying the revenue percentages as a trend line and the total revenues for each category and year as a clustered bar graph. The data table for the chart is contained below for transparency.

\section{A chart showing the percentage of full-time faculty at all HEIs in the U.S. for} the years 1970 to 2016. The rationale for this chart was to show the declining rate of full-time faculty over the period neoliberal policies were instituted at HEIs, highlighting the increasing use of casualized instructors. The statistics are taken from the Digest of Education Statistics 2017 (Snyder et al., 2019). The chart is designed for visual clarity, with the data labels listed above each data point.

\section{A series of four charts, showing the occupational categories of personnel for}

the years 2000, 2006, 2012, and 2018 at PSU. These charts were designed to display the increasing share of both contingent faculty and non-instructional professionals at the university. The chart draws from statistics collected from IPEDS (2020) survey data for each year, using the categories defined by Desrochers and Kirshtein (2014). The category of Full-Time Faculty is comprised of T/TT faculty and full-time instructional and research personnel, while the category of Contingent Faculty is made up of NTT adjunct faculty and GSEs. The categories of EAM, Professional, and Nonprofessional are 
collected based on the occupational classifications defined by the U.S. Department of Labor (2018). These charts are used to provide a contextual comparison against the national patterns of HEI employment of contingent faculty and non-instructional professionals.

Each chart shows how professional personnel take up a larger share of the total personnel headcounts for the university. As granular statistics became available, I included the different categories of professionals to offer context to the kinds and effects of administrative intensity, as discussed in the analysis of the literature. I included nonprofessional personnel to reflect the historical changes discussed by the literature, and the EAM category to compare the reality at PSU against the assertions presented in the literature (Ginsberg, 2011). The statistics draw from the IPEDS (2020) database, looking at institutional reports for each of those years. The instructional category includes research positions, partially due to the relationship graduate students maintain to research faculty and partially due to the ambiguity around faculty who engage in research, teaching, and public service.

Each chart is designed to prioritize visual clarity and transparency, providing percentages of total staff shares as well as raw headcounts for each category. I provided Table 3 to ease the comparison of data between each of the four years. The 18-year period was chosen to place it in contextual comparison with the Desrochers and Kirshstein report (2014) and because this period represents the largest change in administrative intensity. Finally, the four time periods were chosen for their equidistance and the desire to simplify patterned trends over a more extensive period. 
A chart showing the percentage change in annual salary for all academic ranks of faculty at HEIs for the years 1971 to 2018, adjusted by the CPI-U. The rationale for this chart was to highlight the stagnant growth of faculty compensation since the institution of neoliberal policies in higher education. The addition of the CPI-U modifies the data to show the real wage growth after adjusting for inflation, showing that, while wages may technically increase year to year, real income may drop due to changes in the cost of living. The statistics were drawn from "The Annual Report on the Economic Status of the Profession, 2017-18” by the American Association of University Professors (2018). The chart was designed for visual clarity, with each year contained in a vertical gridline.

A chart showing the percentage of total U.S. workers claiming membership to a labor union for the years 1917 to 2014. The rationale for this chart is to visually display the decline in union membership over the past century, complementing the information presented in the literature, and setting up the following charts showing the relationship between union membership and wealth inequality. The data was collected from the Economic Policy Institute report, "How today's unions help working people." (Bivens et al., 2017). The chart was designed for visual clarity. Table 4 contains the data for each point in this chart and can be found in Appendix B.

A chart showing the relationship between the percentage of total workers in the United States claiming membership to a union to the percentage of total wealth owned by the top $10 \%$ and $1 \%$ of households in the U.S. for the years 1917-2014. The rationale for this chart was to expand on the previous chart showing union membership and highlight the outcome of wealth inequality produced by neoliberalism. I 
used both the top $10 \%$ of households and the top $1 \%$ to show the fact that, even amongst the elite members of society, only a small percentage of people benefit from neoliberal policies. The data for union membership was collected from the Economic Policy Institute report "How today's unions help working people," (Bivens et al., 2017), while the data for wealth inequality was taken from the World Inequality Database (2020), looking at the categories for the percentage of total wealth owned by the top $10 \%$ and top $1 \%$ of households. The chart was designed to highlight the relationship between union membership and wealth owned by the top $10 \%$ and $1 \%$, as well as to show the relationship between the top $10 \%$ and $1 \%$. Table 4 contains the information for each category and can be found in Appendix B.

\section{A diagram representing the socio-ecological model as used by Pocock (2012).}

The rationale for this diagram was to visually display the information discussed in Pocock's article and provides the visual foundation for the Systems Ecology Framework of Transformative Care. The model represents a visual recreation of Urie Bronfenbrenner's (1981) socio-ecological model of human development, as applied to understanding union member identity. I tried to faithfully reproduce each element of the visual model as shown by Pocock (2012).

\section{A diagram representing the Systems Ecology Framework of Transformative}

Care (SETC). The rationale for this diagram was to visually show the components of the SETC framework, situating the union in the center and describing its relationships to the fields of Work, Community, and Family, along with examples of elements in those fields. Additionally, I added concentric circles to represent the personal, relational, structural, and cultural conflict domains, showing their relationship in facilitating each other and in 
rough relationship to the union's contextual fields. Each domain has a brief description of the way it confronts neoliberalism, and for clarity, I marked out the micro-, meso-, and macro-systems. The diagram draws from Pocock's visual representation of the socioecological union member identity model (2012), Lederach's conflict domains (2014, p. 25), and Tronto's framework of care ethics (2017). The diagram is designed to represent the core elements each idea contributes to it, visually as well as descriptively.

A diagram showing the cycle of conflict described by Lederach (2014, p. 35). The purpose of the diagram is to show a simple, visual representation of the cycle of conflict, primarily to set up the following diagram visualizing the mechanics of the transformational platform. The diagram is designed to represent Lederach's mechanics of the conflict process, though the labels are changed for textual clarity here. Lederach's labels for each section of the diagram are "Things Move Forward," "Things Hit a Wall; Movement Stops," “Things Move Backwards,” and "Things Collapse.” (2014, p. 35). I used the labels "Conflict Erupts," "Resolution Occurs," "Progress Falters," and "Discord Renews."

\section{A diagram showing the mechanics of the transformational platform, as}

designed by Lederach $(2014$, p. 38). The rationale for this diagram was to visualize the function of the transformational platform as it addresses the epicenter of conflict within its discrete episodes. It expands on the cycle of conflict Lederach previously described (2014, p. 35). The diagram is designed to represent the diagram in his text faithfully. A series of three charts, showing the trends of compensation for HEI staff based on occupational category, for 2003-2017 for instructional staff, and 2012-2017 for non-instructional staff, contained in Appendix A. Each chart shows comparisons 
for national averages versus averages for PSU over the same period. Instructional categories are determined by PSU's classification system (2020). Non-instructional categories are defined by the U.S. Department of Labor (2018).

The first chart shows different categories of instructional staff, including tenure and tenure-track faculty and non-tenure-track full-time instructors. The second and third charts show non-instructional "professional" and "non-professional" categories, as defined by Desrochers and Kirshstein (2014). Each compared national salary averages to averages PSU averages, and instructional categories have had 9- and 12-month contracts averaged out by the Chronicle Data database (2020).

These charts are multipurpose in construction. They display the salary comparisons of instruction versus non-instructional staff, providing context for the increased economic pressure of administrative intensity. Second, they display the comparative salaries of Portland State University versus the national average, offering context for the economic situation at the university compared to other locations. Third, the adjustment for inflation shows the flat growth for almost all categories, providing a contextual comparison against the compensation of senior administrative executives and the effects of neoliberal wealth sequestration. Finally, they are used to provide a comparison against the average annual salaries of contingent faculty, both nationally and at PSU.

Each chart is designed for visual clarity around the occupational categories. The separation of occupations by instructional, professional, and non-professional is defined by the Desrochers and Kirshstein (2014) report to highlight the impacts of administrative intensity and complement the series of charts I designed around staffing patterns at PSU. 
The source of the data, Chronicle Data (2020), draws their statistics from the IPEDS (2020) database, and I chose it for its ease of accessibility to the data. The periods chosen reflect the available statistics for that dataset, and each chart has a data table below them for transparency. 
Chapter 4: Results and Discussion

This paper sought to uncover the epicenter lying at the heart of both the conflicts occurring in higher education and the labor movement in the U.S., using that knowledge to construct a transformative framework capable of shifting the academic labor conflict toward lasting, sustainable peace. The research questions I needed to answer focused on understanding the historical changes that occurred in higher education, the factors leading to the American labor movement's decline, and the underlying issues present in both conflicts. The literature provided answers to the first two questions, wherein the scholars such as Turkel (2009), Giroux (2014), and Saunders (2010) indicted neoliberal ideology as the primary element driving postsecondary education's shift over the last half-century. Within organized labor, Voss and Sherman (2000) effectively described the inner turmoil faced by unions, while Rosenfeld (2014) articulated the constellation of external adversity organized labor faced. These problems within and beyond the movement explained the slow, yet steady decline of its influence over the latter part of the $20^{\text {th }}$ century, while the meta-study by Murray (2017) delineated both the strategies and challenges unions face in attempted to reclaim power and influence.

However, the third question - which seeks to understand the underlying factors fueling the labor movement's deterioration - remained extant and required an answer regarding organized labor before identifying a transformational platform. To address it, I used the first lens of inquiry to understand how the presenting issues in higher education connected the historical trends and patterns to the neoliberal restructuring imposed by Congress in the early 1970s. The literature already makes this argument explicit, but employing the lens here creates an experimental model with which to understand how 
neoliberalism affects the personal, relational, structural, and cultural aspects of postsecondary education. I then used the same approach to interpret the presenting issues in the labor movement, bridging the academy and unions. This provided the basis to answer the third question and identify a transformational platform.

\section{Inquiry 1: The Presenting Issues}

The presenting issues expressed by the contingent faculty in the literature center on four points:

- Concerning graduate student employees, the rising cost of education, leading to increased debt and economic instability.

- The corporatization of the university, leading to significant changes across the policies and practices of higher education institutions.

- Unsustainable compensation, including salaries and benefits, for contingent faculty.

- Precarious positions for both GSEs and adjunct faculty, with a lack of stable contracts, job protections, and professional growth.

Where possible, I reinforced the arguments made in the literature with statistics

relevant to the conditions present at Portland State University to ground its conflict with the Graduate Employees Union contextually. Additionally, I discovered that each of the four points readily connected, further cementing the interconnected relationship between these issues.

\section{The rise in graduate student debt and its impacts on borrowers.}

The data from Table 1: Average Graduate Student Loan Debt, 2000-2015, which uses figures from the National Center for Education Statistics (2019), showed a clear, consistent, and dramatic increase in the overall debt held by post-baccalaureate students over the last 20 years. The cause of this increase stems from an equally precipitous rise in student tuition and fees over the past half-century. Looking at the available data for 
public, 4-year institutions from the Digest of Education Statistics 2017 (Snyder et al., 2019), I compiled the rates of average undergraduate tuition and fees for the years 196364 to 2017-18, and average graduate tuition and fees for the years $1989-90$ to $2017-18$, in constant 2019-20 dollars, displaying them visually in Figure 9. To track the change over time with these statistics, I placed the statistics in Table 2, showing the percentage change in tuition for both categories of students for every decade available, along with the available tuition and fees statistics for undergraduate and graduate students at Portland State University for the years 2001-02 to 2017-18 (IPEDS, 2020).

Figure 7: Change in Average Annual Student Tuition and Fees Over Time at Public, 4-Year Higher Education Institutions, 1963-2017, in Constant 2019-2020 Dollars (Snyder et al., 2019)

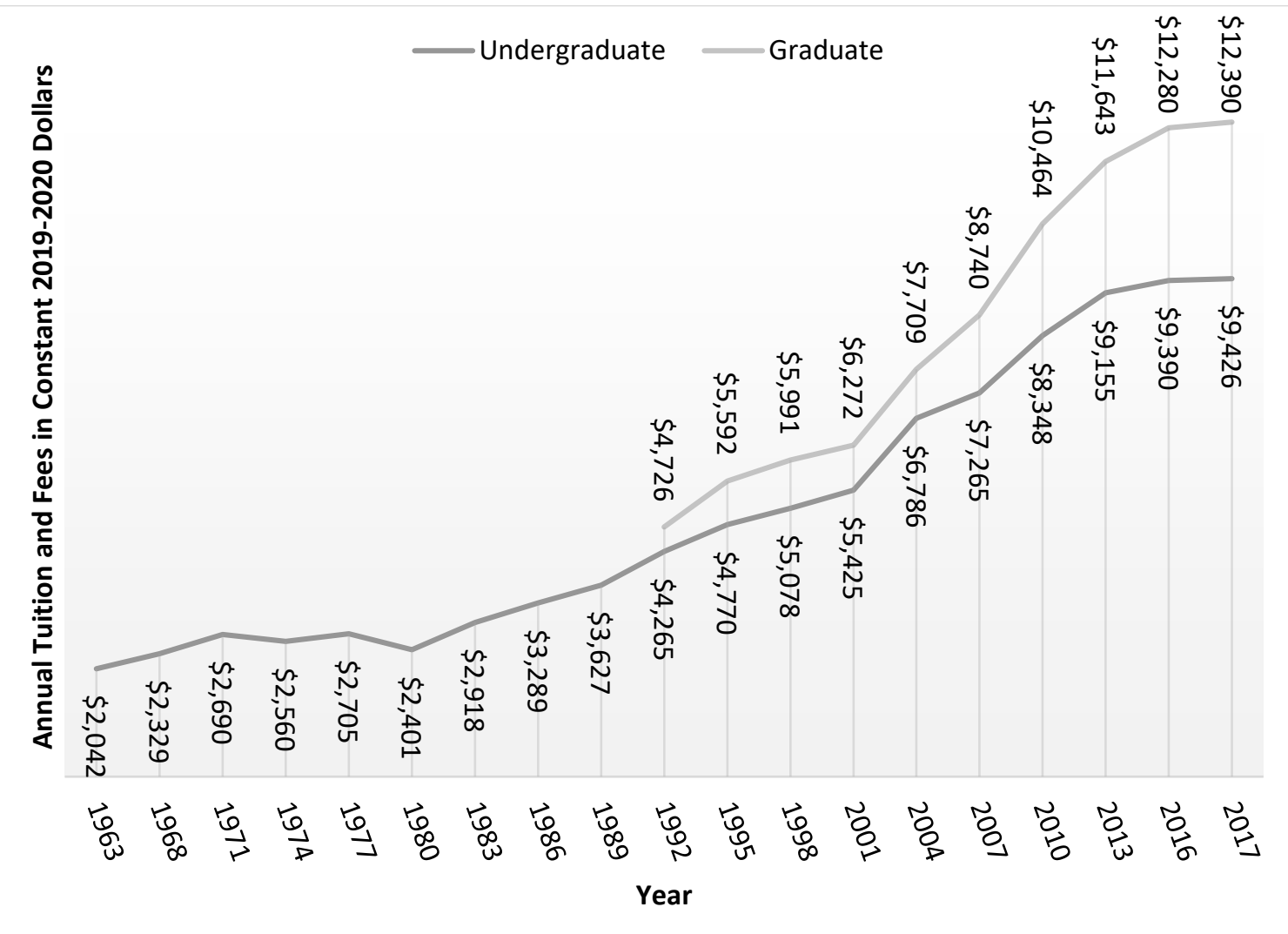


Table 2: Average, Public 4-Year and PSU Student Tuition and Fees, 1963-2017, in Constant 2019-2020 Dollars (IPEDS, 2020; Snyder et al., 2019)

\begin{tabular}{|c|c|c|c|c|}
\hline Year & Avg UG & Avg G & PSU UG & PSU G \\
\hline 1963 & $\$ 2,042$ & & & \\
\hline 1966 & $\$ 2,377$ & & & \\
\hline 1967 & $\$ 2,360$ & & & \\
\hline 1968 & $\$ 2,329$ & & & \\
\hline 1969 & $\$ 2,455$ & & & \\
\hline $\begin{array}{r}\text { \% Change Over } \\
\text { Prior Period }\end{array}$ & $+20.22 \%$ & & & \\
\hline 1970 & $\$ 2,565$ & & & \\
\hline 1971 & $\$ 2,690$ & & & \\
\hline 1972 & $\$ 3,039$ & & & \\
\hline 1973 & $\$ 2,851$ & & & \\
\hline 1974 & $\$ 2,560$ & & & \\
\hline 1975 & $\$ 2,530$ & & & \\
\hline 1976 & $\$ 2,719$ & & & \\
\hline 1977 & $\$ 2,705$ & & & \\
\hline 1978 & $\$ 2,598$ & & & \\
\hline 1979 & $\$ 2,459$ & & & \\
\hline $\begin{array}{r}\text { \% Change Over } \\
\text { Prior Period }\end{array}$ & $-4.13 \%$ & & & \\
\hline 1980 & $\$ 2,401$ & & & \\
\hline 1981 & $\$ 2,501$ & & & \\
\hline 1982 & $\$ 2,720$ & & & \\
\hline 1983 & $\$ 2,918$ & & & \\
\hline 1984 & $\$ 3,004$ & & & \\
\hline 1985 & $\$ 3,134$ & & & \\
\hline 1986 & $\$ 3,289$ & & & \\
\hline 1987 & $\$ 3,435$ & & & \\
\hline 1988 & $\$ 3,515$ & & & \\
\hline 1989 & $\$ 3,627$ & & & \\
\hline $\begin{array}{r}\text { \% Change Over } \\
\text { Prior Period }\end{array}$ & $+50.06 \%$ & & & \\
\hline 1990 & $\$ 3,649$ & $\$ 4,074$ & & \\
\hline 1991 & $\$ 3,964$ & $\$ 4,263$ & & \\
\hline 1992 & $\$ 4,265$ & $\$ 4,726$ & & \\
\hline 1993 & $\$ 4,490$ & $\$ 5,068$ & & \\
\hline 1994 & $\$ 4,612$ & $\$ 5,398$ & & \\
\hline 1995 & $\$ 4,770$ & $\$ 5,592$ & & \\
\hline 1996 & $\$ 4,865$ & $\$ 5,777$ & & \\
\hline 1997 & $\$ 4,975$ & $\$ 5,874$ & & \\
\hline 1998 & $\$ 5,078$ & $\$ 5,991$ & & \\
\hline 1999 & $\$ 5,119$ & $\$ 6,129$ & & \\
\hline
\end{tabular}




\begin{tabular}{|c|c|c|c|c|}
\hline $\begin{array}{r}\text { \% Change Over } \\
\text { Prior Period }\end{array}$ & $+40.29 \%$ & $+\mathbf{5 0 . 4 4 \%}$ & & \\
\hline 2000 & $\$ 5,174$ & $\$ 6,179$ & & \\
\hline 2001 & $\$ 5,425$ & $\$ 6,272$ & $\$ 5,481$ & $\$ 10,068$ \\
\hline 2002 & $\$ 5,750$ & $\$ 6,529$ & $\$ 5,659$ & $\$ 10,505$ \\
\hline 2003 & $\$ 6,378$ & $\$ 6,880$ & $\$ 6,074$ & $\$ 10,838$ \\
\hline 2004 & $\$ 6,786$ & $\$ 7,709$ & $\$ 6,632$ & $\$ 12,737$ \\
\hline 2005 & $\$ 6,959$ & $\$ 8,208$ & $\$ 6,603$ & $\$ 12,805$ \\
\hline 2006 & $\$ 7,183$ & $\$ 8,445$ & $\$ 6,778$ & $\$ 12,484$ \\
\hline 2007 & $\$ 7,265$ & $\$ 8,740$ & $\$ 7,345$ & $\$ 13,822$ \\
\hline 2008 & $\$ 7,610$ & $\$ 9,065$ & $\$ 7,513$ & $\$ 13,764$ \\
\hline 2009 & $\$ 8,020$ & $\$ 9,643$ & $\$ 8,264$ & $\$ 15,486$ \\
\hline $\begin{array}{r}\% \text { Change Over } \\
\text { Prior Period }\end{array}$ & $+\mathbf{5 0 . 0 1 \%}$ & $+56.06 \%$ & $+\mathbf{5 0 . 7 9 \%}$ & $+53.81 \%$ \\
\hline 2010 & $\$ 8,348$ & $\$ 10,464$ & $\$ 8,488$ & $\$ 12,822$ \\
\hline 2011 & $\$ 8,772$ & $\$ 10,814$ & $\$ 9,095$ & $\$ 15,969$ \\
\hline 2012 & $\$ 9,027$ & $\$ 11,348$ & $\$ 8,710$ & $\$ 15,245$ \\
\hline 2013 & $\$ 9,155$ & $\$ 11,643$ & $\$ 8,825$ & $\$ 15,167$ \\
\hline 2014 & $\$ 9,342$ & $\$ 11,812$ & $\$ 8,596$ & $\$ 15,097$ \\
\hline 2015 & $\$ 9,534$ & $\$ 12,005$ & $\$ 8,868$ & $\$ 15,564$ \\
\hline 2016 & $\$ 9,390$ & $\$ 12,280$ & $\$ 8,748$ & $\$ 15,859$ \\
\hline 2017 & $\$ 9,426$ & $\$ 12,390$ & $\$ 9,330$ & $\$ 16,802$ \\
\hline $\begin{array}{r}\% \text { Change Over } \\
\text { Prior Period }\end{array}$ & $+12.91 \%$ & $+18.41 \%$ & $+9.92 \%$ & $+31.04 \%$ \\
\hline $\begin{array}{r}\text { \% Change Over } \\
\text { Total Period }\end{array}$ & $+461.61 \%$ & $+\mathbf{3 0 5 . 3 3 \%}$ & +70.24 & $+66.87 \%$ \\
\hline
\end{tabular}

This data reflects the trends discussed by the literature, showing the results of the policies that shifted the cost of education onto individuals. While the available data for PSU only shows the turn of the $21^{\text {st }}$ century, it follows similar patterns as other HEIs. The State Higher Education Executive Officers Association (2019) and Urban Institute (Baum \& Johnson, 2015) reports discussed the gradual yet consistent defunding of public institutions, which required HEIs to make up the difference through tuition recovery. To visualize this, I recreated the SHEEO (2019, p. 22) report's chart, adding in data from the IPEDS (2020) database for Portland State University, looking at the variable "Tuition as a percentage of core revenues" for the years 2006-2017, showing the relationship between the two in Figure 8. 
Figure 8: Tuition as a Percentage of Total HEI Core Revenues, 1993-2018 (IPEDS, 2020; SHEEO, 2019)

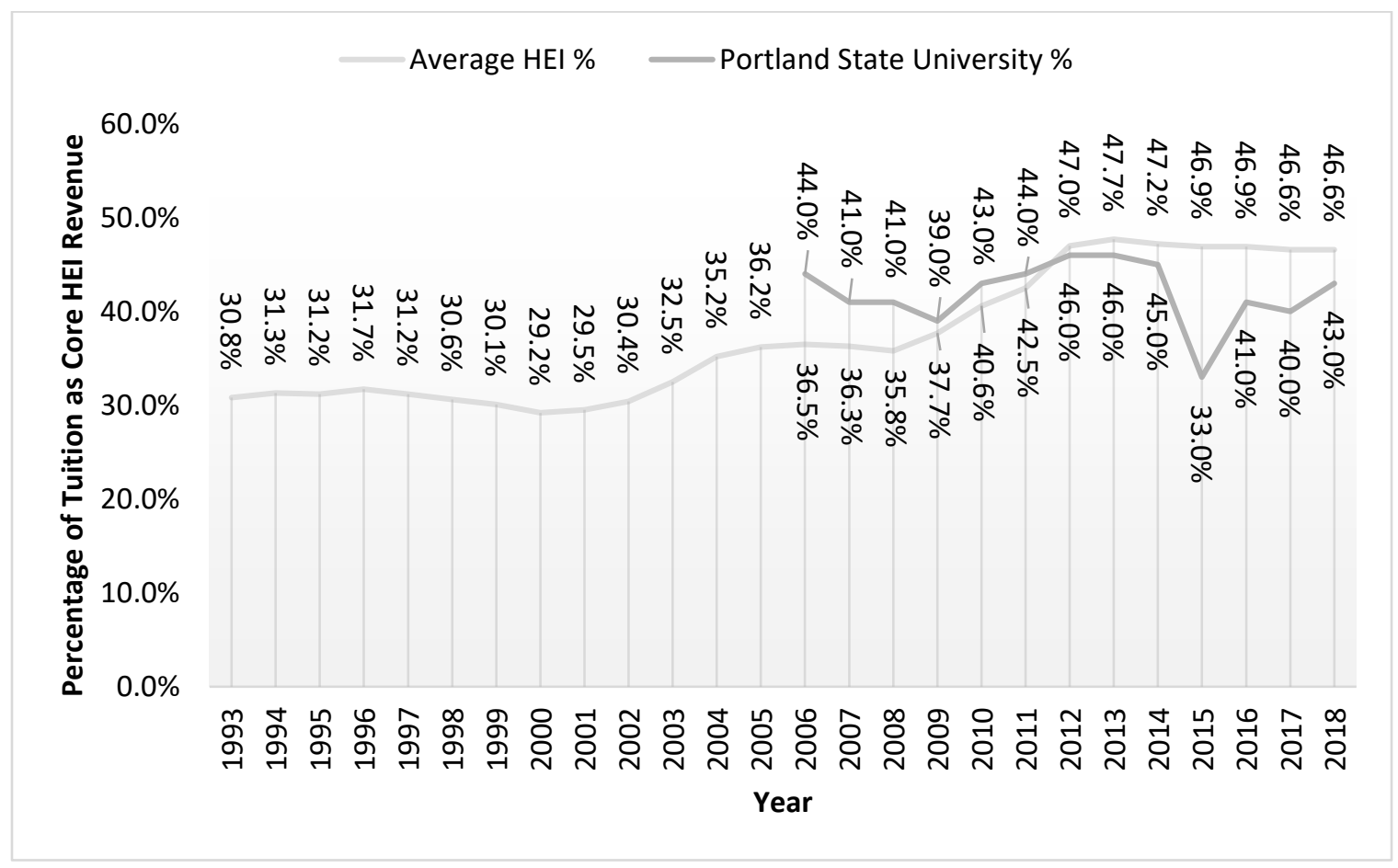

Again, the patterns present at PSU and other colleges and universities point to the historical consequences of neoliberal policies, as HEIs make up the loss of public funding in the form of tuition recovery. These patterns informed the rise of student debt in recent decades, but only explain part of the financial behaviors of universities. This realization leads us to the second presenting issue of the academic labor conflict: The corporatization of the university. This assertion addresses several far-reaching implications over the policies and practices of HEIs, from their behavior in the marketplace to their relationships to faculty and students.

\section{The academy as a marketplace of ideas: Consequences of HEI corporatization.}

As universities transitioned from institutions dedicated to the public good toward private businesses selling education in the marketplace, their policies, practices, and 
cultures all shifted to accommodate this new, privatized mission (Saunders, 2010; Turkel, 2009). Part of this process included sanctions to allow HEIs to sell their knowledge on the open market and deregulate their participation in private partnerships and investments, incentivizing them to prioritize research valued by business interests (Turkel, 2009). As a result, HEIs generated increasing shares of revenue from their participation on the market, partially in response to the loss of funding from public sources. To investigate this pattern, I drew on data from a Delta Cost Project report analyzing trends in HEI revenue between 2000 and 2010 (Kirshstein \& Hurlburt, 2012). The report separates these sources of revenue into four categories (2012, pp. 6-10):

1. Tuition revenue, including tuition and mandatory fees.

2. State and local appropriations, representing direct institutional support from these domains and a primary historical source of institutional funding.

3. Federal appropriations and federal, state, and local grants and contracts, representing other sources of public funding.

4. Auxiliary enterprises, hospitals, independent operations, and other sources, representing revenue generation through the sales of services to students, faculty, and the community unrelated to instruction, research, or public service, termed here as 'market-behavior revenue.'

They found that, over that decade, the revenue generated outside of tuition recovery and public support increased significantly, as displayed in Figure 9. As public funding continued to decline, HEIs principally adjusted for the loss by increasing tuition and revenue generation through market-based transactions, agreeing with the arguments made by Saunders (2010) and Turkel (2009). These actions reflected a necessity for selfpreservation by academic institutions, yet they nonetheless resulted in a significant shift in the relationships between universities, students, faculty, and the wider community. 
Figure 9: Average Higher Education Institution Revenue per Full-Time Equivalent Student, in Constant 2019-2020 dollars, at Public, 4-Year Research Universities, 2000-2010 (Kirshstein and Hurlburt, 2012)

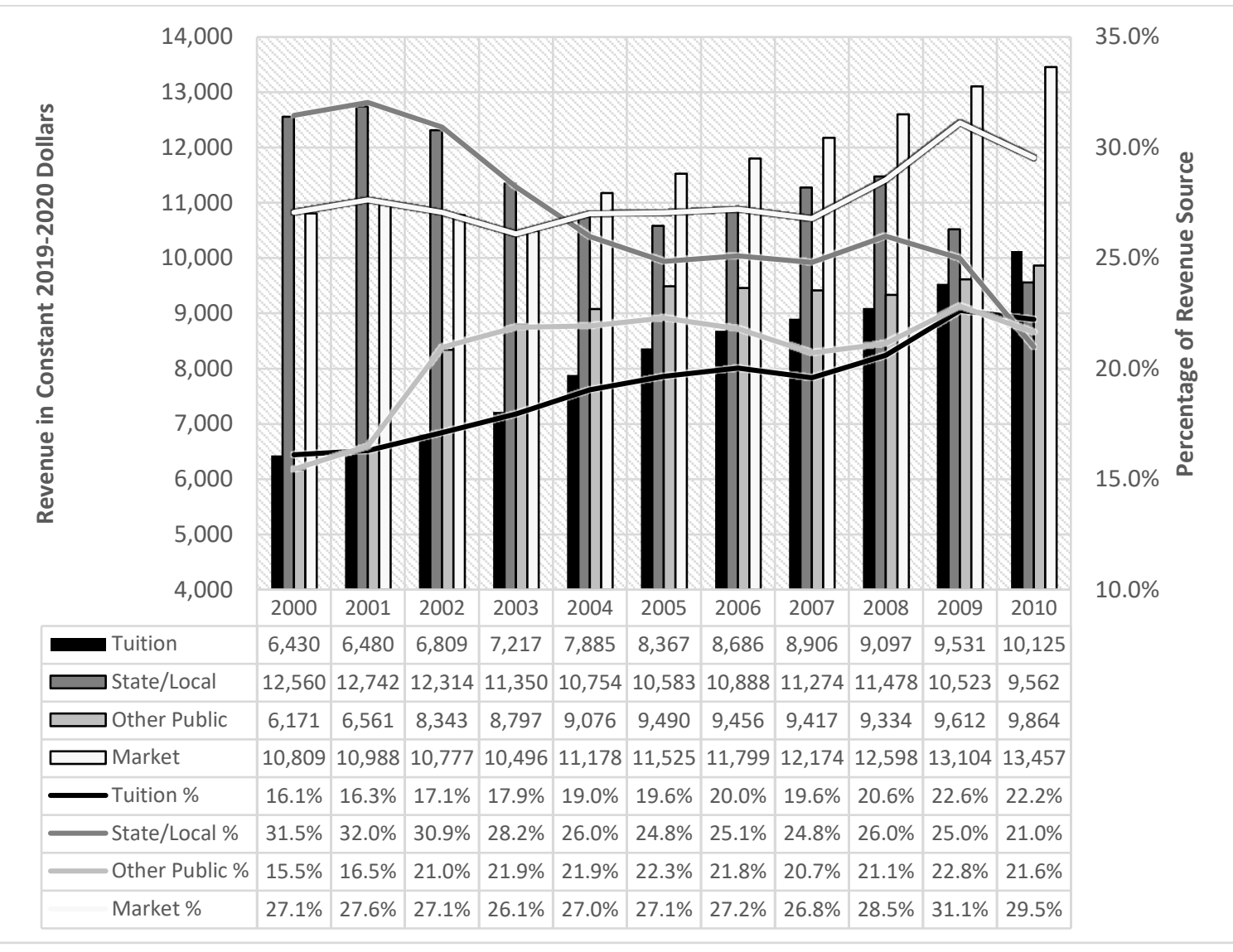

Another outcome of the neoliberal reframe included a transition from

collaborative governance between administrators and faculty to a business-like, labormanagement relationship (Bessant et al., 2015; Saunders, 2010). Decision-making increasingly focused on fiscal indicators, encouraging faculty to perform research based on its financial advantage to the university rather than its value to society (Bessant et al., 2015; Saunders, 2010). The U.K. Research Excellence Framework discussed by Ball (2012, pp. 25-26), which assigns an economic value to different forms of research and assigns grant funding based on those values, provides a concrete example of this phenomenon. Over time, this incentivized HEIs to assess and fund programs based on 
how much economic value they produce through research and student enrollment (Bessant et al., 2015; Brown, 2011; Jemielniak \& Greenwood, 2015; Saunders, 2010).

Faculty, too, find themselves increasingly assessed on the quantity and impact of their research, on their styles of teaching, and a host of other indicators that reflect managerial control over their conduct and profession (Jacob, 2009; Levin \& Aliyeva, 2015; Olssen \& Peters, 2005; Saunders, 2010). As grants and funding increasingly focused on pursuits beneficial to the market, this required an adaptation and adoption of neoliberal principles by faculty in both their areas of study and teaching (Levin \& Aliyeva, 2015). These assessments primarily benefit and are designed by administrators to further the economic success of their institutions, rather than the benefit of communities, students, or faculty (Deem \& Brehony, 2005; Olssen \& Peters, 2005).

The neoliberal worldview eventually extended even to students, whose relationship to education shifted from an apprenticeship focused on learning and selfimprovement to consumers viewing their education solely as an investment in future economic success (Ball, 2012; Saunders, 2010). Over time, these policies began to affect the personnel practices of HEIs, leading to an increase in administrative intensity and the casualization of faculty, producing large numbers of GSEs and adjunct instructors. This pattern can be seen in the ratio of full-time to part-time HEI instructors across the U.S. in higher education. Looking at the percentage of full-time faculty in American HEIs from 1970 to 2016 (Snyder et al., 2019, p. 492), there is a clear trend toward casualized instruction over the decades since the installation of neoliberal policies, as shown in Figure 10. 
Figure 10: Percentage of Full-Time Faculty in All U.S. Postsecondary Institutions, 1970-2016 (Snyder et al., 2019, p. 492)

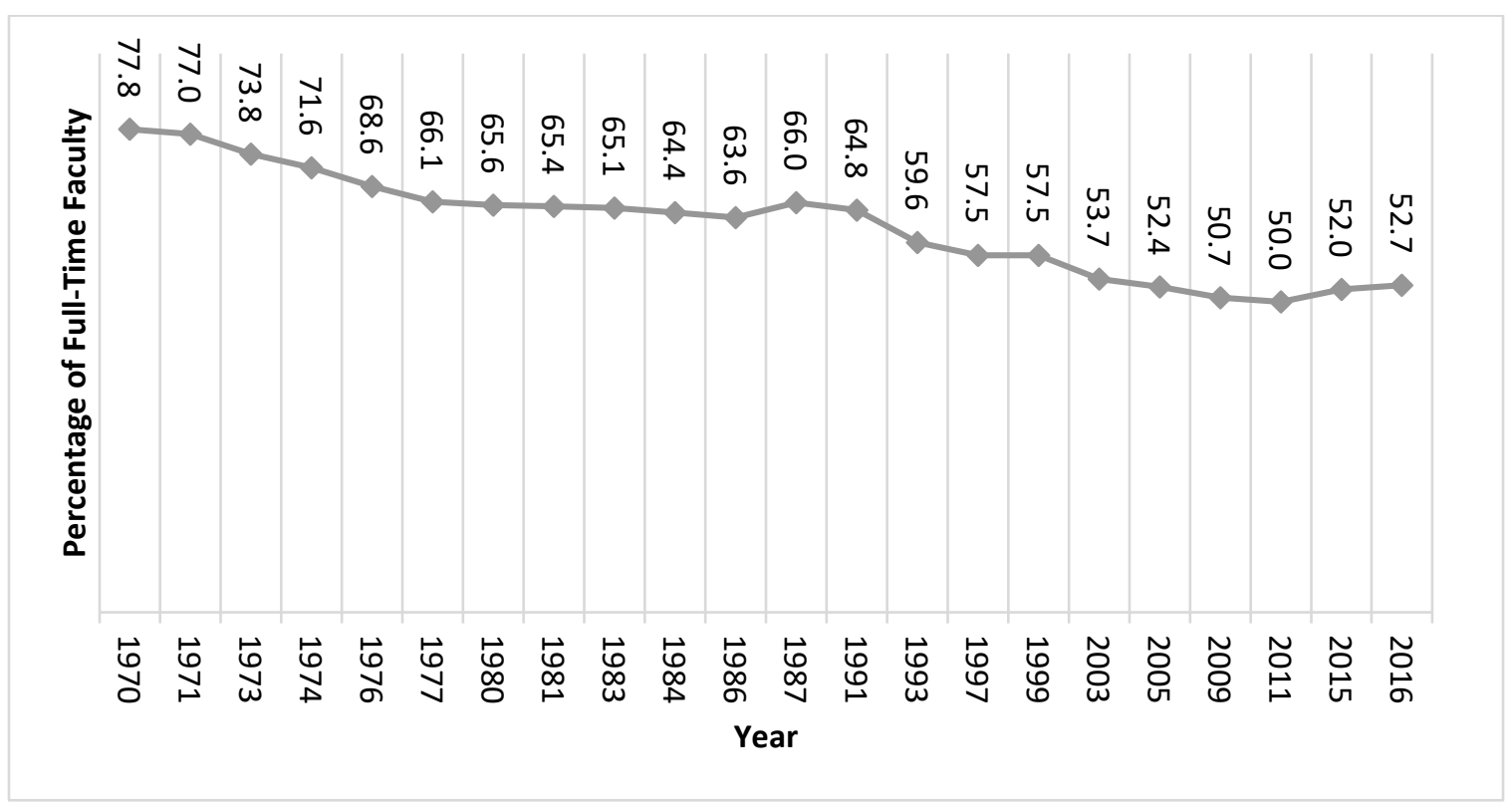

To ground these effects in the context of Portland State University, I drew on survey data collected from the institution in 2001, 2006, 2012, and 2018 from the IPEDS database (2020). Looking at the personnel responses under the category "Human Resources," I tabulated the total headcounts of PSU for each year, classifying staff into five categories based on the same delineations discussed by Desrochers and Kirshstein (2014), seeking to identify the share of non-instructional personnel and share of contingent faculty in comparison to other occupational categories. These statistics are gathered into Table 3, and defined based on the following categories:

- Full-Time Faculty: Personnel whose primary responsibility is instruction, research, public service, or a combination of these roles. This category includes tenure and tenure-track faculty such as professors, assistant professors, and associate professors.

- Contingent Faculty: Personnel whose primary responsibility is instruction, research, public service, or a combination of these roles. This category involves non-tenure-track, contracted faculty, as well as graduate student employees. 
- Executive, Administrative, and Managerial (EAM): Personnel whose work directly involves the management or direct administration of the university and who are not primarily involved in instruction, research, or public service. Examples include presidents, vice presidents, and provosts. Categories defined by the U.S. Department of Labor (2018).

- Professional: Personnel whose work involves non-instructional support and service to the university, and which typically involves at least a bachelor's degree. Examples include human resources personnel, lawyers, and librarians. For the years 2012 and 2018, this is broken down into subcategories as granular access to these statistics improved. All categories are defined by the U.S. Department of Labor (2018) and are listed here to better understand the nature of support each group offers to the university:

○ Library Services: Examples include librarians, library technicians, archivists, and curators.

○ Instructional and Student Support Services: Examples include academic affairs and education specialists.

- Business and Financial Operations: Examples include fundraisers, human resources, budget analysts, and tax preparers.

○ Computer, Engineering, and Science: Examples include programmers, database administrators, civil engineers, and statisticians.

○ Community Service, Legal, Arts, Design, Sports, and Media: Examples include mental health counselors, social workers, lawyers, coaches, public relations specialists, audio-visual technicians, translators, and editors.

o Healthcare: Examples include dentists, doctors, nurses, and related healthcare technicians.

- Nonprofessional: Staff whose work supports other classifications of personnel at the university and who do not typically require a bachelor's degree. Examples include clerical staff, physical plant technicians, and food service workers. Categories are defined by the U.S. Department of Labor (2018). 
Table 3: Total Headcounts by Occupation at Portland State University for the years 2001, 2006, 2012, and 2018 (IPEDS, 2020)

\begin{tabular}{|c|c|c|c|c|}
\hline & 2001 & 2006 & 2012 & 2018 \\
\hline $\begin{array}{r}\text { Tenure and } \\
\text { Tenure-Track } \\
\text { Faculty }\end{array}$ & 454 & 497 & 580 & 542 \\
\hline $\begin{array}{r}\text { Contingent } \\
\text { Faculty and GSEs }\end{array}$ & 1304 & 1643 & 1670 & 1853 \\
\hline$E A M$ & 55 & 52 & 78 & 140 \\
\hline Professional & 459 & 554 & $975^{*}$ & $1113^{*}$ \\
\hline Nonprofessional & 892 & 539 & 358 & 333 \\
\hline $\begin{array}{r}\text { Professional: } \\
\text { Library Services }\end{array}$ & & & $77 * *$ & 40 \\
\hline $\begin{array}{r}\text { Professional: } \\
\text { Student Services }\end{array}$ & & & & 86 \\
\hline $\begin{array}{r}\text { Professional: } \\
\text { Business and } F O\end{array}$ & & & 612 & 414 \\
\hline $\begin{array}{r}\text { Professional: } \\
\text { Comp, Sci, Eng }\end{array}$ & & & 124 & 211 \\
\hline $\begin{array}{r}\text { Professional: } \\
\text { Community, } \\
\text { Legal, Art, Sport }\end{array}$ & & & 131 & 244 \\
\hline $\begin{array}{r}\text { Professional: } \\
\text { Healthcare }\end{array}$ & & & 31 & 18 \\
\hline
\end{tabular}

*: Summative statistic. See the categorical breakdown for more details.

**: Number includes both library and student services for 2012.

I then visually arranged these statistics in Figures 11, 12, 13, and 14 for each year analyzed to show the percentage shares of both professionals and contingent faculty at PSU. As the data shows, contingent faculty make up a significant majority of instructional staff at the university. Additionally, non-instructional professionals grew from $15 \%$ to $25 \%$ of all personnel between 2001 and 2018 , showing that PSU follows the staffing trends identified in the literature (Desrochers \& Kirshstein, 2014; Saunders, 2010). Notably, the university has not crossed the $30 \%$ line marked as the ideal level of administrative intensity noted by Rutherford (2016) but has significantly increased its share of EAM personnel from 2012 to 2018 - from $2 \%$ to $4 \%$. 
Figure 11: Portland State University Staffing by Occupation, 2001 (IPEDS, 2020)

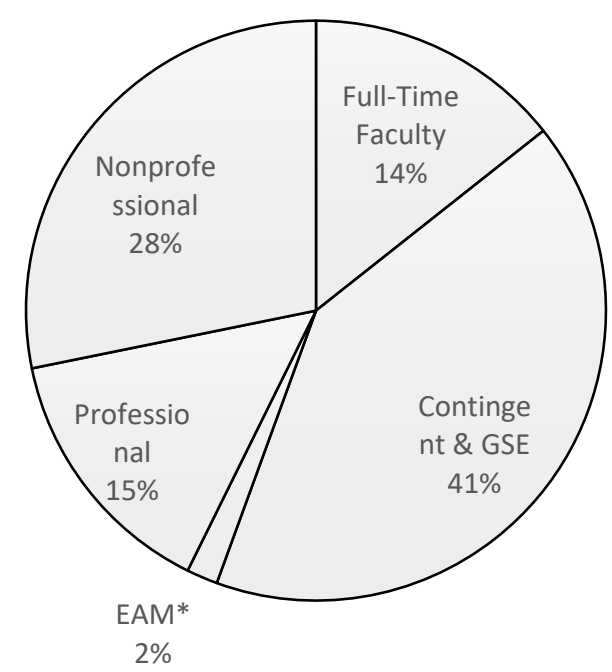

*: EAM represents executive, administrative, and managerial staff.

Figure 12: Portland State University Staffing by Occupation, 2006 (IPEDS, 2020)

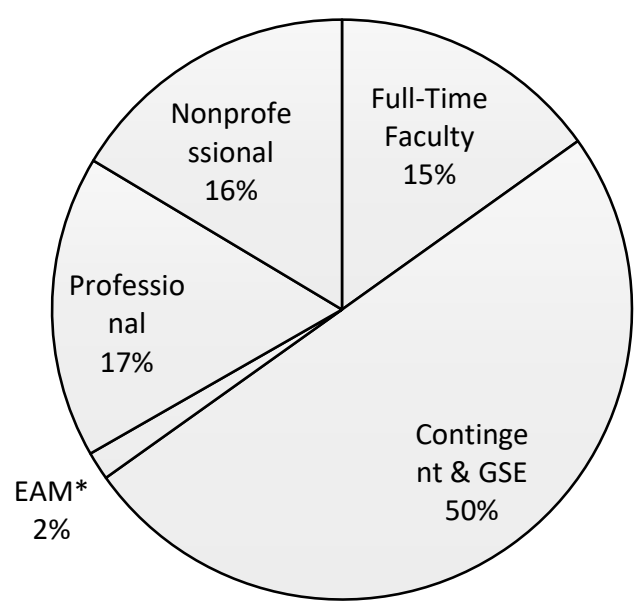

*: EAM represents executive, administrative, and managerial staff. 
Figure 13: Portland State University Staffing by Occupation, 2012 (IPEDS, 2020)

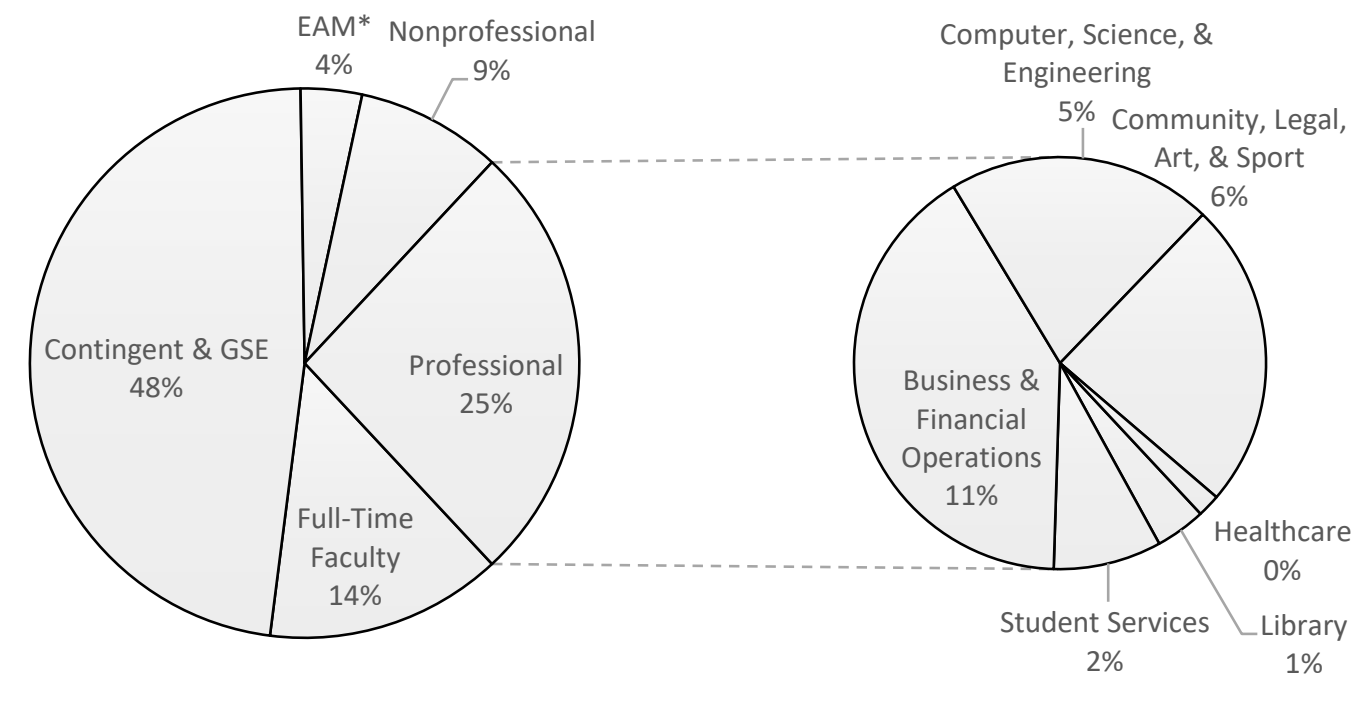

*: EAM represents executive, administrative, and managerial staff.

Figure 14: PSU Staffing by Occupation, 2018 (IPEDS, 2020)

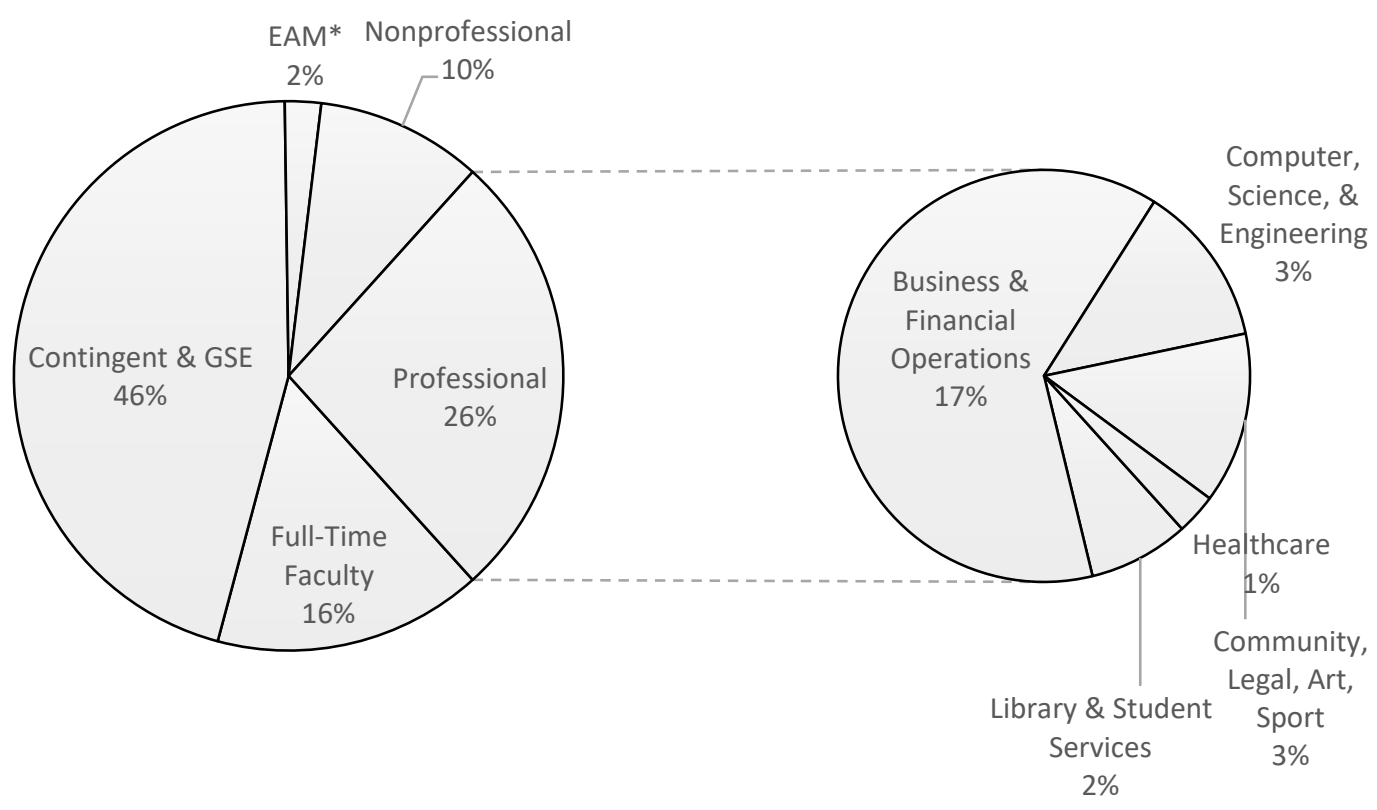

*: EAM represents executive, administrative, and managerial staff. 
PSU follows the trend of increased administrative intensity and casualized faculty as other HEIs in the U.S. These staffing trends represent the same economic calculus by which universities both sought to reduce costs and become more business-like in nature, reflecting the transition spurred on by neoliberalism. While HEIs utilize non-instructional professionals to help support student learning, they also wield them to increase economic efficiency, assessment of teaching and programs, and managerial control (Olssen \& Peters, 2005). These factors connected the final two issues discussed in this lens of inquiry: Compensation and job precarity.

\section{Unsustainable wages and precarious conditions in HEI personnel practices.}

The literature describes the unsustainable economic situation faced by contingent faculty at length (Bauer, 2017; Cadambi Daniel, 2016; Desrochers \& Kirshstein, 2014; Hurlburt \& McGarrah, 2016; Julius \& Gumport, 2002; Kroeger et al., 2018; Ramirez, 2018). This issue can be understood in two different expressions, speaking to the longterm outcomes of neoliberal policy. First, there is the issue of stagnant wages, a sideeffect of the accumulation process of neoliberal capitalism (Kotz, 2008; Wisman, 2013). While this effect represents a more general outcome of neoliberalism, its impact on higher education requires consideration. To investigate this, I collected data from the annual report of the American Association of University Professors (2018) discussing the economic conditions of postsecondary teachers. This data looked at the percentage change in salaries for all ranks of instructors, after adjusting for the consumer price index for all urban consumers, which represents the cost-of-living increase for each year based on inflation, from 1971 to 2018, representing them in Figure 15. I found that salaries remained relatively stagnant for the average teacher, warranting further investigation. 
Figure 15: Percentage Change in Average U.S. Postsecondary Faculty Salaries After Adjusting for Consumer Price Index for All Urban Consumers, 1971-2018 (AAUP, 2018)

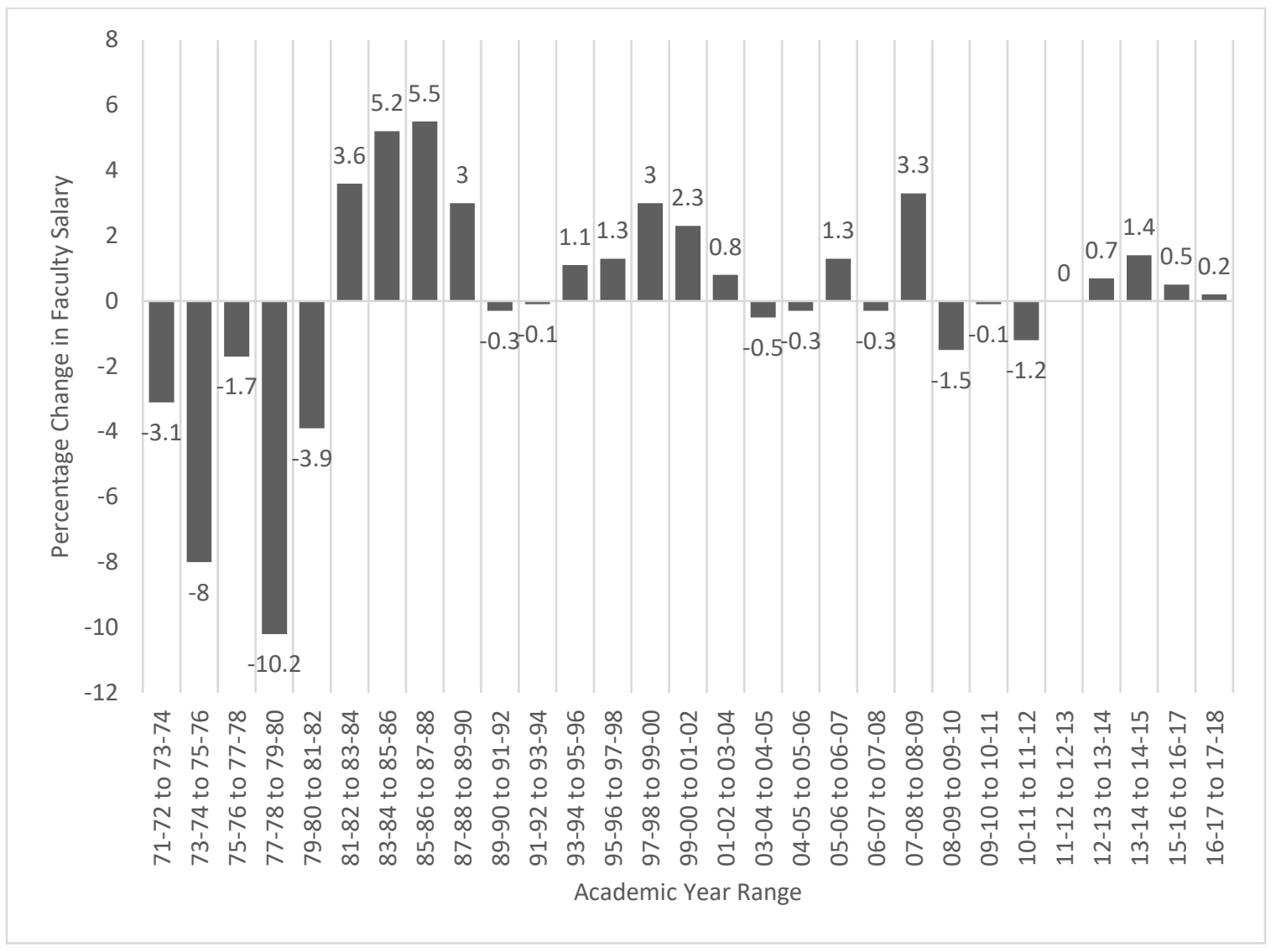

To expand this exploration, I looked at the data collected for the average salaries of public, 4-year HEI personnel in the U.S. and at PSU from the Chronicle Data database of the Chronicle of Higher Education (2020), looking at the available data for instructional personnel from 2003 to 2017, and non-instructional personnel from 2012 to 2017, with occupational categories defined by the U.S. Department of Labor (2018). I found that, after adjusting for inflation, salary growth in almost every category of staff was nearly flat. These statistics can be found in Appendix A.

No single variable can explain the complex results of faculty compensation. Economic vitality at both the national and local level, regional regulations, and the 
individual performance of faculty all represent potential factors impacting average salaries. However, the neoliberal principle of market-rationality demands efficiency by reducing the cost of producing goods where possible. In this context, corporatized universities produce knowledge for the consumption of students as customers and, as a result, neoliberalism demands that universities reduce the cost of the production of that knowledge - resulting in the diminishment of compensation for academic labor.

Postsecondary teachers represent commodified academic labor in this equation, and administrations, therefore, must reduce their value - their salaries - to maximize efficiency. Ultimately, neoliberalism's effects extend even to most administrators; by the data collected in Appendix A, even their salary growth remained relatively flat over the period analyzed. In this way, the broader policies of neoliberalism profoundly affected the wages of every class of employee within higher education, to the benefit of a vanishingly small number of individuals in American society (Wisman, 2013). This resulted in an increasingly unsustainable economic environment for all workers in the U.S., which then complements the precarious nature of work noted as the final presenting issue. As corporate universities sought to cut costs, they utilized casualized faculty in the form of contracted, non-tenure-track adjunct instructors and graduate student employees who lacked the protections and affordances usually granted to the traditional professoriate. These decisions allowed universities to massively expand the ranks of teachers offering instruction but did so by harming the well-being of contingent faculty.

Drawing once more from the annual economic report of AAUP (2018, pp. 27-28) an average graduate teaching assistant at a public university like Portland State would earn $\$ 16,530$ a year, while the average and median pay-per-section - with section 
representing a course, term, quarter, or other classification discrete educational unit - for adjunct faculty are $\$ 13,125$ a year and $\$ 11,403$ respectively (2018, pp. 27-28). Many institutions restrict their contingent faculty to working below .5 FTE, disqualifying them from the benefits and protections normally afforded those employees (Desrochers \& Kirshstein, 2014). PSU restricts both adjunct faculty and GSEs to .49 FTE, based on the collective bargaining agreements established by the Portland State University Faculty Association (PSUFA) and GEU, which represent adjuncts and GSEs, respectively (GEU \& PSU, 2018; PSUFA \& PSU, 2018).

Fortunately, the collective bargaining contracts at PSU have increased fortunes of GSEs and adjuncts at the university. According to PSUFA's CBA (2018), the minimum fee paid to adjuncts for a course at Portland State for 2019-2020 is $\$ 1,009$ per credit hour and stipulates that 45 credit hours represent full-time employment with the university. At .49 FTE - which equates to roughly 22 credit hours - an adjunct instructor at maximum employment will make $\$ 22,198$ before taxes. Comparatively, on a 9-month contract, a graduate student employee from GEU's CBA (2018) will make $\$ 24,000$ annually. While these figures are a substantial improvement over the average statistics identified by AAUP, they cannot, by any definition, be described as economically sustainable.

To put them into perspective, a full-time, minimum-wage job in the Portland metropolitan area in 2020 will make $\$ 13.25$ an hour, or $\$ 26,500$ before taxes (State of Oregon, 2016). In effect, the majority of instructors teaching postsecondary students at Portland State University make significantly less than the full-time store clerk selling the textbook for their courses. Furthermore, the minimum wage is itself a terrible indicator of 
economic sustainability. According to a report by the National Low Incoming Housing Coalition (Aurand et al., 2019), the fair market rent - that is, the rate at which the U.S. Department of Housing and Urban Development values as the fair rental price for a moderately-sized dwelling (HUD, 2020) - for a 1-bedroom apartment in Oregon is $\$ 999$ a month. A worker's minimum annual salary to make such an apartment "affordable" that is, requiring no more than $30 \%$ of their total income - is $\$ 39,960$, or $\$ 19.98$ an hour (Aurand et al., 2019, p. 204). These figures illustrate the dire straits experienced by contingent faculty today.

The final element touches on the nature of the work in which contingent faculty engage. Without the protections afforded by full employment, these teachers face restrictions on their research, activities, and voices on campus (Bauer, 2017) as their contracts can be reduced or eliminated term-to-term with little or no notice, most often without any form of compensation (Courtois \& O'Keefe, 2015). This tacitly punishes instructors for the time and effort spent designing and preparing a course if it gets canceled before the term begins. PSUFA (2018) covers this effect in their CBA with PSU, which provides between $\$ 50-100$ per credit in compensation if the university cancels a contract with short notice.

\section{Understanding organized labor through the presenting issues.}

Each of the presenting issues in higher education connects to the historical events wrought by neoliberalism through clear patterns shown by the data and literature. Understanding this framework is essential because it helps highlight how neoliberalism affected each of the personal, relational, structural, and cultural conflict domains described by Lederach (2014, p. 25). It also provides a window to understand how the 
lens interprets the events of the literature. With the exploration of higher education complete, I turned to the labor movement and its presenting issues - the systemic problems in its dispute resolution system, its low membership and influence, and the structural and political opposition it faced. Through this exploration, I found similar patterns, leading to the same epicenter.

\section{The labor movement's long, slow fall from power.}

Today, labor union membership in the United States stands near its lowest point since the turn of the $20^{\text {th }}$ century, but this decline occurred slowly, over the course of half a century. To visualize this information, I reproduced the data collected by Bivens et al. (2017) to show the percentage of workers in claiming membership to a union from 1917 to 2014, represented in Figure 16. The overall timeline of their decline closely follows the structural changes driven by neoliberalism in higher education. This only represents a temporal correlation to the ideology. However, it does provide a useful timeline to connect the events discussed by Rosenfeld (2014). He described four external events that contributed to the fall of unions through the latter half of the $20^{\text {th }}$ century: The loss of public approval, a comprehensive shift in the American economic landscape, the deconstruction of public institutions protecting organized labor, and hostile opposition from various political forces. 
Figure 16: Percentage of U.S. Workers Claiming Membership to a Labor Union, 1917-2014 (Bivens et al., 2017) - Data Table in Appendix B.

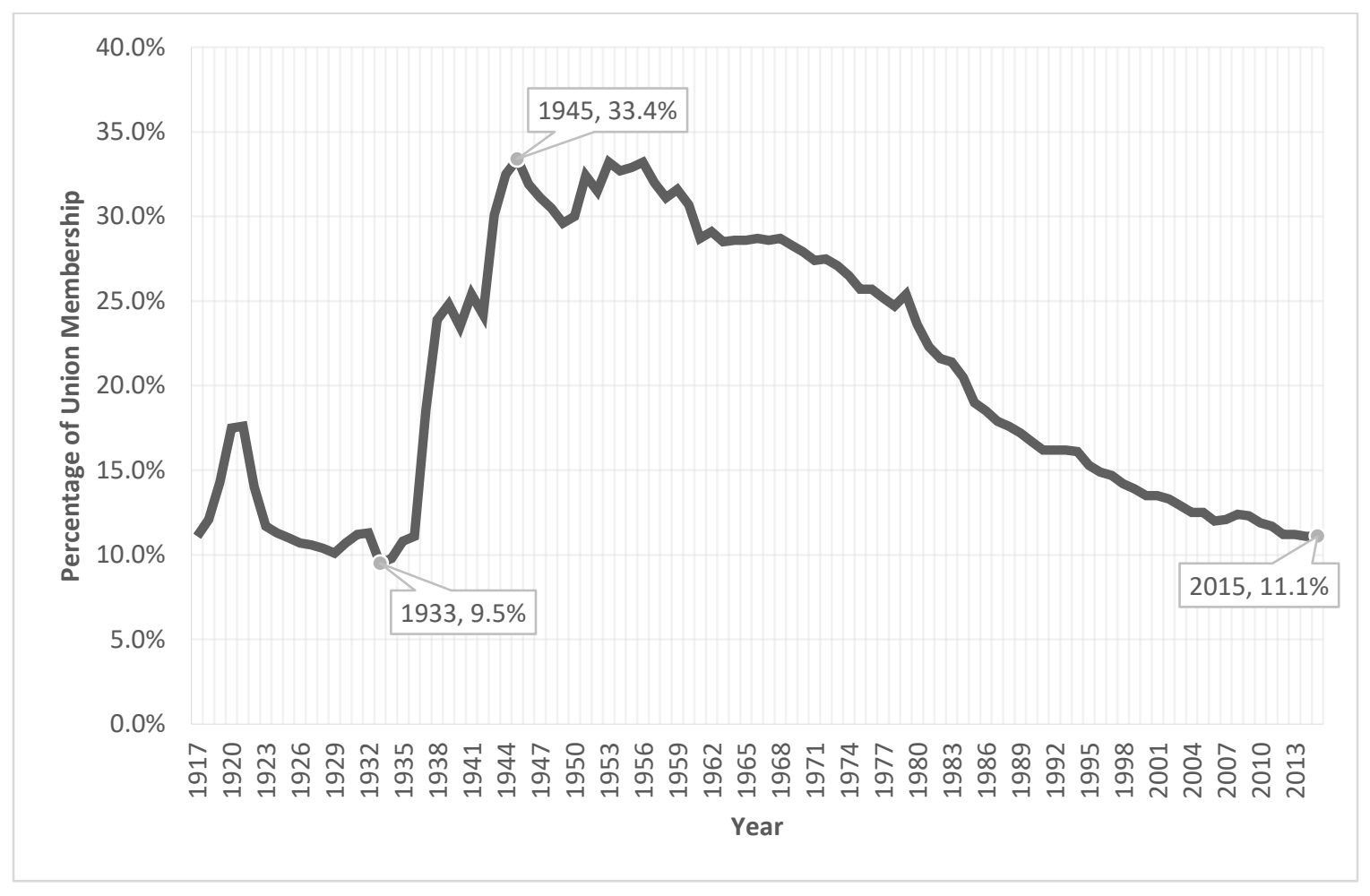

Rosenfeld (2014, pp. 10-12) acknowledges that many internal issues plagued the labor movement during this time, but asserts that the real damage to unions stemmed from these external sources, pointing to the movement's failure to recruit new members even with new strategies, and the parallel challenges faced by other labor movements internationally. From this premise, I argue that the sea change faced by organized labor is, in fact, tied to the more substantial shift toward neoliberal ideology in the United States. In his book, Masters of the Universe, scholar Daniel Stedman Jones (2012) writes of the ascendancy of neoliberal policy and practice in both the United States and the United Kingdom over the $20^{\text {th }}$ century, growing in the post-war period after 1945 before becoming mainstream and embedded in American politics by the 1970s. His timeline builds a parallel course of history that follows both the fortunes of organized labor and 
the changes occurring in higher education, accelerated by the policies of the Reagan presidency of the 1980s and becoming a hegemonic ideology by the turn of the millennium (2012).

\section{Under the bed and around every corner: The political adversity faced by organized labor.}

Rosenfeld (2014, pp. 21-30) writes of the political adversity faced by the labor movement that both sought to limit union power and resisted union attempts to correct the institutional damage done to the National Labor Relations Act and its enforcing body, the National Labor Relations Board. This opposition first arose from conservative, probusiness elements of the American political establishment, but eventually extended to the policies of the Democratic President Bill Clinton, whose party traditionally supported unions. Jones (2012, pp. 264-266) details the very strategies and policies that originated enabled, and enacted this opposition, pointing to the deregulation, tax cuts, and defunding of public institutions that comprised the limited-government philosophy of Reagan's time in office. Additionally, Reagan presided over, and broke, the air traffic controller strike of 1981, discussed by both Jones (2012, p. 266) and Rosenfeld (2014, p. 29) as a pivotal defeat in the union movement.

Outside of the executive branch, pro-business organizations such as the American Enterprise Institute and Foundation for Economic Education fervently advanced neoliberal policies (D. S. Jones, 2012, p. 134), supported by prominent political figures like presidential candidate Barry Goldwater and federal reserve chairman Alan Greenspan (2012, p. 12). Arguably, systemic forces such as racism even facilitated the rise of neoliberal policies by fragmenting and precluding social unity in American society, as 
occurred in the denial of welfare state benefits to black communities in the south $(2012$, p. 26) and the racist exclusion of black union members in the labor movement (Rosenfeld, 2014, p. 109). For unions, this cost them valuable membership that would only be redressed by the organizing of influential figures such as Cesar Chavez and Eliseo Medina (2014, pp. 131-132). For American society at large, the fragmentation contributed to the long-term failure of New Deal legislation and other socially-oriented policies that reduced societal inequity (D. S. Jones, 2012, p. 26).

\section{The failure of American labor institutions and the subversion of its dispute resolution} system.

The political opposition that emerged in the post-war United States drove the degradation of the institutions created to protect organized labor. Regulations unfairly disadvantaging unions in the NLRA were entrenched by anti-union politicians (Rosenfeld, 2014, pp. 22-23), while political legislation defanged the enforcement of NLRB mechanisms, allowing businesses to flout labor laws with little consequence (2014, pp. 23-24). These factors contributed to the subversion of the NLRB's dispute resolution system, ultimately leading to the present-day situation where the organization's mediation and arbitration processes fail to provide justice in labor-management disputes. The deconstruction of the institutions created to protect unions slowly allowed corporate forces to break the influence unions had in collective bargaining. For example, the loss of pattern bargaining in the 1980 s reduced unions to engaging with companies at the enterprise level, allowing those companies to weaken union positions by arguing that unionization would prevent them from competing with nearby, non-union companies (2014, pp. 21-22). Combined with the political resistance to legislative change and the 
lack of access to government apparatuses Rosenfeld discusses in countries such as Norway, this shut out the labor movement from equitable participation in the institutions governing workers in the U.S (2014).

The economic (r)evolution: Globalization, deregulation, and free trade agreements.

Rosenfeld (2014, pp. 18-19) also points to the economic transitions occurring through the latter half of the $20^{\text {th }}$ century as another source of union woes. The opening of global markets, facilitated by advancements in technology and aided by organizations such as the International Monetary Fund, expanded and extended neoliberal policies and practices globally (D. S. Jones, 2012). As American unions focused solely on the concrete concerns of their economic fiefdoms within specific businesses, they were unable to adapt to the changing labor market and the sudden availability of cheaper international workers and products. The creation of economic accords such as the North American Free Trade Agreement (2012, p. 8) established liberalized free-trade trade policies that allowed companies to treat workers in one part of the world as identical to another area, both justifying and facilitating the exploitation of more impoverished workers while weakening the power of labor in more developed countries. The neoliberal principle of individual freedom ostensibly described each worker as equal, regardless of their social context, enabling businesses to begin treating American workers like their economically deprived counterparts.

\section{The decline of public support for organized labor.}

The final element Rosenfeld (2014, p. 15) discusses relates to the decline in public opinion over the past century, pointing to the approval rates drawn from Gallup polls over that time. He points to opposition from various media outlets, think tanks, and 
public figures as the fomenters of this cultural disapproval, buttressed by the weakening of unions over past decades. This neoliberal messaging influenced several generations of people in the United States, leading to a longer-term cultural affect in society's understanding of labor and the markets. However, as the disparities of neoliberal policy become more and more apparent, these views are shifting. Rosenfeld's work, published in 2014, could not foresee the recent shifts in public opinion on the labor movement, which grew from its low point of $48 \%$ approval to one of its highest points in 50 years in 2019 , 64\% (J. Jones \& Saad, 2019).

\section{A clear view: The results of the first lens of inquiry.}

While the literature clearly implicates neoliberalism as the epicenter of the conflict in higher education, contextualizing the impacts discussed in the literature with data from postsecondary education broadly and in the concrete example of Portland State University helps solidify these effects. Additionally, I also needed to establish the ideology's connection to organized labor. By examining the patterns and connections between the external forces identified by Rosenfeld (2014) and Jones (2012), I confirmed neoliberalism as the epicenter of the changes affecting the labor movement by exploring its connections to the dimensions Rosenfeld (2014) discusses as the driving forces of union decline. This cemented an answer for the third research question, creating a solid foundation with which to explore the second lens of inquiry and identify the change goals that framed the conflict domains and development of change processes.

\section{Inquiry 2: The Horizon of the Future}

Lederach's (2014, pp. 30-31) second lens asks us to imagine the parameters of a future world, transformed by constructive peacebuilding. The purpose of this exercise is 
to establish a framework to construct solutions, extrapolating their impacts on the relationships and systems of the conflict. By affixing our vision to the horizon of peace, we can chart a path toward peaceful relations using this vantage point to understand the different elements of the discord. Here, I started by investigating the moral principles of neoliberalism, seeking to incorporate its ethical justifications into the peacebuilding framework.

Neoliberalism's central philosophical tenets anchor well-being to the existence of free markets and the valorization of individualism. It argues for the deconstruction and privatization of public institutions, governed by the consumptive, self-interested actions of individuals. Its moral argument stems from a desire to protect the voice and agency of citizens within society, arguing that the representative forms of government established by traditional liberalism create leaders and institutions that are unaccountable, inefficient, and ultimately undemocratic. This position is not without merit; one does not need to look far to find examples of poorly managed, autocratic, yet nominally representative governance. The problem lies in two places: The inequitable concentration of wealth leading to increasingly dire economic consequences, and the destructive reality created by conceptualizing individuals as market-rational agents. These two issues are intricately tied together in their expression through neoliberal philosophy.

\section{The contradictions of capital: Inequity, accumulation, and crisis.}

One of the central issues faced by neoliberalism is its propensity to create inequity. Recall the chart showing the trend of union membership over the past century. By drawing data from the World Inequality Database (2020), I collected statistics for the percentage of wealth owned by the top $10 \%$ and top $1 \%$ of households over the same 
period as union membership, displayed here in Figure 17. The relationship between the concentration of organized labor and wealth inequality is striking - as union membership increased, the share of wealth sequestered by the wealthiest elite of American society decreased. Similarly, this inverse relationship held true as the fortunes of unions in the latter half of the last century. Other scholars have also commented on this relationship (Bivens et al., 2017; Collins \& Niemesh, 2019), noting that, while it is highly improbable that one variable can adequately explain the phenomenon of wealth inequality, unions have nonetheless helped reduce inequity through their impacts on the policies, practices, and culture of the United States (Collins \& Niemesh, 2019).

Figure 17: Percentage of Union Membership to Percentage of Total Wealth Owned by Top $10 \%$ and $1 \%$ of Households in the U.S., 1917-2014 (Bivens et al., 2017) World Inequality Database, 2020)

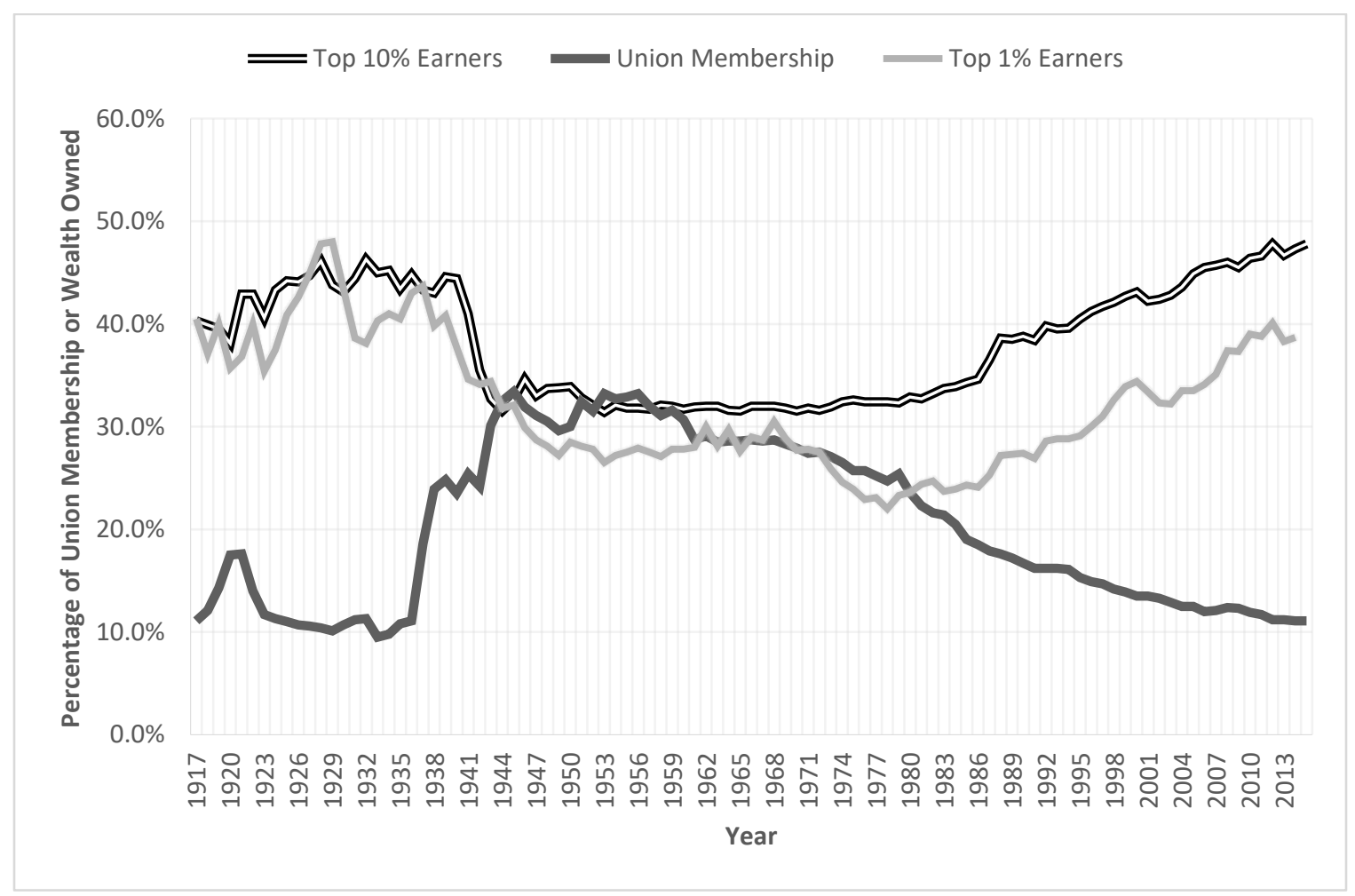


The importance of the data examining the top $10 \%$ and $1 \%$ of households lies in the fact that, as the chart shows, only the ultra-elite - the $1 \%$ themselves - ultimately control the wealth attributed to the wealthiest members of society. This result is not an accident; it represents an intended consequence of neoliberal policy (Harvey, 2007; Saez \& Zucman, 2016). Unfortunately, a serious consequence of this rise in wealth inequality is the production of increasingly severe economic crises, as discussed by the economist David Kotz (2008). Kotz explains that these crises result from overaccumulation, wherein the excess production of capital - the totality of assets and wealth - created by the marketplace is no longer able to reconcile the overproduction of goods with a devalued labor force unable to acquire those goods, generating a crash. Kotz (2008, p. 13) used this idea to analyze the 2001 economic recession, predicting that the subsequent economic crisis would prove more challenging to solve as the problem of neoliberal overaccumulation worsened. As history showed, this prediction proved true in the financial crash of 2008 (Wisman, 2013).

The mechanism that concentrates wealth does so by taking it from others, expressed through a system that advantages the economically powerful (Saez \& Zucman, 2016). Within the arena of higher education, these effects show through my earlier analysis of the flat wage growth of faculty salary and, indirectly, through the growth of student debt as individuals are unable to deal with the rise in tuition. As the scholars in the literature attest, the vast majority of people within a neoliberal society face diminishing returns and mounting losses the longer the marketplace operates in this unregulated fashion (Atkinson et al., 2011; Collins \& Niemesh, 2019; Wisman, 2013). Moreover, these effects represent only one element of the substantive harm produced by 
neoliberalism. Another stems from the way neoliberalism conceives of individuals in society, which degrades their identities and relationships to others and the community. This leads to my second critique: Neoliberalism's enshrinement of hyper-individualism and the flawed premises that construct that view.

\section{The myth of the rational actor: Individuals under neoliberal ideology.}

A cornerstone of neoliberal thought comes from conceptualizing people as "homo economicus": rational, autonomous, utility-maximizing individuals governing the state as consumers in the market (Lemke, 2001; Read, 2009). This idea has its roots in the rational choice theory, which argues that individuals act in a manner that maximizes the utilitarian benefits of their situation while minimizing potential costs (Hodgson, 2012). The issue with this assertion, however, is that rational choice - and therefore, homo economicus - consistently fails to explain behavioral choices (2012, pp. 95-96). Comprehensive research on the subject shows that, across a variety of cultures, individuals regularly choose non-maximizing values such as notions of honor and care to guide their actions, even when engaged single, unrepeated interactions with other actors (Henrich et al., 2005).

An example of this phenomenon even exists within the academy. According to Finnish scholar Alf Rehn (2014), academics regularly participate in a "gift economy," in which complex variables of value are generated outside of commodification and without any economic benefit through the exchange of gifts between individuals. In higher education, researchers often share knowledge and ideas using Creative Commons licensing, open access publishing, or by freely sharing their work amongst each other without expectation of compensation. The gift economy flies in the face of utility- 
maximization principles. Yet academics do so willingly, enthusiastically, and sometimes forcibly, resulting in a robust community of knowledge that exists almost entirely outside of the neoliberal calculus (2014, p. 203). As a result, the conception of homo economicus presents an enormously problematic view of individual interactions within society. At worst, it does not reflect reality at all.

Despite this, neoliberalism has succeeded in producing a shift in the psychology and reality of those under its purview. Drawing on the Foucauldian concept of governmentality, which argues that - over time - individuals governed by state apparatuses come to "self-govern," constructing a worldview consistent with, and in support of, the confines of state control (Sugarman, 2015). In applying this to neoliberalism, individuals begin evaluating every aspect of their lives through the economic interaction and transaction of the marketplace. Their life choices reflect this economic calculus, and they even become desensitized to its destructive outcomes: Poverty and homelessness, invasive marketing and advertising, the collective sale of our digital identities, and the modes of enforcement and control established to protect this state of affairs (Hamann, 2009). Neoliberal governmentality creates destructive consequences for our individual and collective psychologies, which expects constant selfreliance and capacity from citizens, and labels those who cannot "keep up" as morally inferior, lazy, wasteful, or flawed (Sugarman, 2015).

As a result, neoliberalism obfuscates the harm it produces through social expectations and cultural narratives that morally police individuals through their identities and relationships, condemning their "mismanaged" lives (2015, p. 114). As the ideology does not acknowledge the existence of systemic social problems, the people 
most likely to suffer from the inequities it produces are already marginalized groups some examples being low-income and racial or ethnic minorities (Enck-Wanzer, 2011) and women (De Benedictis, 2012). As a further extension of this dehumanizing process, the psychology of market rationality conceives of individuals as self-interestedly sovereign unto themselves, ultimately disincentivizing social cooperation and breaking down bonds of mutual support (Sugarman, 2015, p. 115).

\section{A different path: Liberating individual freedom from neoliberalism.}

The ostensible moral premise of neoliberal individualism holds value: Respect for and valorization of the autonomy and agency of people. This represents the idea of procedural justice Lederach (2014, p. 24) speaks of in his vision of transformative peace. However, he argues it must be combined with substantive justice, which demands that structures and relationships must provide for the basic needs of all participants. Given the results of neoliberal philosophy, this outcome cannot occur through the mechanisms of free-market capitalism and hyper-individualism. Thus, this identified a change goal that supports the rights and protections of individuals without simultaneously devaluing and dehumanizing them.

\section{Academic labor: Sighting the light of peace in a horizon clouded by governmentality.}

Turning the horizon of the future toward academic unions, one of their challenges is how they position themselves in the academic labor conflict. In an article exploring the views of leaders in GSE unions, Deeb-Paul Kitchen II (2010) wrote that several members expressed concerns that the organizing strategies employed by their unions enabled rather than resisted - the corporatization of universities. These views stemmed from the innate relationship contemporary unions exist in that construct the workers they represent 
in opposition to management - in this case, university administrations (2010, pp. 2-3). The historical view of the university - one collaboratively governed by both administrators and faculty - gave way to these "shop floor" relations, reinforcing the dynamic of teachers as labor within the calculus of market-rationality. The change goal identified by the analysis of neoliberalism requires an interaction framework beyond the marketplace, but because unions in the current paradigm explicitly exist within that marketplace, they do not currently offer an alternative framework engagement. Even were academic unions to somehow usurp power from administrators, the concrete economic goals espoused by most organized labor exists squarely within the demesne of neoliberal philosophy.

Transforming the academic labor conflict requires more than merely reversing the economic fortunes of faculty and administrator. The mechanisms of neoliberalism guarantee the concentration of wealth and overaccumulation of capital, achieved through the harm caused by devalued labor in the production of goods and services. Instead, it requires a fundamental shift in how unions conceive of their identity and relations to their opposition and academe more broadly, a sentiment by which Kitchen II agrees (2010, p. 6). This, then, frames the necessary change goal for academic labor: To identify a schema of action and interaction that increases both procedural and substantive justice outside of a neoliberal framework.

Drawing from the arguments put forward by participants in the academic labor conflict, this schema must foster a post-neoliberal vision of education that is emancipatory and empowering for students and the community (Freire, 2005; Giroux, 2014; Julius \& Gumport, 2002; Saunders, 2010). Instead of conceiving of faculty as 
commodified labor, it must conceptualize them as having irreducible values that necessitate care for their well-being. It requires viewing the academy not as a competition between administrative managers and knowledge workers but as a shared community where each stakeholder collaboratively and equitably contributes to its administration and success (Shore \& Taitz, 2012). The conflict does not exist here yet - this is, after all, the horizon of the future - but identifying a post-neoliberal framework is necessary for the long-term transformation of the conflict.

In the short-term, the conflict needs to reach a place where reconciliation between the disputants is possible. Given the disparities between academic labor and HEI administrations, conventional resolution techniques are not possible. Furthermore, the literature describes the existing dispute resolution mechanisms in labor conflicts as problematic. Therefore, achieving the long-term transformation of the conflict also requires a rebalancing of power between academic labor and university administrations beyond the existing conflict apparatuses present in labor-management conflicts. Together, these change goals frame the development of adaptable change processes that can support the conflict in both the short- and long-term.

\section{Inquiry 3: The Development of Change Processes}

Having constructed the first and second lenses, we can now see the impacts neoliberalism imposed on the four conflict domains. I first explored these descriptively, looking at the ways neoliberal systems influenced each of the personal, relational, structural, and cultural elements of the conflict. These descriptions are crucial to grasp both the direct and psychological impact the conflict has created on its participants. Following this, I layered in a prescriptive analysis, focusing on possibilities to reduce 
violence and increase justice. Like each element of Lederach's transformative framework, each domain exists both independently from, and interdependently with, the other domains, and thus the prescriptive analysis blends into each of them.

The personal domain: A Promethean coinage of humanity through the fire of the market and the clay of self-interested individualism.

At the personal level, Neoliberalism reshapes every element of our private and social worlds (Palacios, 2018). As a hegemonic, systemic force, it pervades our everyday interactions and choices through the calculus of market rationality, weighing how our degrees will benefit our financial future. It manifests through our language in idioms and phrases such as, "It's not worth my time," "I don't buy it," and "Put your money where your mouth is." It invades the very blood in our veins and air we breathe from the pollutants and chemicals given legal sanction through environmental deregulation. In higher education, neoliberalism affects the academic paths students take as they struggle to make sustainable economic choices (Callender \& Jackson, 2008). It drives faculty to seek out grants and research projects likely to receive funding and meritorious accolades (Ball, 2012; Jacob, 2009; Olssen \& Peters, 2005). It requires administrators to make hard choices to keep their university doors from shuttering. Within the labor movement, it encourages people to conceive of themselves as either workers or managers, the owning class or the owned.

Simultaneously, neoliberalism's exaltation of individualism minimizes the value of relationships and community. It expects self-interested economic choices from individuals that incentivize antisocial, non-cooperative actions, damaging the fabric of communities and societies (Hamann, 2009; Sugarman, 2015). The process of 
commodification instrumentalizes people, reducing them from whole, multivariate entities to a collection of economic indicators whose worth is determined solely by the market - one which devalues compassion and care in favor of competition, achievement, and merit (Littler, 2013).

These descriptions illustrate the violence inherent to the mechanisms of neoliberal philosophy. The process of commodification dehumanizes individuals by abstracting them into a monetary value and then devaluing those elements to reduce the cost of labor in the marketplace (Hamann, 2009). Simultaneously, it constricts agency by granting worth to people only through their economic value, requiring that individuals limit their activities to the pursuit of economic gain. This perspective encourages individuals to interpret and assess their actions through a market-rational lens. Depending on how the market values some actions, this either incentivizes or disincentivizes particular pursuits. The production of goods and services is of obvious value to the market, but many activities necessary for healthy individuals and societies are not.

Consider the simple act of sleeping: One scholar writes that, in a neoliberal society, sleep's only value relates to its support of future economic efficiency (Urquhart, 2018). She writes that, through governmentality, individuals self-police to carefully track and maintain the necessary levels of sleep to remain healthy, productive workers - with the market enthusiastically offering gadgets and services to support that effort. Another example: Parenting and childcare - roles that patriarchy situates in the domain of women - hold no value in the stock exchange but are critically necessary to society. As a result, parents, and especially women, must contend with the complex and challenging work of raising children without losing step with their economic output, a fact neoliberal societies 
are all too happy to weaponize to explain the ills generated by neoliberal policies (De Benedictis, 2012). Because a person's worth is determined entirely by their value on the marketplace, they find every aspect of their lives directed by the demands of the market. However, because neoliberalism inherently works to devalue individuals as labor, it inflicts violence in each element of life it touches - which is to say, all of them.

The horizon of the future requires a change process that protects individuals while working beyond neoliberal mechanisms. Thus, prescriptively reducing violence at the personal level requires developing alternative forms of social interaction that do not devaluate people through abstractions such as commodification. Simultaneously, increasing justice entails establishing irreducible values for individuals to meet the basic needs of the conflict's stakeholders. The feminist scholar Joan Tronto (2017) articulates such a modality in her discussion of democratic care, which argues for a care ethic ontology for societal governance.

Tronto's framework acknowledges the value and importance of individuals in a community - a caring society supports and values its people. However, she (2017, p. 32) argues that individuals cannot act or be regarded as actors responsible solely to, and for, themselves. Instead, care ethics establishes explicit, reciprocal bonds of relationship and support between a person, their community, and their society. These bonds create mutual obligations of care regarding actions, trade, and governance. At its core, Tronto's (2017) philosophy of democratic care expresses the idea that people have a set of irreducible values, answering the violence caused by commodification. This philosophy provides the scaffold to improve procedural and substantive justice through an alternative schema of interaction: The mechanisms of care. 
In the academic labor conflict, care ethics can be employed in the organizing strategies of unions to frame how they engage with members, the external community, and opposition. Regarding members, it requires accounting for what their care needs are, addressing those needs through organizing, and developing a robust relationship of mutual care between the member and union. In the community, it directs unions to build bonds between other social justice movements, as occurred through SEIU's social movement unionism (Tattersall, 2011). In opposing university administrations, care ethics indicates the use of strategic nonviolence to raise power through confronting adversaries while simultaneously protecting the intrinsic value of adversaries (Held, 2010).

\section{The relational domain: Viewing a connected world from a disconnected market calculus.}

The personal domain identified how neoliberalism transforms our perspective to interpret the world through a market-rational lens, conceptualizing ourselves as commodified entities (Palacios, 2018). These effects extend into how we relate to one another, encouraging us to make choices that maximize personal utility over cooperative or non-economic outcomes while simultaneously attributing success and failure solely to our actions (Sugarman, 2015). This guides people to view the power, privileges, and benefits they have won in competition as their by right (Gilbert, 2013). Further, through governmentality, it encourages us to view others' actions through the same light. Such a framework innately positions leaders against workers, both of whom consider their resources as solely their domain. The result is an intractable, dyadic labor-management relationship that concurrently highlights the concrete economic concerns of each group but that - through the auspices of neoliberalism's erasure of systemic awareness - 
obscures the conditions creating those concerns. This individualized worldview innately positions conflicts in a neoliberal society as solely the domain of the personal values and character of disputants in conflict, driving destructive outcomes (2013).

In the academic labor conflict, neoliberalism coaches each party to view the other in economic terms. Administrations see faculty as budget line items whose cost must be reduced and view students as customers waiting to be upsold their shiny, new degree (Servage, 2009; Turkel, 2009). Faculty, in turn, view administrators as shop floor bosses zealously guarding the purse strings of their paychecks and students through a lens of customer service - transactional, cyclical, and assessment-based. For their part, students experience the entire edifice of education as an enforced enterprise to be endured on the expressway to economic edification, instead of an essential element of self-enlightenment or societal enhancement. These perceptions worsen conflict by decoupling cooperative bonds, fueling destructive conflict through the inequities created by neoliberal structures and regulations in the academy.

As a consequence, the model of shared governance that typified universities earlier in the $20^{\text {th }}$ century gave way to corporate, hierarchical labor-management approaches (Saunders, 2010, p. 43). Because neoliberalism constructs all people as individuals, obscuring social systems in the process, this necessitates a relational framework where actions and consequences solely represent the motivations, agency, and views of those individuals. In the academic labor conflict, administrations casualize teaching as a response to financial stressors without addressing the larger systems that drive those stressors or the resulting opposition from faculty. In turn, academic unions fight to oppose and reverse the economic changes imposed by administrators without 
looking to the underlying force that catalyzed higher education's transformation. In this way, both administrators and faculty have a common enemy and, ultimately, transformation of this conflict requires an evolution beyond the labor-management dyad. Importantly. because of the power disparity caused by the devaluation of labor, administrations - which operate as the management class in this conflict - hold a far greater responsibility to use their capacity to change this system.

Prescriptively, reducing violence here requires rebalancing the power between faculty and administrators in the short-term, and an evolution beyond the dyadic labormanagement relationship in the long-term. The most direct route to this involves improving union organizing strategies that increase membership and influence and using strategic nonviolence to increase academic labor's power relative to the administration (Chenoweth \& Stephan, 2012). This outcome would increase procedural and substantive justice for academic unions and facilitate the future use of conventional conflict resolution techniques such as negotiation and mediation. In the long-term, prescriptively increasing justice requires redefining the relationship between administrators and faculty through mutually beneficial relationships of collaborative, joint governance (Hoppes \& Holley, 2014). Drawing from seminal research in organizational cooperation, arriving at such dynamic cooperation requires a balance of trust and control (Das \& Teng, 1998).

Das and Teng define control as the level of power one actor has over their partner's actions in a cooperative agreement - not merely the ability to direct, assess, and manage other stakeholders but in terms of information, agency, and influence actors have in partnerships and agreements. Trust is defined as the level of positive regard and goodwill stakeholders have toward each other's reliability and integrity. Successful 
cooperative agreements require enough trust and control between stakeholders that each has confidence enough to commit their resources and energy toward such accords. In the academic labor conflict, disputants are likely to have low trust in each other, and thus Das and Teng (1998) recommend that any cooperative agreement grant a high degree of participatory control to each stakeholder in order to build confidence in the success of agreements.

Such agreements would likely involve transparent and interdependent forms of collaborative governance where each stakeholder has a high degree of voice in the decision-making process of the project. This follows the conflict resolution theory of relational power in relationships, the capacity to build power together toward a constructive end, increasing equitable strength between interdependent parties (Wilmot \& Hocker, 2011). Importantly, academic labor must at all times be careful to conserve their resources and establish explicit mechanisms of protection in agreements, as high-power parties have far less to lose in collaborative partnerships and may abuse trust as a façade to harm low-power parties (Cerna, 2014). The development of these collaborative relationships fits within the long-term philosophical orientation of care ethics (Tronto, 2017), aligning it with the solutions of the personal domain and the needs of the horizon of the future.

\section{The structural domain: The visible structures that evoke the invisible hand of the market.}

The neoliberal reformulation of higher education has inflicted substantial harm to the mission, institution, and members of the academy. Its structures have made the governance of HEIs unaccountable to students and faculty through the construction of 
corporate organizational hierarchies and regulations that encourage universities to pursue profit above all other values (Saunders, 2010; Taylor, 2017; Turkel, 2009). Through the withdrawal of public support and the encroachment of market rationality, it has created conditions inimical to the well-being of teachers by reducing wages, benefits, institutional support (Jemielniak \& Greenwood, 2015; Rhoades, 2015; Sproul et al., 2014). By evaluating ideas based on their value to the marketplace, it made research counterproductive to societal welfare (Jacob, 2009; Morrissey, 2013; Shore \& Taitz, 2012). Finally, by placing the burden of education on individuals, it has made education prohibitive and inequitably expensive (McFarland et al., 2019; NCES, 2018; Nissen et al., 2019; Saunders, 2010). Here, reducing violence and increasing justice requires restoring equitable access to higher education, rebuilding structures of collaborative governance, and in the long-term, rectifying the mission of research and knowledge ministration.

Within organized labor, the crumbling infrastructure of the National Labor Relations Board now exists to mock the dispute resolution structures created initially to facilitate constructive outcomes in labor-management disputes (Rosenfeld, 2014). The subversion of the National Labor Relations Act now works to sabotage the survival of unions (2014). Given the deterioration of the regulatory structures built to protect the labor movement, reducing violence ultimately requires an activist stance to reform and reconstruct these structures. In their landmark work, Why Civil Resistance Works, the scholars Erica Chenoweth and Maria Stephan (2012) argue that this activism should utilize strategic nonviolence to build strong bases of power, and call attention to and abase the pillars of power enforcing violence and injustice. By converting or weakening 
these pillars, new structures - addressing the procedural and substantive concerns of higher education and the labor movement - can be created.

To align these structures with the personal and relational conflict domains, the ethics of care should ensure that all the stakeholders involved in collaborative projects have robust, interdependent, and participatory relationships to these new structures (Tronto, 2017). Furthermore, these constructions must ensure low-power stakeholders academic labor, and in some instances, students - have enough power in these structures to provide both sufficient dispute resolution and successful cooperative agreements (Cerna, 2014; Das \& Teng, 1998; Wilmot \& Hocker, 2011). Activist strategies must use strategic nonviolence to rebuild these structures and align them with the ethics of care (Held, 2010). These strategies are mutually reinforcing; Chenoweth and Stephan (2012) note that strategic nonviolence provides the highest possibility for positive post-conflict reconciliation.

\section{The cultural domain: Where the business is greed, and business is good.}

Finally, from a cultural standpoint, neoliberalism produces a narrative that avouches the absolute equality of all people, regardless of the reality of that assertion (Littler, 2017). This claim obscures the social systems producing enormous disparity in society (Enck-Wanzer, 2011; Harvey, 2007; Lazzarato, 2009; Lyon-Callo, 2008; Ortner, 2014) and polices people through the phenomenon of governmentality. This script constructs all persons in a neoliberal society as equally capable of, and responsible for, self-management and decision-making that maximizes their economic output (Sugarman, 2015). Governmentality then blames those who cannot keep up with the staggering demands of the market (Hamann, 2009), and legitimizes both societal outrage against 
these individuals (Lyon-Callo, 2008; Sugarman, 2015) and legitimizes institutional structures that further harm these already marginalized groups (Wacquant, 2009). The example of parenting discussed earlier provides an excellent illustration of the policing effect driven by these cultural scripts.

In the U.K., patriarchy obligates women to be the primary caregivers of children, but neoliberalism does not assign economic value to parenting (De Benedictis, 2012). Because neoliberalism expects all individuals to maximize their economic output and simultaneously conceives of them as equal, this obscures the patriarchal responsibility expected of women while incentivizing men to reject parental responsibilities because of the economic cost. As a result, neoliberalism societally sanctions men to abandon parenting while demonizing women for being either bad workers or bad parents (2012). From top to bottom, the cultural script of neoliberalism gives nothing and expects everything and functions best when workers are precarious (Harvey, 2007). This precarity, as one might expect, inflicts worrisome psychological damage to society: Social anxiety, a psychological disorder that affected less than $3 \%$ of the population in the U.S. only a few decades ago, has grown to afflict $13 \%$ of Americans, the third-most common mental health issue after alcoholism and depression (Sugarman, 2015).

In higher education, neoliberal culture guided the transformation of the academy into a corporate enterprise and, through this process, the reconceived of faculty as labor, knowledge as goods, and students as customers. It maintains its legitimacy through the mechanism of governmentality. HEI administrations, empowered by neoliberal policy and culture to wield their institutions like corporations, taking radical steps to increase production and reduce expenses at the cost of the ostensible mission of universities 
serving the public good (Taylor, 2017). They expand governmentality by using increasingly granular forms of assessment for teaching and research, squeezing more economic value from faculty at the cost of their academic freedom and well-being (Levin \& Aliyeva, 2015; Morrissey, 2013). The result of these practices extends neoliberalism into the ideas and curriculum taught to students (Saunders \& Blanco Ramírez, 2017; Servage, 2009; Taylor, 2017).

To invoke the peace researcher Johan Galtung, culture legitimizes the harm created by structures $(1969,1990)$. This enables systemic oppression by criminalizing and demonizing the poor (Cooper et al., 2016; Lyon-Callo, 2008; Wacquant, 2009), the non-white (Enck-Wanzer, 2011), and the non-male (De Benedictis, 2012; Ortner, 2014). In higher education, it justifies the casualization of faculty, the ballooning of tuition, and the market's control of research and programming (Bal \& Dóci, 2018; Saunders, 2010; Shore \& Taitz, 2012). Finally, it morally justifies the dehumanization of labor (Hamann, 2009; Sugarman, 2015) yet contemporaneously requires its existence as a crucial resource in the creation of capital. Thus, to reduce violence here, a transformative framework must enact new cultural scripts that bolster peacebuilding structures. Academic labor can realize this by employing organizing strategies that articulate ethics of care in their relations with their members, community, bargaining, and their opposition to administrations. At the same time, unions must conscientize individuals and organizations to the cultural narratives engendered by neoliberalism.

\section{Identifying the change process to deploy care ethics.}

The lenses of inquiry centered on neoliberalism's role as the epicenter of the academic labor conflict and described its effects on its participants. Prescriptively, I 
identified the philosophy of democratic care described by Joan Tronto (2017) as a framework to ameliorate neoliberalism's dehumanization of labor and degradation of higher education. Next, I pinpointed strategies of power balancing, collaborative governance, and nonviolent activism as avenues to reduce violence and increase justice in each of the four conflict domains. The delineation of these elements sets the stage for developing a transformational platform, which lays the groundwork for our path toward sustainable peace (2014, p. 37). Lederach (1995, p. 28) writes that transformative peacebuilding should employ appropriate technology: Tools, concepts, and ideas already present and utilized by existing parties. By using knowledge and capacities already known by stakeholders, peacebuilding interventions help preserve agency and autonomy while avoiding unintended, destructive consequences. Returning to Murray’s (2017) exploration of the labor renewal literature, I identified a capable vehicle for transformation in the work of the feminist labor scholar Barbara Pocock (2012).

\section{Uniting the World of the Workers: The Socio-Ecological Model of Union Organizing}

In "Rethinking Unionism in a Changing World of Work, Family, and Community Life," Pocock (2012) argues that union organizing must address not only the economic concerns of its members but the points at which those issues intersect with other parts of their lives. She writes that labor organizing began at a time when workplaces primarily employed ethnically homogenous men whose jobs provided the primary or sole source of income for households. Pocock writes that, consequently, union activities and strategies typically reflected the needs and ideas of these workers. Strikes, for example, often relied on support from caregivers at home to provide food and other necessities for strikers 
(2012, p. 568). However, as the economic landscape shifted, with more women and immigrants entering the workforce, those strategies grew outmoded (2012, pp. 563-564). Pocock writes that workers maintain multiple identities, depending on the context and societal role in which they participate, with some examples being parents with children at home, immigrants whose economic or social status makes strike actions especially risky, or casualized workers with multiple jobs. To remain relevant, she writes that unions must adapt their strategies to understand and account for these contexts, offering an approach to union activity derived from Urie Bronfenbrenner's (1981) socioecological model of human development (Pocock, 2012, p. 569). Pocock's application of the model directs unions to account for the different contexts and systems comprising a worker's life, separating them into three intersecting fields, as visualized in Figure 18. 
Figure 18: Pocock's (2012) Visual Adaptation of Bronfenbrenner's (1981) SocioEcological Model of Human Development

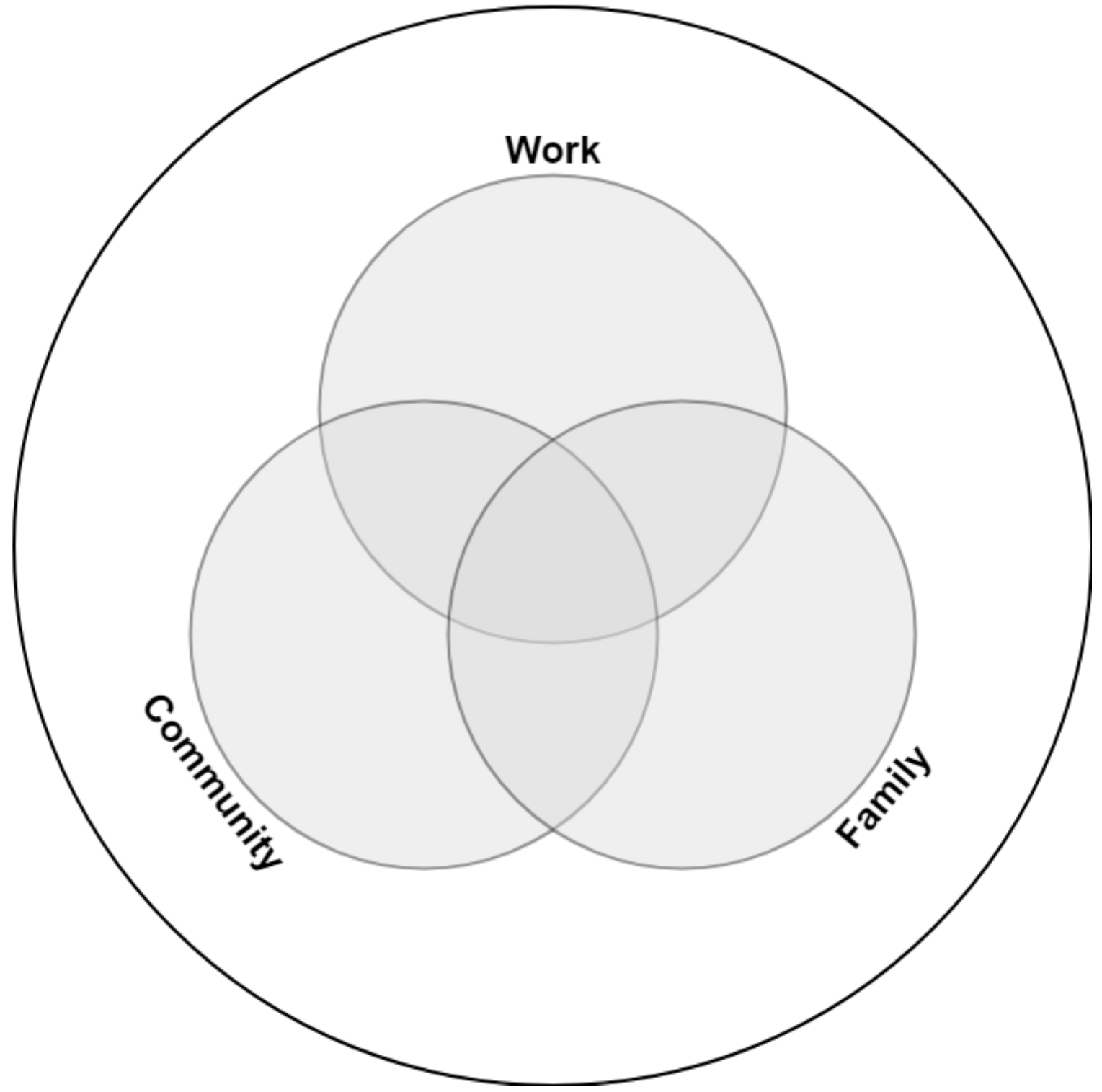

Pocock (2012, pp. 569-570) writes that each of the three fields represents a

microsystem containing the various elements of a worker's life - for example, the "work" field contains not only their workplace but their industry and connection to the broader economic landscape. The four intersections of the microsystems represent mesosystems where interactions between the fields give or take resources and energy. Finally, these 
fields are situated within a macrosystem - the broader context that defines a worker's location in the world and society (Pocock, 2012). To apply this idea to the academic labor conflict, a graduate student employee's position fits within the field of work, while their academic studies might apply to the community field. Each field and intersection require time and energy, such as when the GSE needs to balance time between one field or the other. Conversely, the fields may provide resources to one another as well, such as when the GSE's studies complement their teaching.

The significance of Pocock's model lies in its ability to both contend with systemic influences such as neoliberalism and provide a holistic way to support the contextual needs of union members (2012, p. 573). Extending the portfolio of union organizing beyond economic responsibilities requires additional energy and resources, but Pocock (2012, pp. 578-579) argues it also creates opportunities for resources, recruitment, and meaningfully incorporating historically excluded groups into the movement. Crucially, the socio-ecological framework additionally provides the starting point to deploy the ethics of care necessary for long-term peacebuilding.

\section{Toward a Systems Ecology of Transformative Care}

Lederach defines the transformational platform as a framework that provides adaptive responses to immediate episodes conflict - the presenting disputes between HEI administrations and academic labor unions - while also addressing its underlying epicenter, represented here by neoliberalism (2014, pp. 37-38). The socio-ecological model provides this framework by facilitating an awareness of the neoliberalism's systemic obtrusion. Its contextual approach to individuals' identities and needs also complements the mechanics of both transformative peacebuilding and the ethics of care. 
To that end, I have integrated these frameworks to create a Systems Ecology Framework of Transformative Care (SETC) for labor organizing, visualized in Figure 19. This model employs Pocock's (2012) implementation of the socio-ecological model to guide union strategy using the transformative peacebuilding construction of the conflict domains (2014, pp. 30-32) to deploy the ethics of care delineated by Tronto (2017).

Figure 19: The Systems Ecology Framework of Transformative Care, Adapted from Lederach (2014), Pocock (2012), and Tronto (2017).

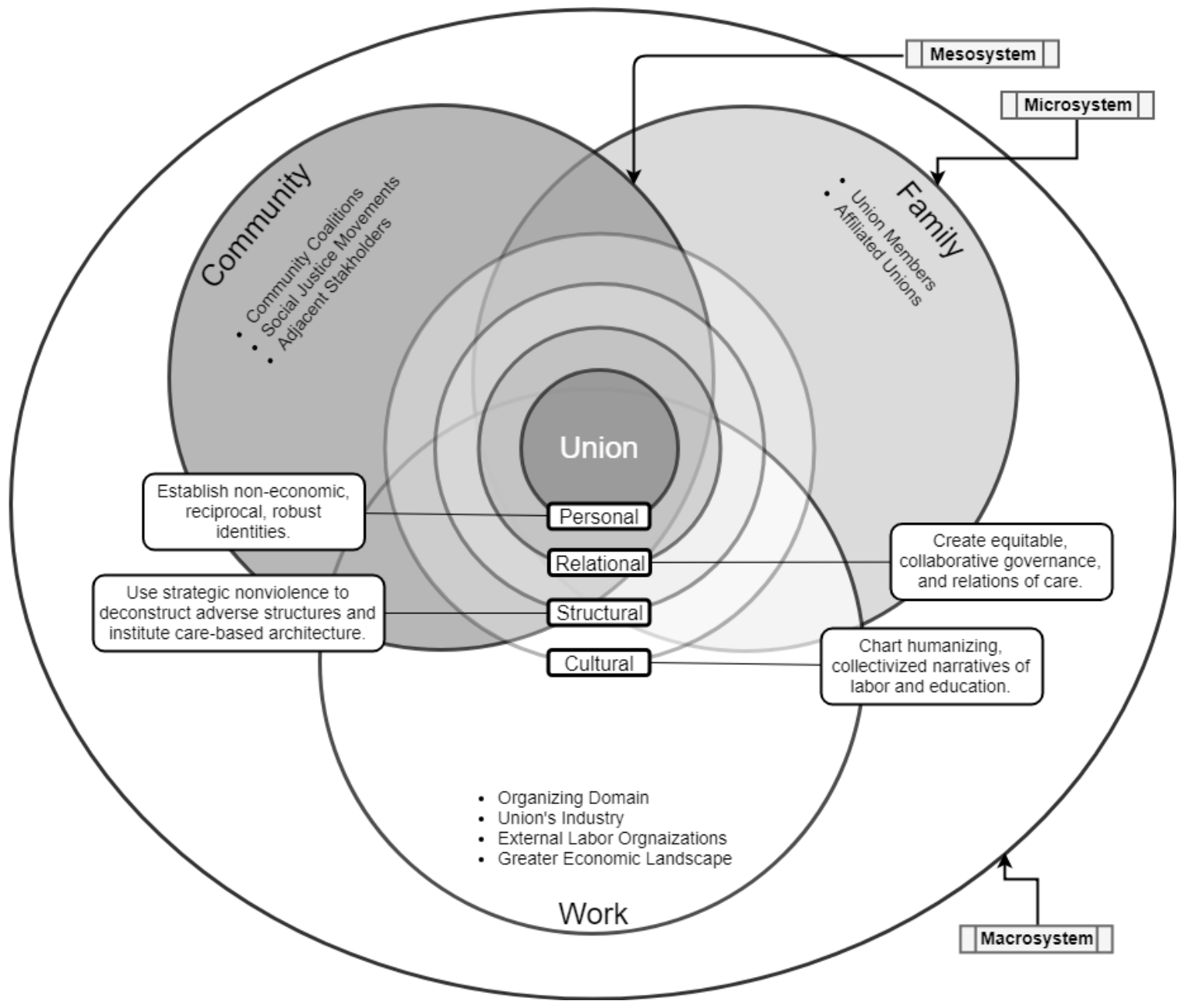

In this model, I centered the union at the framework's center, filtering its actions and strategy through the socio-ecological model. Here, each field represents specific domains of the union: 
- Family: This represents a union's membership and closely related union affiliates. To apply this model to the Graduate Employees Union, this would include its members and other academic unions on the PSU campus.

- Community: This field signifies community ties and obligations outside of direct, analogous connections. Examples include other social movements, stakeholders adjacent to the labor-management context, and locally situated non-union groups and organizations. In applying this to GEU's context, community might include student groups, social justice groups such as the National Association for the Advancement of Colored People, or civic organizations such as the Boys \& Girls Clubs of America.

- Work: The final field relates to the union's organizing domain - that is, the physical and abstract area the union represents, the union's industry as a whole, labor organizations external to the union's local context, and the broader economic landscape. Concerning GEU's context, this field includes PSU's campus and the organizational boundaries incorporating GSEs and the university's administration; its extended union affiliates such as AFT, SEIU, and AAUP; contingent faculty more broadly; and higher education itself.

The SETC framework applies the socio-ecological framework to the union itself, relating to the three fields in the same manner as individuals and applying the care ethics framework through the lenses of the conflict domains. To exemplify this concept, an academic labor union acting through the SETC model could build collaborative coalitions with other social movements, constructing reciprocal relationships of care that redefine individual identity beyond neoliberal constructions - addressing each of the conflict domains. Another endeavor might establish a structure for research administration or education utilizing the ethics of care to determine its goals, beneficiary, or method. Regardless of its application, the core philosophy of the Systems Ecology Framework of Transformative Care articulates a long-term peacebuilding approach aimed at deconstructing the underlying effects of neoliberalism in the episodic conflicts occurring within higher education. 


\section{Chapter 5: Implications}

Lederach's (2014, p. 29) transformative framework seeks to create sustainable, dynamic peace over the long-term timeline of a conflict. As a result, the solutions it poses in discrete expressions of conflict may not generate profound resolutions in the discord. Nevertheless, using SETC as a transformational platform progressively builds toward peace by affecting change to its present issues, historical events and patterns, and future expressions. Lederach (2014, pp. 35-36) writes that the road toward constructive peacebuilding is neither straight nor simple. We walk a linear path in conflict, but this trail is also fraught with obstructions, dead ends, and backslides. In this way, conflict also operates as a cycle, as visualized in Figure 20.

\section{Figure 20: The Cycle of Conflict, Adapted from Lederach (2014, p. 35)}

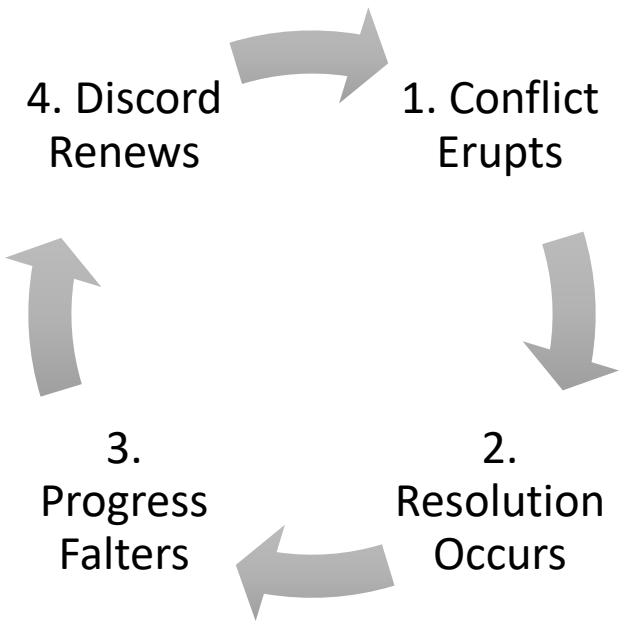

Conventional resolution paradigms struggle against complex conflicts because the underlying factors - the epicenter - fuel hostility, distrust, and inequity, corroding agreements and losing us in the weeds and wilderness of discord. The potency of the transformative framework rests on its capacity to address these underlying forces in each formulation of conflict. In this way, while conflict may inevitably cycle through success 
and failure, the transformational platform enacts long-term change in the conflict system, bringing us closer to the edge of the wilds (Lederach, 2014, pp. 35-38). Lederach (2014, p. 38) visualizes this process, recreated here in Figure 21, writing that, "Conflict transformation is a circular journey with a purpose."

Figure 21: Long-Term Change Through the Transformational Platform (Lederach, 2014, p. 38)

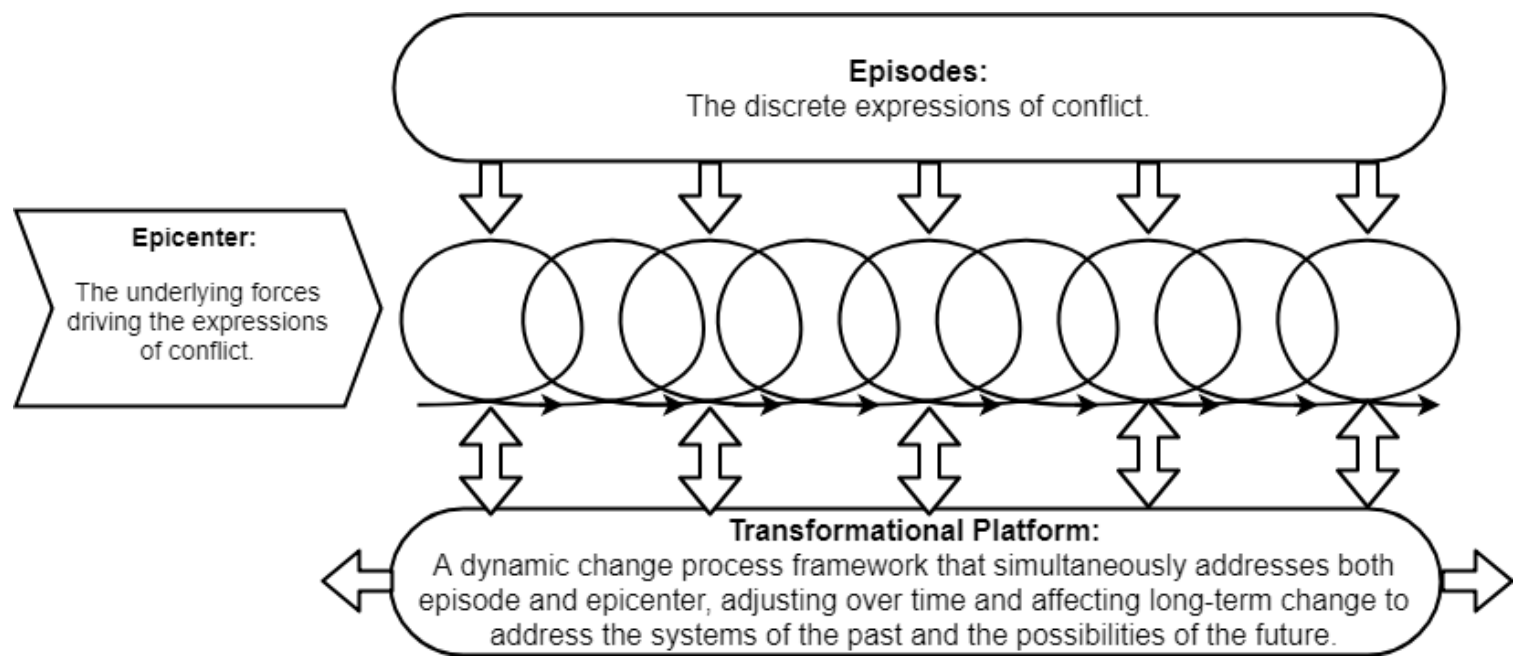

Each time a transformational platform undercuts the epicenter of a conflict, it builds a compounding effect that changes the nature of the relationship disputants have to the historical and future expressions of discord (2014, p. 38). Lederach cautions that a pivotal element of this change, however, similarly alters the conflict and its epicenter. As peacebuilders navigate the wilderness of conflict, they must periodically triangulate the path to peace. Fortunately, the Systems Ecology Framework of Transformative Care offers an adaptable, strategic framework without requiring specific - and, therefore, inflexible - action. The SETC approach, therefore, provides a reliable compass to navigate the wilderness of the academic labor conflict. 


\section{Surveying the Map of the Academic Labor Conflict}

With the articulation of the transformational platform, our exploration of the conflict is complete. From this vantage point, we can both see and comprehend the complex components of the conflict raging in postsecondary academies. At first glance, our vision is drawn to the high peaks of discord, represented by the economic and social instability experienced by contingent faculty and the debt incurred by students. Tracing the contours of those mountains down through history, I identified the source of these tectonic conflicts: The neoliberal reformulation of American higher education from an institution built to serve the public good into a corporate enterprise, bereft of public support and dominated by destructive narratives of governmentality. These alps form a range whose ridges are connected by the casualization and devaluation of faculty, dominated by an unaccountable administrative hierarchy.

These crags shadow and obscure a dense forest of policies and decisions that reformed programming and research along market-driven, neoliberal lines. Propelled by these untenable conditions, a rising tide of academic labor sought to protect their wellbeing through unionization. However, these unions found the flood of their efforts dammed up by powerful opposition and a debased system of protections and dispute resolution. Overlaying everything - the terroir that defines the entire geography - is the systemic force of neoliberalism. It reshaped the landscape and the people in it through its ideological premises of a hyper-individualistic society dominated by market rationality and the commodification of the social fabric of the U.S. The results led to levels of inequality unseen in a century, incalculable damage to our relationships to knowledge, the 
academy, and each other, the dehumanization of academic labor, and - at the end of the road - a clear path forward for transformative peacebuilding.

The conflict map clarifies the relationships and interdependencies of each terrain element but requires the application of the transformative framework to convert its information into an atlas. These last sections focus on implications for academic labor both at Portland State University more broadly - and the field of conflict resolution. One final note: Like all representations of geography, the map is not the territory. The Systems Ecological Framework of Transformative Care offers both flexible and adaptable guidance, but direct conflict assessments must be utilized in tandem with the model to support constructive peacebuilding.

\section{Implications for the Academic Labor Conflict at Portland State University}

PSU follows a similar pattern as other HEIs, matching national trends regarding tuition recovery, administrative intensity, and the casualization of faculty. As a result, many of the recommendations offered here apply to both the broader academic labor movement and PSU. However, Portland State University differs from other HEIs in several ways. First, every classification of faculty has a labor union associated with it, creating opportunities for union coalitions that may not exist elsewhere. Second, according to a 2018 evaluation by the State of Oregon's Higher Education Coordinating Commission (2018), the university struggles with significant financial stress, compounded by a pattern of declining enrollment. Thus, the economic precarity of the institution limits its ability to redress the instability experienced by GEU. Finally, the university may already be preparing to resist labor negotiations, based on the recent 
impasse between the administration and the classified employee union represented by SEIU (2019).

To speak to the broader implications for academic labor, I explored the four themes discussed by Murray (2017) in his exploration of union renewal. Many of the strategies indicated by Murray's research are inherent to the SETC framework, but where possible, I differentiated between the liberalized economic strategies that typify union organizing and the methods directed by the ethics of care. For each theme, I offered several recommendations, framed through the four conflict domains. This list is by no means exhaustive and, instead, simply offers some examples of activities for academic unions.

Modernization, innovation, and strategic renewal: The development of innovations in strategies and organizational health.

At its core, Murray (2017) describes this theme as the broader strategies the labor movement employs to increase its efficacy. Rosenfeld (2014) discusses the challenges unions face on this front, given the disadvantaged regulatory and social position they occupy in society, while Murray (2017, p. 11) mentions the organizational paralysis many unions face. However, given the rapid growth of (Julius \& DiGiovanni Jr., 2019; Kroeger et al., 2018) and innovative strategies employed by (Julius \& DiGiovanni Jr, 2013) contingent faculty unions, these issues appear less salient. In applying the SETC model, several strategies come fit within this theme.

Within the personal domain and relational domains, the ethics of care schema argues for the development of reciprocal relationships of care between unions and their members. Research on the subject is limited, but one study exploring the managerial 
styles of educational leaders found that approaches employing care ethics improved outcomes in organizational activities (Berkovich \& Eyal, 2015). Care-based structures might include projects that work within academic departments to identify the contextual needs of members and develop symbiotic structures that help address those needs while developing resources for unions. Examples include research and editing collectives or workshops focused on emancipatory pedagogy and subverting assessment schemes.

Within the structural domain, the SETC framework recommends developing civil resistance campaigns using the principles outlined by Chenoweth and Stephan (2012) to reconstruct the debased National Labor Relations Act, building just systems of dispute resolution. They write that coalitions of diverse demographics - such as ones that include students, community members, and their families - that concentrate on contesting and converting the pillars of power are potent approaches to confront and destabilize oppressive regimes. Chenoweth and Stephan (2012) illustrate this idea with the campaign of anti-apartheid efforts in South Africa, which used targeted boycotts against whiteowned business leaders to diminish support for the apartheid state government.

Regarding the cultural domain, SETC recommends ameliorating neoliberal governmentality. As an example, developing strategies to countervail assessment can help reverse its effects on faculty, students, and programming. One tactic might include bargaining priorities to protect against or gain control of certain forms of teaching or research evaluation. Another option could focus on developing departmental partnerships to affect structural change in curriculum and programming, which synchronously builds interdependent relationships with faculty. 


\section{Representative spaces: How unions represent themselves to their members, their}

\section{adversaries, and others.}

This theme concerns the way unions represent themselves in contextual spaces.

Here, Murray (2017, pp. 22-23) discusses two categories: Re-engineered social structures that tackle the thorny question of centralization, and strategies around organizing and recruitment. Murray writes that centralization may offer unions increased power and influence but also poses the risk of identity fragmentation or the breakdown of interunion alliances. Another facet to consider here is Rosenfeld's (2014) discussion of industry-level pattern bargaining, which would undoubtedly require a significant level of centralized organization. The SETC framework supports interdependent relationships between unions but would lose efficacy through substantial centralization.

Several other factors require consideration regarding the SETC model and representative spaces. In deploying ethics of care, the framework necessarily focuses on membership recruitment and reciprocal community bonds, understood and managed through the socio-ecological framework. From a structural perspective, establishing collaborative, joint governance projects may provide sustainable methods to develop and maintain these bonds by distributing the organizational load across stakeholders. Moreover, such projects can help unions better understand contexts in which their community and members exist. An example in academic labor might involve partnerships with community service organizations. These partnerships may obligate support and energy to sustain them but can, in turn, offer practicum, research opportunities, or support services for union members. Within these structures, unions should continually work to 
deconstruct neoliberal cultural narratives such as competition for resources, seeking instead to identify opportunities for mutual gain and shared costs.

From the relational and personal domains, recruitment must actively involve and solicit the needs of potential members, using these needs as springboards to both care for members and develop resources of support. Both Murray (2017) as well as Voss and Sherman (2000) write of the need to develop younger leadership and ideas in the labor movement, discussing both their understanding of current labor trends and innovative strategies. Examples might include cooperative childcare services, thesis and dissertation support groups for GSEs, or leadership development cadres. These approaches sustain the contextual needs of union members outside neoliberal structures, requiring some resource expenditures but - as before - generating new asset, recruitment, and assistance opportunities. Developing reciprocal relationships with community partners can help make these services sustainable. An example of such a partnership might involve editing support for publishing companies or writer's groups, which in turn could provide services for researchers and students.

From the cultural domain, SETC directs academic labor to conscientize stakeholders around the effects of neoliberalism in the academy and the work the union does to confront those effects. This strategy can complement care-based efforts in recruitment and coalition-building. One example could consist of financial wellness workshops for students or faculty, which simultaneously politicize participants to the neoliberal systems surrounding wages and tuition. In conscientizing stakeholders to systemic neoliberalism, unions should affect care-based cultural alternatives wherever possible. 
Collective action repertoires: The development of tactics to succeed in union actions.

In this theme, Murray's (2017, pp. 15-20) discussion focuses on the tactics unions employ to achieve their aims. Here, much of the research focuses on techniques to challenge employers though this approach contains unions within the neoliberal labormanagement dyad. Within the academic labor conflict, while administrators reify neoliberalism, they do not benefit from its results and do not represent the actual adversaries in the conflict (Deem \& Brehony, 2005). Transformation peacebuilding requires providing for the needs of union members as well as creating the long-term conditions and solutions that establish dynamic, sustainable change. Here, the SETC model offers a multitude of innovative approaches.

Unions should create joint agreements and collaborative governance projects between administrators and faculty that build long-term structures circumventing neoliberal conceptions of personal and relational identity. Such endeavors might provide opportunities to circumvent neoliberal mechanisms of control and governmentality over grant funding, such as joint governance over assessment schemes or research grants. To protect against harm and manipulation by higher-power administrations (Cerna, 2014) and build confidence in the success of these projects, unions should build mechanisms to ensure transparency and equitable participation (Das \& Teng, 1998). However, despite the risks, they represent prospects both for the long-term transformation of relationships and to build relational power through increased interdependence (Wilmot \& Hocker, 2011).

Another tactic involves developing care-based, social-movement campaigns that call attention to the commodification of research and faculty. By buildings connections in 
the community, these campaigns can provide alternative means of research support through collaborative coalitions with socially-oriented organizations. Beyond supporting the contextual needs of union members, these operations also offer opportunities to recruit new members, create post-neoliberal structures and narratives, and critique neoliberalism's impacts in higher education. Thus, while these campaigns represent asset and energy expenditures, they also provide significant opportunities for support and resources.

To develop long-term networks of societal change, the SETC framework recommends activism campaigns focused on connecting the economic elements of unionism to higher education access and social well-being. This approach presents inroads to building regional and national ties to broader social justice movements, union networks, and member demographics, while also developing prospective narratives to counter neoliberal culture. Moreover, these connections create opportunities to develop professional networks for contingent faculty by bridging their work to other HEIs and organizations. This also allows unions to take greater control of the cultural story around what values are essential in society.

To develop organizing strength, larger union organizations might consider regional unionization campaigns, as occurred with SEIU's Faculty Forward campaign in St. Louis, Missouri (Ramirez, 2018). Besides opening unions to larger membership pools and community coalitions, these operations address the specific needs of adjunct faculty, who often maintain contracts at multiple institutions to pay their bills. At the regional level, union organizing can additionally conscientize communities around the outsized effects neoliberalism inflicts on the social and economic fabric of society. Finally, these 
campaigns may generate opportunities for pattern bargaining, allowing the labor movement to create constructive impacts beyond its membership.

To strengthen union power in relation to administrations, academic unions should consider building reciprocal relationships with the service-learning organizations universities use. These partnerships offer practicum and professional development resources for contingent faculty while also providing access to the pillars of power discussed by Chenoweth and Stephan (2012) that socially legitimize HEIs. This access can improve academic labor's bargain capacity if these organizations back unions during contract renegotiations. Developing such relationships also provides prospective strategies to strengthen ties with students by building access to these service-learning opportunities.

A final strategy touching on Murray's (2017, pp. 18-19) discussion of new political campaigns, involves expanding the dialogue between unions and university student bodies about the effects of neoliberalism. These conversations can involve education on the far-reaching impacts of neoliberal policies in higher education as well as its effects on the wider personal, professional, and relational lives of individuals. This strategy may generate resilient support for unions amongst students, building power bases for future union action. Furthermore, it creates opportunities to write new cultural scripts that delegitimize neoliberal philosophy.

\section{Connectedness: The means by which unions conceptualize and incorporate outsiders.}

Murray's (2017, p. 20) final theme addresses the challenges unions face regarding recruitment and legitimacy. This addresses the fragmentation of labor identities caused by changes in the economic landscape and the movement's historical exclusion of 
immigrants, black, brown peoples. These changes exacerbated the systemic and adversity weakening union influence, contributing to its historically low membership and power in the U.S. Murray $(2017$, p. 22) writes that a pivotal challenge to contemporary recruitment rests in connecting the different identities of modern workers to union values. Through the socio-ecological approach and care-based ethics, the SETC model offers a useful framework to build inroads with these disparate groups. Aside from contextual sensitivity to the different needs of workers, academic labor can connect to traditionally disconnected disciplines of knowledge by connecting neoliberalism's effects on their fields and the academy more generally.

\section{Summarizing the implications for the academic labor conflict.}

At its core, the Systems Ecology Framework of Transformative Care presents numerous approaches to addressing systemic neoliberalism in union organizing. While the framework demands certain forms of strategies that explicitly articulate postneoliberal identities, relationships, structures, and narratives, it also creatively broadens the toolkit of effective labor tactics. The implementation of care ethics and the socioecological vehicle require a significant shift in union responsibilities and activities but simultaneously represent powerful sources of new membership, resources, and support. The framework holds an additional advantage in its capacity to develop symbiotic relationships with stakeholders through mutually reciprocal relationships of care and its multilayered interpretation of the four conflict domains. The illustrative applications discussed here represent only a few of SETC's possibilities, exemplifying its dynamic, adaptive capacity. Furthermore, while I use it here to address the academic labor conflict, 
it holds salience for the broader labor movement, as its strategies apply equally well on the shop floor as in the academy.

\section{Implications for Peacebuilding and Conflict Resolution Practice}

The Systems Ecology Framework of Transformative Care holds significance beyond labor conflicts as well. Using transformative peacebuilding as the mechanism of analysis, it functions as a robust organizational framework to tackle systemic forces through the complex and layered domains of conflict. Moreover, it grounds the philosophy of transformative peacebuilding in a concrete organizational model, providing a blueprint for its use in other complex social conflicts. For this reason, peacebuilding efforts should consider using the SETC framework in other complex social conflicts, such as in addressing systemic racism or sexism. It also represents an important contribution to the field of conflict resolution by extending peacebuilding into the challenging social conflicts that pervade industrialized societies like the United States. These cultures present challenging contexts because they often have established, welldefined processes of conflict management and dispute resolution that nevertheless fail to reduce violence or provide justice for low-power and marginalized groups. These societies are critically important to our work; often, they are the home of conflict resolution and peacebuilding scholarship, yet instead of tackling these problems, we often turn away from them, focusing instead on interpersonal resolution or international peace work.

Consequently, I would like to gently advance the argument that neoliberalism like so many other fields of knowledge, including psychology (Bal \& Dóci, 2018) and sociology (Schmidt \& Engelen, 2020) - has profoundly intruded on our profession. 
Consider how much of our research reflects its influence: Interest-based negotiation, originating from the Harvard Business School (Roger et al., 2011), dispute system design and the reinforcement of systemic inequities (Cohen, 2009), the absence of cultural analysis in peace and conflict studies (Richmond, 2018), and liberalized peacebuilding in the international arena (Richmond \& Mitchell, 2011). This is not to diminish the vital necessity or importance of our ideas or trade. Like all systemic forces, neoliberalism's impacts are inescapably present throughout society and cannot be avoided - only accommodated. For this reason, it is crucial that we reconcile our craft with our calling, and confront the harms caused by systemic forces like neoliberalism in ourselves, our work, and our communities.

This text intentionally stands at the intersection of activism and reconciliation and argues for the necessity of both. Our field often strays on the safe side of resolution practice, fearing - perhaps justifiably - that engaging in activist work jeopardizes our ability to objectively locate the conditions of a just peace. However, given the nature and virulence of the systemic forces arrayed in many crucial conflicts today, we do ourselves, our mission, and the world a disservice by not choosing, in the words of Lederach (1995, p. 12), "to stand by one side for justice's sake." Long is the road from conflict to concord, its way often shrouded and fraught with twists and turns, requiring us to shift directions and strategies - from revolution to resolution. Yet its path is never traveled alone, and so long as our compass points toward peace, it should not matter if we are the ones holding that compass at the road's end.

In the academic labor conflict, the Systems Ecology Framework of Transformative Care is the compass that points the way toward peace. Paired with this 
map of the conflict's features and elements, future peacebuilders have a robust set of tools to navigate the complex and murky terrain of strife in the halls of the academy. Already, the hour is late, and neoliberalism has wrought devasting effects on the integrity of the academe and the dream of an accessible, equitable society. We must address this conflict now, before the gloom of neoliberalism further desolates the mission of emancipatory education. However, like all conflicts, if we carefully walk the path of constructive peace, we will find ourselves in a brighter future. 


\section{Works Cited}

AAUP. (2017). Background Facts on Contingent Faculty Positions. https://www.aaup.org/issues/contingency/background-facts

AAUP. (2018). The Annual Report on the Economic Status of the Profession, 2017-18.

Addo, F. R., Houle, J. N., \& Simon, D. (2016). Young, Black, and (Still) in the Red: Parental Wealth, Race, and Student Loan Debt. Race and Social Problems, 8(1), 64 76. https://doi.org/10.1007/s12552-016-9162-0

Alinsky, S. D. (1989). Rules for Radicals: A Practical Primer for Realistic Radicals (2nd ed.). Vintage Books. https://doi.org/10.2307/j.ctt1vz4931.4

Andrews, R., Boyne, G., \& Mostafa, A. M. S. (2017). When Bureaucracy Matters for Organizational Performance: Exploring the Benefits of Administrative Intensity in Big and Complex Organizations. Public Administration, 95(1), 115-139. https://doi.org/10.1111/padm.12305

Atkinson, A. B., Piketty, T., \& Saez, E. (2011). Top incomes in the long run of history. Journal of Economic Literature, 49(1), 3-71. https://doi.org/10.1257/jel.49.1.3

Aurand, A., Cooper, A., Emmanuel, D., Rafi, I., \& Yentel, D. (2019). Out of Reach: 30th Anniversary. www.nlihc.org/oor

Avruch, K., \& Mitchell, C. R. (Eds.). (2013). Conflict Resolution and Human Needs: Linking Theory and Practice. Routledge. http://ebookcentral.proquest.com/lib/psu/detail.action?docID=1181009

Bal, P. M., \& Dóci, E. (2018). Neoliberal ideology in work and organizational psychology. European Journal of Work and Organizational Psychology, 27(5), 536548. https://doi.org/10.1080/1359432X.2018.1449108

Ball, S. J. (2012). Performativity, Commodification and Commitment: An I-Spy Guide to the Neoliberal University. British Journal of Educational Studies, 60(1), 17-28. https://doi.org/10.1080/00071005.2011.650940

Bauer, L. B. (2017). Professors-in-Training or Precarious Workers? Identity, Coalition Building, and Social Movement Unionism in the 2015 University of Toronto Graduate Employee Strike. Labor Studies Journal, 42(4), 273-294. https://doi.org/10.1177/0160449X17731877

Baum, S., \& Johnson, M. (2015). Financing Public Higher Education: The Evolution of State Funding.

Bauman, D., Davis, T., \& O’Leary, B. (2020). Executive Compensation at Public and Private Colleges. The Chronicle of Higher Education. https://www.chronicle.com/interactives/executivecompensation\#id=17274_209807_2018_public

Berkovich, I., \& Eyal, O. (2015). Educational Leaders and Emotions: An International Review of Empirical Evidence 1992-2012. Review of Educational Research, 85(1), 129-167. https://doi.org/10.3102/0034654314550046

Bessant, S. E. F., Robinson, Z. P., \& Ormerod, R. M. (2015). Neoliberalism, new public management and the sustainable development agenda of higher education: history, contradictions and synergies. Environmental Education Research, 21(3), 417-432. https://doi.org/10.1080/13504622.2014.993933

Bivens, J., Engdahl, L., Gould, E., Kroeger, T., Mcnicholas, C., Mishel, L., Mokhiber, Z., 
Shierholz, H., Von Wilpert, M., Zipperer, B., \& Wilson, V. (2017). How today's unions help working people. epi.org/133275

Bollen, K., Euwema, M., \& Munduate, L. (Eds.). (2016). Advancing Workplace Mediation Through Integration of Theory and Practice. https://doi.org/10.1007/9783-319-42842-0

Bronfenbrenner, K., Friedman, S., Hurd, R. W., Oswald, R. A., \& Seeber, Ronald, L. (1998). Organizing to Win: New Research on Union Strategies (1st ed.). ILR Press.

Bronfenbrenner, U. (1981). The Ecology of Human Development: Experiments by Nature and Design. In American Anthropologist. Harvard University Press.

Brown, W. (2011). Neoliberalized Knowledge. History of the Present: A Journal of Critical History, 1(1), 113-129.

Buell, S. W. (2016). Capital offenses : business crime and punishment in America's corporate age (First edit). W.W. Norton \& Company.

Cadambi Daniel, M. (2016). Contingent Faculty of the World Unite! Organizing to Resist the Corporatization of Higher Education. New Labor Forum, 25(1), 44-51. https://doi.org/10.1177/1095796015620408

Cain, T. R. (2010). The first attempts to unionize the faculty. Teachers College Record, $112(3), 875-913$.

Calhoun, C. (2002). labor union. In Oxford Reference. Oxford University Press. https://doi.org/10.1093/acref/9780195123715.013.0915

Callender, C., \& Jackson, J. (2008). Does the fear of debt constrain choice of university and subject of study? Studies in Higher Education, 33(4), 405-429. https://doi.org/10.1080/03075070802211802

Cassell, M., \& Halaseh, O. (2014). The Impact of Unionization on University Performance. Journal of Collective Bargaining in the Academy, 6(December), 3. http://thekeep.eiu.edu/jcbahttp://thekeep.eiu.edu/jcba/vol6/iss1/3

Cerna, L. (2014). Trust: What it is and why it matters for governance and education. OECD Education Working Papers, 108, 0-66. https://doi.org/10.1787/5jxswcg0t6wl-en

Chenoweth, E., \& Stephan, M. J. (2012). Why Civil Resistance Works: The Strategic Logic of Nonviolent Conflict (1st ed.). Columbia University Press.

Cohen, A. (2009). Dispute Systems Design, Neoliberalism, and the Problem of Scale. Harvard Negotiation Law Review, 14(116), 51-80.

Collins, W. J., \& Niemesh, G. T. (2019). Unions and the Great Compression of wage inequality in the US at mid-century: evidence from local labour markets. Economic History Review, 72(2), 691-715. https://doi.org/10.1111/ehr.12744

Cooper, C., Graham, C., \& Himick, D. (2016). Social impact bonds: The securitization of the homeless. Accounting, Organizations and Society, 55(September 2013), 63-82. https://doi.org/10.1016/j.aos.2016.10.003

Courtois, A., \& O'Keefe, T. (2015). Precarity in the ivory cage: Neoliberalism and casualisation of work in the Irish higher education sector. Journal for Critical Education Policy Studies, 13(1), 43-66.

Curle, A. (1971). Making Peace. Tavistock Publications.

Curran, M. J., Kowalewsky, R., Trosky, R. J., \& Payne, C. A. (2015). It/Is Faculty Perceptions of the Unionization Process of Adjunct Faculty: A Case Study. Issues in 
Information Systems, 16(2), 53-62.

Currie, J. (1998). Globalization Practices and the Professoriate in Anglo-Pacific and North American Universities. Comparative Education Review, 42(1), 15-29.

Das, T. K., \& Teng, B. S. (1998). Between trust and control: Developing confidence in partner cooperation in alliances. Academy of Management Review, 23(3), 491-512. https://doi.org/10.5465/AMR.1998.926623

Davies, B., \& Bansel, P. (2007). Neoliberalism and education. International Journal of Qualitative Studies in Education, 20(3), 247-259. https://doi.org/10.1080/09518390701281751

De Benedictis, S. (2012). Feral Parents: austerity parenting under neoliberalism. Studies in the Maternal, 4(2). https://doi.org/10.16995/sim.40

Deem, R., \& Brehony, K. J. (2005). Management as ideology: The case of "new managerialism" in higher education. Oxford Review of Education, 31(2), 217-235. https://doi.org/10.1080/03054980500117827

Desrochers, D. M., \& Hurlburt, S. (2016). Trends in College Spending: 2003-2013, Where does the money come from? Where does it go? What does it buy? In Delta Cost Project (Issue January). http://www.air.org/system/files/downloads/report/Delta-Cost-Trends-in-College Spending-January-2016.pdf

Desrochers, D. M., \& Kirshstein, R. (2014). Labor Intensive or Labor Expensive? Changing Staffing and Compensation Patterns in Higher Education (Issue February).

Enck-Wanzer, D. (2011). Barack Obama, the Tea Party, and the Threat of Race: On Racial Neoliberalism and Born Again Racism. Communication, Culture \& Critique, 4(1), 23-30. https://doi.org/10.1111/j.1753-9137.2010.01090.x

Essaji, A., \& Horton, S. (2010). Silent escalation: Salaries of senior university administrators in Ontario, 1996-2006. Higher Education, 59(3), 303-322. https://doi.org/10.1007/s10734-009-9249-2

Fisher, R., \& Shapiro, D. (2006). Beyond Reason: Using Emotions as You Negotiate (2005th ed.). Penguin Books.

Foucault, M. (1995). Discipline \& Punish: The Birth of the Prison (A. Sheridan (Ed.); 2nd ed.). Vintage Books.

Freeman, R. B., \& Medoff, J. L. (1984). What do unions do? Basic Books.

Freire, P. (2005). Pedagogy of the Oppressed (30th Anniv). Continuum.

Galtung, J. (1969). Violence, Peace, and Peace Research. Journal of Peace Research, 6(3), 167-191. https://doi.org/10.1177/1476127007087155

Galtung, J. (1990). Cultural Violence. Journal of Peace Research, 27(3), 291-305.

GEU, \& PSU. (2018). Collective Bargaining Agreement between Graduate Employees Union, AFT/AAUP and Portland State University.

Gilbert, J. (2013). What Kind Of Thing Is "Neoliberalism”? New Formations, 80(80), 722. https://doi.org/10.3898/nEWF.80/81.IntroductIon.2013

Ginsberg, B. (2011). The Fall of the Faculty: The Rise of the All-Administrative University and Why It Matters (1st ed.). Oxford University Press.

Giroux, H. (2014). Neoliberalism's War on Higher Education. Haymarket Books. http://ebookcentral.proquest.com/lib/psu/detail.action?docID=1321794 
Godard, J. (2011). What Has Happened to Strikes? British Journal of Industrial Relations, 49(2), 282-305. https://doi.org/10.1111/j.1467-8543.2011.00853.x

Halverson Cross, K., \& Halverson, K. (2017). Unionization and the Development of Policies for Non-Tenure Track Faculty: A Comparative Study of Research Universities. Journal of Collective Bargaining in the Academy, 9(December). http://thekeep.eiu.edu/jcbaAvailableat:http://thekeep.eiu.edu/jcba/vo19/iss1/5

Hamann, T. H. (2009). Neoliberalism, governmentality, and ethics. Foucault Studies, 6, 37-59. https://doi.org/10.22439/fs.v0i0.2471

Harvey, D. (2007). Neoliberalism as creative destruction. Annals of the American Academy of Political and Social Science, 610(1), 22-44. https://doi.org/10.1177/0002716206296780

HECC. (2018). 2018 University Evaluation: Portland State University.

Held, V. (2010). Can the Ethics of Care Handle Violence? Ethics and Social Welfare, 4(2), 115-129. https://doi.org/10.1080/17496535.2010.484256

Henrich, J., Boyd, R., Bowles, S., Camerer, C., Fehr, E., Gintis, H., McElreath, R., Alvard, M., Barr, A., Ensminger, J., Henrich, N. S., Hill, K., Gil-White, F., Gurven, M., Marlowe, F. W., Patton, J. Q., \& Tacer, D. (2005). "Economic man” in crosscultural perspective: Behavioral experiments in 15 small-scale societyies.

Behavioral and Brain Sciences, 28(6), 795-855. https://doi.org/10.1017/S0140525X0535014X

Herman, J. (2015). Trauma and Recovery (1st Revise). Basic Books.

Hodgson, G. M. (2012). On the Limits of Rational Choice Theory. Economic Thought, $1(1), 94-108$.

Hoppes, C. R., \& Holley, K. A. (2014). Organizational Trust in Times of Challenge: The Impact on Faculty and Administrators. Innovative Higher Education, 39(3), 201216. https://doi.org/10.1007/s10755-013-9275-y

HUD. (2020). Fair Market Rents: Introductory Overview.

Hurlburt, S., \& McGarrah, M. (2016). The Shifting Academic Workforce: Where Are the Contingent Faculty? https://www.deltacostproject.org/products/shifting-academicworkforce-where-are-contingent-faculty

IPEDS. (2020). IPEDS Data Center. In Integrated Postsecondary Education Data System. https://nces.ed.gov/ipeds/datacenter/Facsimile.aspx?unitid=adabb4b3abb2

Jacob, M. (2009). On Commodification and the Governance of Academic Research. Minerva, 47(4), 391-405. https://doi.org/10.1007/s11024-009-9134-2

Jemielniak, D., \& Greenwood, D. J. (2015). Wake up or perish: Neo-liberalism, the social sciences, and salvaging the public university. Cultural Studies - Critical Methodologies, 15(1), 72-82. https://doi.org/10.1177/1532708613516430

Jones, D. S. (2012). Masters of the Universe Hayek, Friedman, and the Birth of Neoliberal Politics ([New editi). Princeton University Press.

Jones, J., \& Saad, L. (2019). Gallup Poll Social Series: Labor and Education.

Julius, D. J., \& DiGiovanni Jr., N. (2019). Academic Collective Bargaining: Status, Process, and Prospects. Academic Labor: Research and Artistry, 3(1), 11. https://digitalcommons.humboldt.edu/alra/vol3/iss1/11

Julius, D. J., \& DiGiovanni Jr, N. (2013). Academic Collective Bargaining: On Campus Fifty Years. Center for Studies in Higher Education, 1-31. 
Julius, D. J., \& Gumport, P. J. (2002). Graduate student unionization: Catalysts and consequences. Review of Higher Education, 26(2), 187-216. https://doi.org/10.1353/rhe.2002.0033

Kezar, A., \& Sam, C. (2013). Institutionalizing equitable policies and practices for contingent faculty. Journal of Higher Education, 84(1), 56-87. https://doi.org/10.1353/jhe.2013.0002

Kirshstein, R. J., \& Hurlburt, S. (2012). Revenues: Where Does the Money Come From?

Kitchen II, D.-P. (2010). On Graduate Unions and Corporatization. Journal of Collective Bargaining in the Academy, 2(1), 1-7.

Kochan, T. A., Eaton, A. E., McKersie, R. B., \& Adler, P. S. (2009). Healing Together: The Labor-Management Partnership at Kaiser Permanente. Cornell University Press. http://ebookcentral.proquest.com/lib/psu/detail.action?docID=3137955

Kochan, T. A., \& Riordan, C. A. (2016). Employment relations and growing income inequality: Causes and potential options for its reversal. Journal of Industrial Relations, 58(3), 419-440. https://doi.org/10.1177/0022185616634337

Kotz, D. M. (2008). Contradictions of economic growth in the neoliberal era: Accumulation and crisis in the contemporary U.S. economy. Review of Radical Political Economics, 40(2), 174-188. https://doi.org/10.1177/0486613407310569

Kroeger, T., McNicholas, C., Wilpert, M. von, \& Wolfe, J. (2018). The state of graduate student employee unions. epi.org/138028

Krupnick, M., \& Marcus, J. (2015). Think university administrators 'salaries are high? Critics say their benefits are lavish. The Hechinger Report. https://hechingerreport.org/think-university-administrators-salaries-are-high-criticssay-their-benefits-are-lavish/

Lazzarato, M. (2009). Neoliberalism in Action: Inequality, Insecurity and the Reconstitution of the Social. Theory, Culture \& Society, 26(6), 109-133. https://doi.org/10.1177/0263276409350283

Leavy, Z. (2015). Interest-Based Bargainings' Impact on Collective Bargaining Outcomes. Seminar Research Paper Series. Paper, 23, 1-26. http://digitalcommons.uri.edu/lrc_paper_series/23

Lederach, J. P. (1995). Preparing for Peace: $\bar{C}$ Conflict Transformation Across Cultures (1st ed.). Syracuse University Press.

Lederach, J. P. (2014). The Little Book of Conflict Transformation (1st ed.). Good Books.

Lemke, T. (2001). "The birth of bio-politics": Michel Foucault's lecture at the Collège de France on neo-liberal governmentality. Economy and Society, 30(2), 190-207. https://doi.org/10.1080/03085140120042271

Levin, J. S., \& Aliyeva, A. (2015). Embedded neoliberalism within faculty behaviors. Review of Higher Education, 38(4), 537-563. https://doi.org/10.1353/rhe.2015.0030

Lipman, P. (2011). The New Political Economy of Urban Education : Neoliberalism, Race, and the Right to the City. Routledge. http://ebookcentral.proquest.com/lib/psu/detail.action?docID $=672396$

Littler, J. (2013). Meritocracy as Plutocracy: The Marketising of "Equality" Under Neoliberalism. New Formations, 80(80), 52-72. https://doi.org/10.3898/NewF.80/81.03.2013

Littler, J. (2017). Against Meritocracy: Culture, Power and Myths of Mobility. In Against 
Meritocracy: Culture, Power and Myths of Mobility. https://doi.org/10.4324/9781315712802

Lyon-Callo, V. (2008). Inequality, poverty, and neoliberal Governance : activist ethnography in the homeless sheltering industry. UTP.

Manning, J. (2019). Shoureshi exits Portland State with \$855,985 golden parachute; two years of health insurance, even his legal fees. The Oregonian. https://www.oregonlive.com/education/2019/05/shoureshi-exits-portland-state-with855985-golden-parachute-two-years-of-health-insurance-even-his-legal-fees.html

McCarthy, J., \& Prudham, S. (2004). Neoliberal nature and the nature of neoliberalism. Geoforum, 35(3), 275-283. https://doi.org/10.1016/j.geoforum.2003.07.003

McFarland, J., Hussar, B., Zhang, J., Wang, X., Wang, K., Hein, S., Diliberti, M., Cataldi, E. F., Mann, F. B., \& Barmer, A. (2019). The Condition of Education 2019. http://www.voced.edu.au/content/ngv10426

McKersie, R. B., Sharpe, T., Kochan, T. A., Eaton, A. E., Strauss, G., \& Morgenstern, M. (2008). Bargaining Theory Meets Interest-Based Negotiations: A Case Study. Industrial Relations, 47(1), 66-96. https://doi.org/http://www.blackwellpublishing.com/journal.asp?ref=0019-8676

Michels, R. (1915). Political parties: a sociological study of the oligarchical tendencies of modern democracy. Jarrold \& Sons.

Miller, J. K., Farmer, K. P., Miller, D. J., \& Peters, L. M. (2010). Panacea or Snake Oil? Interest-Based Bargaining in the U.S. Airline and Rail Industries. Negotiation Journal, 26(2), 177-201. https://doi.org/10.1111/j.1571-9979.2010.00268.x

Mishel, L., Gould, E., \& Bivens, J. (2015). Wage stagnation in nine charts.

Morrissey, J. (2013). Governing the academic subject: Foucault, governmentality and the performing university. Oxford Review of Education, 39(6), 797-810. https://doi.org/10.1080/03054985.2013.860891

Murray, G. (2017). Union renewal: what can we learn from three decades of research? Transfer: European Review of Labour and Research, 23(1), 9-29. https://doi.org/10.1177/1024258916681723

NCES. (2018). Trends in Student Loan Debt for Graduate School Completers. In The Condition of Education 2018. https://nces.ed.gov/programs/coe/indicator_tub.asp

NCES. (2020). IPEDS Finance Data FASB and GASB - What's the Difference? A Guide for Data Users. https://nces.ed.gov/ipeds/report-your-data/data-tip-sheetdistinguishing-finance-standards-fasb-gasb

Nissen, S., Hayward, B., \& McManus, R. (2019). Student debt and wellbeing: a research agenda. Kōtuitui: New Zealand Journal of Social Sciences Online, 14(2), 245-256. https://doi.org/10.1080/1177083X.2019.1614635

Olssen, M., \& Peters, M. A. (2005). Neoliberalism, higher education and the knowledge economy: From the free market to knowledge capitalism. Journal of Education Policy, 20(3), 313-345. https://doi.org/10.1080/02680930500108718

Ortner, S. B. (2014). Too Soon for Post-Feminism: The Ongoing Life of Patriarchy in Neoliberal America. History and Anthropology, 25(4), 530-549. https://doi.org/10.1080/02757206.2014.930458

Palacios, C. (2018). Society, like the market, needs to be constructed: Foucault's critical project at the dawn of neoliberalism. History of the Human Sciences, 31(1), 74-96. 
https://doi.org/10.1177/0952695117746045

Paquet, R., Gaétan, I., \& Bergeron, J. G. (2000). Does interest-based bargaining (IBB) really make a difference in collective bargaining outcomes? Negotiation Journal, 16(3), 281-296. https://doi.org/10.1111/j.1571-9979.2000.tb00219.x

Pocock, B. (2012). Rethinking Unionism in a Changing World of Work, Family and Community Life. Relations Industrielles, 66(4), 562-584. https://doi.org/10.7202/1007633ar

Portland State University. (2020). Academic Classification and Compensation (p. 12).

Powell Jr., L. F. (1971). Attack On American Free Enterprise System. In Snail Darter Documents. papers3://publication/uuid/10503BC4-7AF6-413A-AF8D40314C552483

Practitioners Research and Scholarship Institute. (2008). A Conversation With Hasshan Batts. In M. A. Trujillo, S. Y. Bowland, L. J. Myers, B. Roy, \& P. M. Richards (Eds.), Re-Centering: Culture and Knowledge in Conflict Resolution Practice (1st ed.). Syracuse University Press.

PSUFA, \& PSU. (2018). Collective Bargaining Agreement between Portland State University Faculty Association: Local 3571 American Federation of Teachers, AFLCIO and Portland State University, Portland, Oregon. https://static1.squarespace.com/static/5796d55e3e00bed6c0ec9446/t/5e2b7952df9b0 864121ed0be/1579907417349/PSUFA_CBA_3.26.2019+\%5Bcorrect\%2C+without + signature+pages\%5D.pdf

Ramirez, J. (2018). Bargaining for Adjuncts: An Assessment of Adjunct Union Growth in the Saint Louis Region. Journal of Collective Bargaining in the Academy, 10(4), 118. https://thekeep.eiu.edu/jcba/vol10/iss 1/4\%0AThis

Read, J. (2009). A Genealogy of Homo-Economicus: Neoliberalism and the Production of Subjectivity. Foucault Studies, 6, 25-36.

Rehn, A. (2014). Gifts, gifting and gift economies: On challenging capitalism with blood, plunder and necklaces. In M. Parker, G. Cheney, V. Fournier, \& C. Land (Eds.), The Routledge Companion to Alternative Organization (1st ed., pp. 195-209). Routledge.

Rhoades, G. (2015). Creative Leveraging in Contingent Faculty Organizing. The Journal of Labor and Society, 18(3), 435-445. https://doi.org/10.1111/wusa.12191

Rhoads, R. A., \& Rhoades, G. (2005). Graduate employee unionization as symbol of and challenge to the corporatization of U.S. Research universities. Journal of Higher Education, 76(3), 243-275. https://doi.org/10.1353/jhe.2005.0022

Richmond, O. P. (2018). Rescuing peacebuilding? Anthropology and peace formation. Global Society, 32(2), 221-239. https://doi.org/10.1080/13600826.2018.1451828

Richmond, O. P., \& Mitchell, A. (2011). Peacebuilding and critical forms of agency: From resistance to subsistence. Alternatives, 36(4), 326-344. https://doi.org/10.1177/0304375411432099

Roger, F., Ury, W. L., \& Patton, B. (2011). Getting to Yes: Negotiating Agreement Without Giving In (Second). Penguin Books.

Rogers, S. E., Eaton, A. E., \& Voos, P. B. (2013). Effects of Unionization on Graduate Student Employees: Faculty-Student Relations, Academic Freedom, and Pay. Industrial and Labor Relations Review, 66(2), 487-510. 
Romine, K. D., Baker, R. M., \& Romine, K. A. (2018). The relationship between administrative intensity and student retention and success: A three-year study. Education Sciences, 8(4). https://doi.org/10.3390/educsci8040159

Rosenfeld, J. (2014). What Unions No Longer Do (1st ed.). Harvard University Press. https://ebookcentral-proquestcom.proxy.lib.pdx.edu/lib/psu/reader.action?docID=3301410\&ppg=1

Roy, B. (2008). Power, Culture, Conflict. In M. A. Trujillo, S. Y. Bowland, L. J. Myers, P. M. Richards, \& B. Roy (Eds.), Re-Centering: Culture and Knowledge in Conflict Resolution Practice (1st ed., pp. 179-194). Syracuse University Press.

Rutherford, A. (2016). Reexamining Causes and Consequences: Does Administrative Intensity Matter for Organizational Performance? International Public Management Journal, 19(3), 342-369. https://doi.org/10.1080/10967494.2015.1032459

Saad, L. (2018). Labor Union Approval Steady at 15-Year High. Gallup. https://news.gallup.com/poll/241679/labor-union-approval-steady-year-high.aspx

Saez, E., \& Zucman, G. (2016). Wealth Inequality in the United States since 1913: Evidence from Capitalized Income Tax Data. The Quarterly Journal of Economics, 131(2), 519-578. https://doi.org/10.1093/qje/qjw004

Saunders, D. B. (2010). Neoliberal Ideology and Public Higher Education in the United States. Journal for Critical Education Policy Studies, 8(1), 41-77.

Saunders, D. B., \& Blanco Ramírez, G. (2017). Against 'teaching excellence': ideology, commodification, and enabling the neoliberalization of postsecondary education. Teaching in Higher Education, 22(4), 396-407. https://doi.org/10.1080/13562517.2017.1301913

Savage, L., Webber, M., \& Butovsky, J. (2012). Organizing the Ivory Tower. Labor Studies Journal, 37(3), 293-310. https://doi.org/10.1177/0160449X12463077

Schirch, L. (2013). Conflict Assessment \& Peacebuilding Planning. Kumarian Press. www.rienner.com

Schmidt, A. T., \& Engelen, B. (2020). The ethics of nudging: An overview. Philosophy Compass, November 2019, 1-13. https://doi.org/10.1111/phc3.12658

SEIU. (2019). University Employees Rally at Portland State as Strike is Authorized. Service Employees International Union. https://seiu503.org/member_news/university-employees-rally-at-portland-state-asstrike-is-authorized/

Servage, L. (2009). The Scholarship of Teaching and Learning and the NeoLiberalization of Higher Education: Constructing the "Entrepreneurial Learner." Canadian Journal of Higher Education, 39(2), 25-44.

SHEEO. (2019). State Higher Education Finance: FY 2018. https://sheeo.org/wpcontent/uploads/2019/04/SHEEO_SHEF_FY18_Report.pdf

Shore, C., \& Taitz, M. (2012). Who "owns" the university? Institutional autonomy and academic freedom in an age of knowledge capitalism. Globalisation, Societies and Education, 10(2), 201-219. https://doi.org/10.1080/14767724.2012.677707

Sieg, H., \& Wang, Y. (2018). The impact of student debt on education, career, and marriage choices of female lawyers. European Economic Review, 109, 124-147. https://doi.org/10.1016/j.euroecorev.2017.05.009

Slaughter, S. (1998). Federal Policy and Supply-Side Institutional Resource Allocation at 
Public Research Universities. The Review of Higher Education, 21(3), 209-244. https://doi.org/10.1353/rhe.1998.0007

Smith, L. T. (2012). Decolonizing Methodologies: Research and Indigenous Peoples (2nd ed.). Zed Books.

Snyder, T. D., de Brey, C., \& Dillow, S. A. (2019). Digest of Education Statistics 2017. https://nces.ed.gov/programs/digest/d17/

Sproul, C. R., Bucklew, N., \& Houghton, J. D. (2014). Academic Collective Bargaining: Patterns and Trends. Journal of Collective Bargaining in the Academy, 6(5), 1-11.

State of Oregon. (2016). Oregon Minimum Wage Rate Summary. Oregon Bureau of Labor and Industry. https://www.oregon.gov/boli/whd/omw/pages/minimum-wagerate-summary.aspx

Stripling, J., \& Fuller, A. (2011). Presidents Defend Their Pay as Public Colleges Slash Budgets. The Chronicle of Higher Education. https://www.chronicle.com/article/Presidents-Defend-Their-Pay-as/126971

Sugarman, J. (2015). Neoliberalism and psychological ethics. Journal of Theoretical and Philosophical Psychology, 35(2), 103-116. https://doi.org/10.1037/a0038960

Tattersall, A. (2011). The power of union-community coalitions. Renewal, 19(1), 75-82.

Taylor, A. (2017). Perspectives on the university as a business: The corporate management structure, neoliberalism and higher education. Journal for Critical Education Policy Studies, 15(1), 108-135.

The Chronicle of Higher Education. (2020). Chronicle Data. Chronicle Data. https://data.chronicle.com/209807/Portland-State-University/faculty-salaries/

Tronto, J. (2017). There is an alternative: homines curans and the limits of neoliberalism . International Journal of Care and Caring, 1(1), 27-43. https://doi.org/10.1332/239788217x14866281687583

Trujillo, M. A., Bowland, S. Y., Myers, L. J., Richards, P. M., \& Roy, B. (Eds.). (2008). Recentering: Culture and Knowledge in Conflict Resolution Practice (1st ed.). Syracuse University Press.

Turkel, G. (2009). Financing Higher Education: Privatization, Resistance, and Renewal. Journal of Collective Bargaining in the Academy, 1(1), 1-28. https://www.researchgate.net/publication/237684916

U.S. Bureau of Labor Statistics. (2018). Standard Occupational Classification. https://www.bls.gov/soc/2018/major_groups.htm\#13-0000

Urahn, S. K., Conroy, T. P., Shcroeder, I., Stauffer, A., Oliff, P., Robyn, M., Theal, J., Goodwin, M., \& Hillary, K. (2015). Federal and State Funding of Higher Education: A changing landscape (Issue June).

http://www.pewtrusts.org/en/research-and-analysis/issue-briefs/2015/06/federal-andstate-funding-of-higher-education

Urquhart, E. I. (2018). Power Nap: Visualising sleep and neoliberal governmentality. Lund University.

Van der Kolk, B. (2015). The Body Keeps the Score (1st ed.). Penguin Books.

Vandaele, K. (2016). Interpreting strike activity in western Europe in the past 20 years: the labour repertoire under pressure. Transfer, 22(3), 277-294. https://doi.org/10.1177/1024258916658804

Voss, K., \& Sherman, R. (2000). Breaking the Iron Law of Oligarchy: Union 
Revitalization in the American Labor Movement. American Journal of Sociology, $106(2), 303-349$.

Wacquant, L. J. D. (2009). Punishing the Poor: The Neoliberalism Government of Social Insecurity. Duke University Press.

Waterman, P. (1993). Social-Movement Unionism: A New Union Model for a New World Order? Review (Fernand Braudel Center), 16(3), 245-278.

Western, B., \& Rosenfeld, J. (2011). Unions, Norms, and the Rise in U.S. Wage Inequality. American Sociological Review, 76(4), 513-537. https://doi.org/10.1177/0003122411414817

Wexler, E. (2016). Dual Loyalties. Inside Higher Ed. https://www.insidehighered.com/news/2016/04/13/presidents-public-universitiescriticized-joining-boards-profit-university

Wickens, C. M. (2008). The Organizational Impact of University Labor Unions. Higher Education, 56(5), 545-564. https://doi.org/10.1007/s10734-008-9110-z

Wilmot, W., \& Hocker, J. (2011). Interpersonal Conflict (8th ed.). McGraw Hill.

Wing, L. (2008). Whither Neutrality? Mediation in the Twenty-First Century. In M. A.

Trujillo, S. Y. Bowland, L. J. Myers, P. M. Richards, \& B. Roy (Eds.), Re-Centering: Culture and Knowledge in Conflict Resolution Practice (1st ed.). Syracuse University Press.

Wisman, J. D. (2013). Wage stagnation, rising inequality and the financial crisis of 2008. Cambridge Journal of Economics, 37(4), 921-945. https://doi.org/10.1093/cje/bes085

World Inequality Database. (2020). World Inequality Database. https://wid.world/country/usa/ 


\section{Appendix A: Average Staff Salaries in the U.S. 4-Year Public Universities and Portland State}

The following statistics represent data collected from the Chronicle of Higher Education's "Chronicle Data" database (2020) and shows average salaries of instructional occupations from 2003-2017, and non-instructional occupations from 2012-2017. All data has been adjusted for 2020 inflation, and where possible, it compares national averages to Portland State University's average salaries.

\section{Occupational Classifications}

For clarity, I have included a brief description of the classifications for each occupation:

- Professor, Associate Professor, and Assistant Professor: These represent tenure and tenure-track faculty (Portland State University, 2020).

- Instructor: This falls under the category of contingent faculty, representing non-tenure-track faculty (2020).

- Non-Instructional Staff: These categories are based on the classifications of the Bureau of Labor Statistics (U.S. Bureau of Labor Statistics, 2018). 
Figure 22: Average Annual Salaries for Instructional Staff, National and Portland State University, 2003-2017 (IPEDS, 2020)

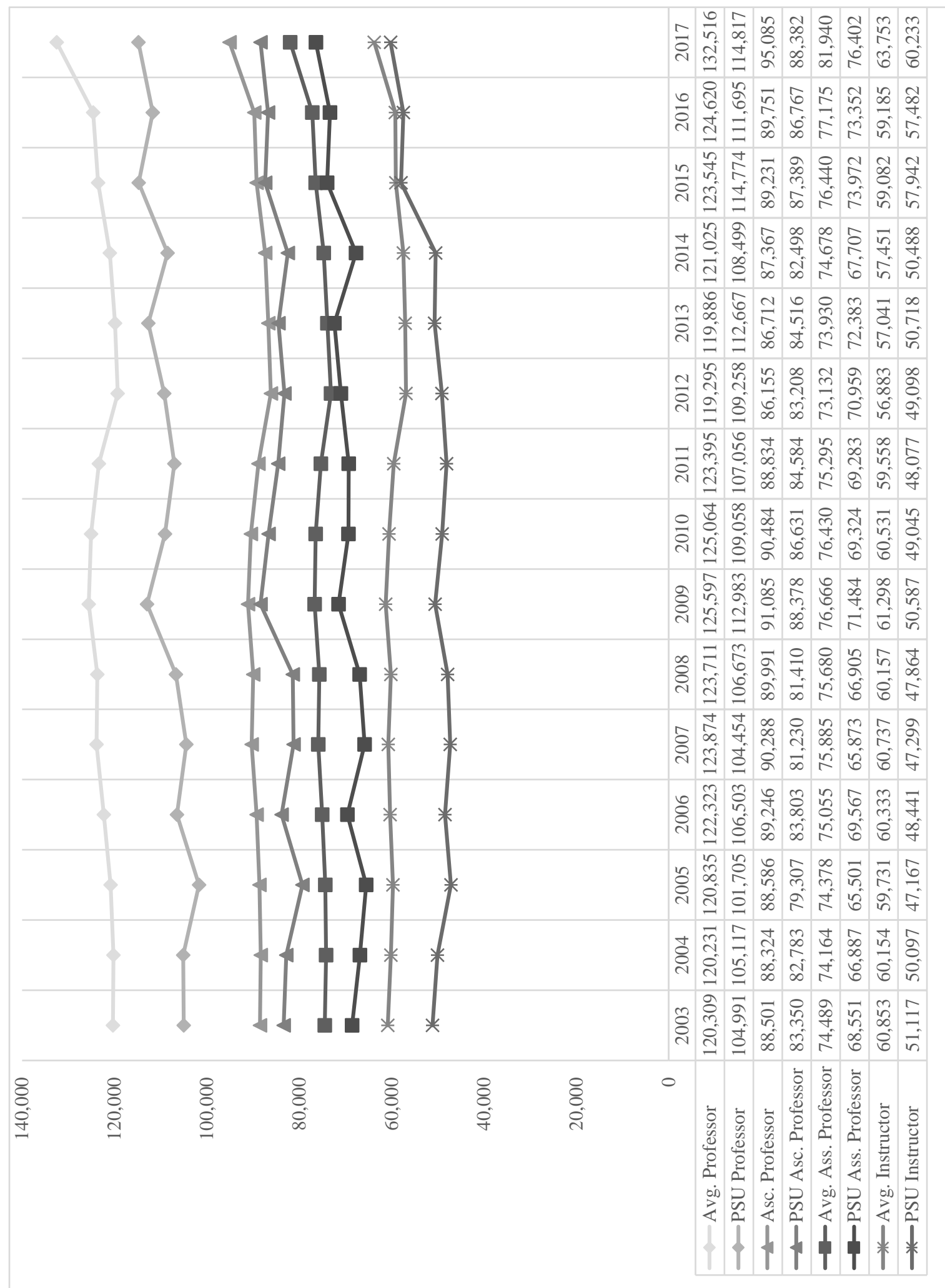


Figure 23: Average Annual Salaries for Non-Instructional Professionals, National and Portland State University, 2012-2017 (IPEDS, 2020)

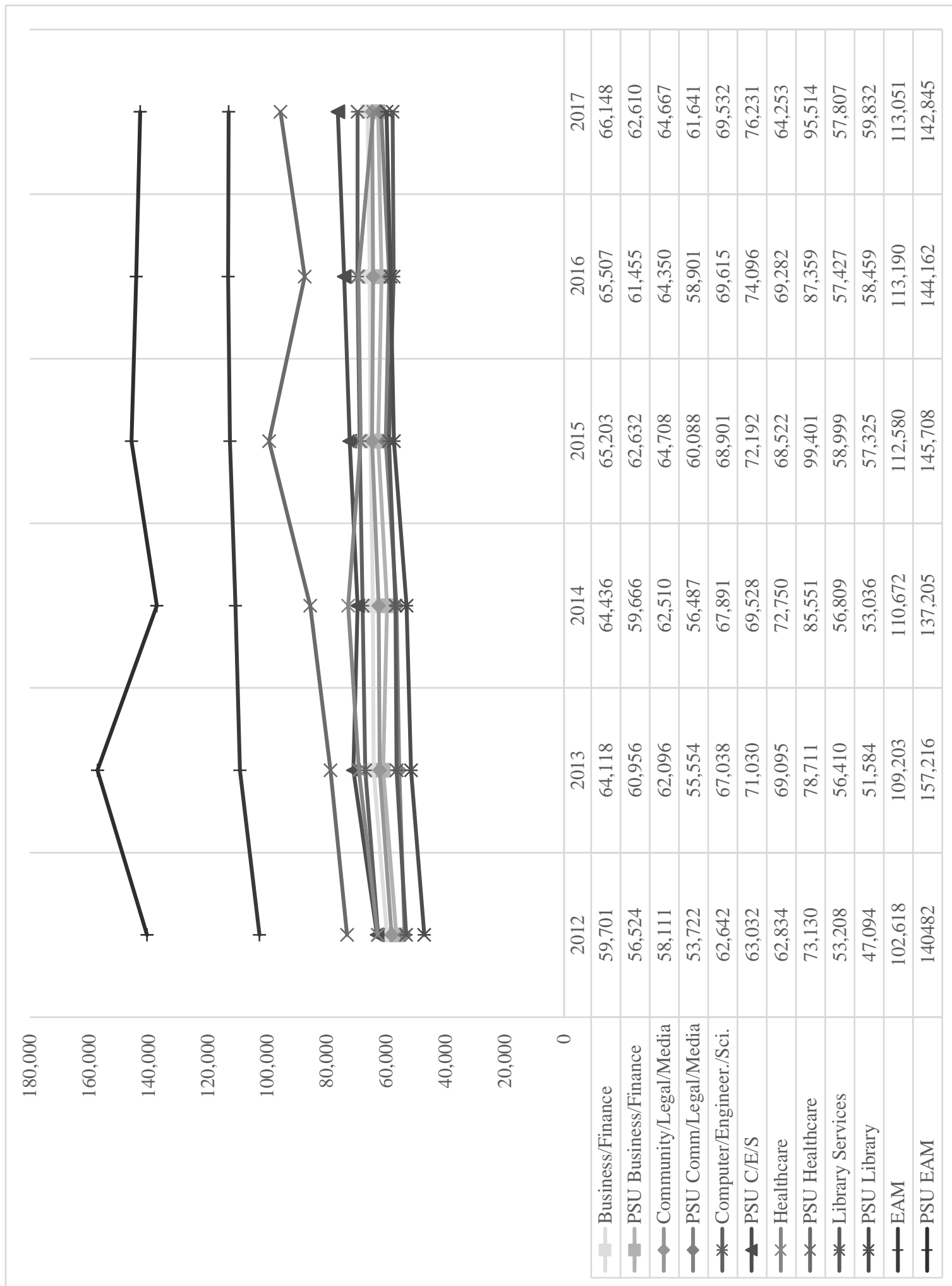


Figure 24: Average Annual Salaries for Nonprofessional Staff, National and Portland State University, 2012-2017 (IPEDS, 2020)

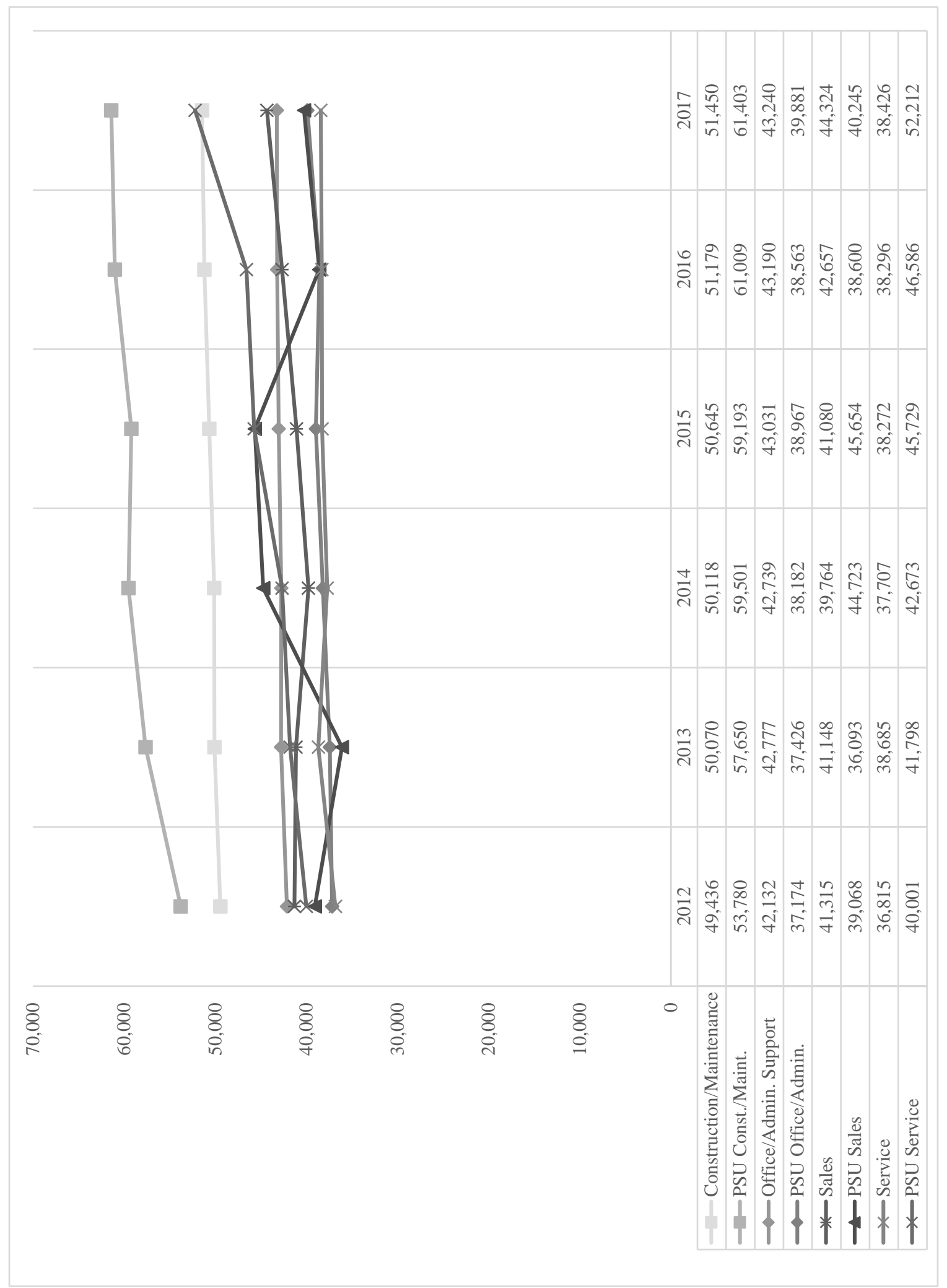


Appendix B: National Union Membership to Percentage of Total U.S. Wealth Owned by Top 10\% of Households, 1917-2015 (Bivens et al., 2017; World Inequality Database, 2020)

Statistics for union membership have been collected from the Economic Policy Institute (Bivens et al., 2017), with information for wealth owned by the top $10 \%$ and $1 \%$ of households collected from the World Inequality Database (2020), displayed in Table 4.

Table 4: National Union Membership to Percentage of Total U.S. Wealth Owned by Top Households, 1917-2014

\begin{tabular}{|c|c|c|c|c|c|c|c|}
\hline \multirow[t]{2}{*}{ Year } & \multirow{2}{*}{$\begin{array}{l}\text { \% Union } \\
\text { Member }\end{array}$} & \multirow{2}{*}{$\begin{array}{l}\text { Wealth, } \\
\text { Top } 10 \%\end{array}$} & \multirow{2}{*}{$\begin{array}{l}\text { Wealth, } \\
\text { Top 1\% }\end{array}$} & 1955 & $32.9 \%$ & $31.8 \%$ & $27.5 \%$ \\
\hline & & & & 1956 & $33.2 \%$ & $31.8 \%$ & $27.9 \%$ \\
\hline 1917 & $11.1 \%$ & $40.3 \%$ & $40.5 \%$ & 1957 & $32.0 \%$ & $31.7 \%$ & $27.5 \%$ \\
\hline 1918 & $12.1 \%$ & $39.9 \%$ & $37.1 \%$ & 1958 & $31.1 \%$ & $32.1 \%$ & $27.1 \%$ \\
\hline 1919 & $14.3 \%$ & $39.5 \%$ & $40.0 \%$ & 1959 & $31.6 \%$ & $32.0 \%$ & $27.8 \%$ \\
\hline 1920 & $17.5 \%$ & $38.1 \%$ & $35.7 \%$ & 1960 & $30.7 \%$ & $31.7 \%$ & $27.8 \%$ \\
\hline 1921 & $17.6 \%$ & $42.9 \%$ & $36.8 \%$ & 1961 & $28.7 \%$ & $31.9 \%$ & $28.0 \%$ \\
\hline 1922 & $14.0 \%$ & $42.9 \%$ & $40.0 \%$ & 1962 & $29.1 \%$ & $32.0 \%$ & $30.0 \%$ \\
\hline 1923 & $11.7 \%$ & $40.6 \%$ & $35.4 \%$ & 1963 & $28.5 \%$ & $32.0 \%$ & $28.1 \%$ \\
\hline 1924 & $11.3 \%$ & $43.3 \%$ & $37.5 \%$ & 1964 & $28.6 \%$ & $31.6 \%$ & $29.7 \%$ \\
\hline 1925 & $11.0 \%$ & $44.2 \%$ & $40.9 \%$ & 1965 & $28.6 \%$ & $31.5 \%$ & $27.6 \%$ \\
\hline 1926 & $10.7 \%$ & $44.1 \%$ & $42.6 \%$ & 1966 & $28.7 \%$ & $32.0 \%$ & $29.0 \%$ \\
\hline 1927 & $10.6 \%$ & $44.7 \%$ & $44.9 \%$ & 1967 & $28.6 \%$ & $32.0 \%$ & $28.7 \%$ \\
\hline 1928 & $10.4 \%$ & $46.1 \%$ & $47.8 \%$ & 1968 & $28.7 \%$ & $32.0 \%$ & $30.5 \%$ \\
\hline 1929 & $10.1 \%$ & $43.8 \%$ & $48.0 \%$ & 1969 & $28.3 \%$ & $31.8 \%$ & $28.9 \%$ \\
\hline 1930 & $10.7 \%$ & $43.1 \%$ & $43.4 \%$ & 1970 & $27.9 \%$ & $31.5 \%$ & $27.7 \%$ \\
\hline 1931 & $11.2 \%$ & $44.4 \%$ & $38.6 \%$ & 1971 & $27.4 \%$ & $31.8 \%$ & $27.8 \%$ \\
\hline 1932 & $11.3 \%$ & $46.3 \%$ & $38.1 \%$ & 1972 & $27.5 \%$ & $31.6 \%$ & $27.5 \%$ \\
\hline 1933 & $9.5 \%$ & $45.0 \%$ & $40.3 \%$ & 1973 & $27.1 \%$ & $31.9 \%$ & $25.9 \%$ \\
\hline 1934 & $9.8 \%$ & $45.2 \%$ & $41.0 \%$ & 1974 & $26.5 \%$ & $32.4 \%$ & $24.6 \%$ \\
\hline 1935 & $10.8 \%$ & $43.4 \%$ & $40.5 \%$ & 1975 & $25.7 \%$ & $32.6 \%$ & $23.9 \%$ \\
\hline 1936 & $11.1 \%$ & $44.8 \%$ & $43.0 \%$ & 1976 & $25.7 \%$ & $32.4 \%$ & $22.9 \%$ \\
\hline 1937 & $18.6 \%$ & $43.3 \%$ & $43.7 \%$ & 1977 & $25.2 \%$ & $32.4 \%$ & $23.1 \%$ \\
\hline 1938 & $23.9 \%$ & $43.0 \%$ & $39.8 \%$ & 1978 & $24.7 \%$ & $32.4 \%$ & $22.0 \%$ \\
\hline 1939 & $24.8 \%$ & $44.6 \%$ & $40.8 \%$ & 1979 & $25.4 \%$ & $32.3 \%$ & $23.3 \%$ \\
\hline 1940 & $23.5 \%$ & $44.4 \%$ & $37.7 \%$ & 1980 & $23.6 \%$ & $32.9 \%$ & $23.6 \%$ \\
\hline 1941 & $25.4 \%$ & $41.0 \%$ & $34.6 \%$ & 1981 & $22.3 \%$ & $32.7 \%$ & $24.4 \%$ \\
\hline 1942 & $24.2 \%$ & $35.5 \%$ & $34.1 \%$ & 1982 & $21.6 \%$ & $33.2 \%$ & $24.7 \%$ \\
\hline 1943 & $30.1 \%$ & $32.7 \%$ & $34.4 \%$ & 1983 & $21.4 \%$ & $33.7 \%$ & $23.7 \%$ \\
\hline 1944 & $32.5 \%$ & $31.5 \%$ & $31.8 \%$ & 1984 & $20.5 \%$ & $33.9 \%$ & $23.9 \%$ \\
\hline 1945 & $33.4 \%$ & $32.6 \%$ & $32.1 \%$ & 1985 & $19.0 \%$ & $34.3 \%$ & $24.3 \%$ \\
\hline 1946 & $31.9 \%$ & $34.6 \%$ & $29.9 \%$ & 1986 & $18.5 \%$ & $34.6 \%$ & $24.1 \%$ \\
\hline 1947 & $31.1 \%$ & $33.0 \%$ & $28.7 \%$ & 1987 & $17.9 \%$ & $36.5 \%$ & $25.3 \%$ \\
\hline 1948 & $30.5 \%$ & $33.7 \%$ & $28.1 \%$ & 1988 & $17.6 \%$ & $38.6 \%$ & $27.2 \%$ \\
\hline 1949 & $29.6 \%$ & $33.8 \%$ & $27.2 \%$ & 1989 & $17.2 \%$ & $38.5 \%$ & $27.3 \%$ \\
\hline 1950 & $30.0 \%$ & $33.9 \%$ & $28.5 \%$ & 1990 & $16.7 \%$ & $38.8 \%$ & $27.4 \%$ \\
\hline 1951 & $32.4 \%$ & $32.8 \%$ & $28.1 \%$ & 1991 & $16.2 \%$ & $38.4 \%$ & $26.9 \%$ \\
\hline 1952 & $31.5 \%$ & $32.1 \%$ & $27.8 \%$ & 1992 & $16.2 \%$ & $39.8 \%$ & $28.6 \%$ \\
\hline 1953 & $33.2 \%$ & $31.4 \%$ & $26.5 \%$ & 1993 & $16.2 \%$ & $39.5 \%$ & $28.8 \%$ \\
\hline 1954 & $32.7 \%$ & $32.1 \%$ & $27.2 \%$ & 1994 & $16.1 \%$ & $39.6 \% \mathrm{~s}$ & $28.8 \%$ \\
\hline
\end{tabular}




\begin{tabular}{l|l|l|l|}
\cline { 2 - 4 } 1995 & $15.3 \%$ & $40.5 \%$ & $29.1 \%$ \\
\cline { 2 - 4 } 1996 & $14.9 \%$ & $41.2 \%$ & $30.0 \%$ \\
\cline { 2 - 4 } 1997 & $14.7 \%$ & $41.7 \%$ & $31.0 \%$ \\
\cline { 2 - 4 } 1998 & $14.2 \%$ & $42.1 \%$ & $32.6 \%$ \\
\cline { 2 - 4 } 1999 & $13.9 \%$ & $42.7 \%$ & $33.9 \%$ \\
\cline { 2 - 4 } 2000 & $13.5 \%$ & $43.1 \%$ & $34.4 \%$ \\
\cline { 2 - 4 } 2001 & $13.5 \%$ & $42.2 \%$ & $33.4 \%$ \\
\cline { 2 - 4 } 2002 & $13.3 \%$ & $42.4 \%$ & $32.3 \%$ \\
\cline { 2 - 4 } 2003 & $12.9 \%$ & $42.8 \%$ & $32.2 \%$ \\
\cline { 2 - 4 } 2004 & $12.5 \%$ & $43.6 \%$ & $33.5 \%$ \\
\hline 2005 & $12.5 \%$ & $44.9 \%$ & $33.5 \%$ \\
\hline 2006 & $12.0 \%$ & $45.5 \%$ & $34.1 \%$ \\
\cline { 2 - 4 } 2007 & $12.1 \%$ & $45.7 \%$ & $35.1 \%$ \\
\cline { 2 - 4 } 2008 & $12.4 \%$ & $46.0 \%$ & $37.4 \%$ \\
\cline { 2 - 4 } 2009 & $12.3 \%$ & $45.5 \%$ & $37.3 \%$ \\
\cline { 2 - 4 } 2010 & $11.9 \%$ & $46.4 \%$ & $39.0 \%$ \\
\cline { 2 - 4 } 2011 & $11.7 \%$ & $46.6 \%$ & $38.8 \%$ \\
\cline { 2 - 4 } 2012 & $11.2 \%$ & $47.8 \%$ & $40.1 \%$ \\
\cline { 2 - 4 } 2013 & $11.2 \%$ & $46.7 \%$ & $38.3 \%$ \\
\cline { 2 - 4 } 2014 & $11.1 \%$ & $47.3 \%$ & $38.7 \%$ \\
\cline { 2 - 4 } 2015 & $11.1 \%$ & $47.8 \%$ & \\
\cline { 2 - 4 } & & &
\end{tabular}

